
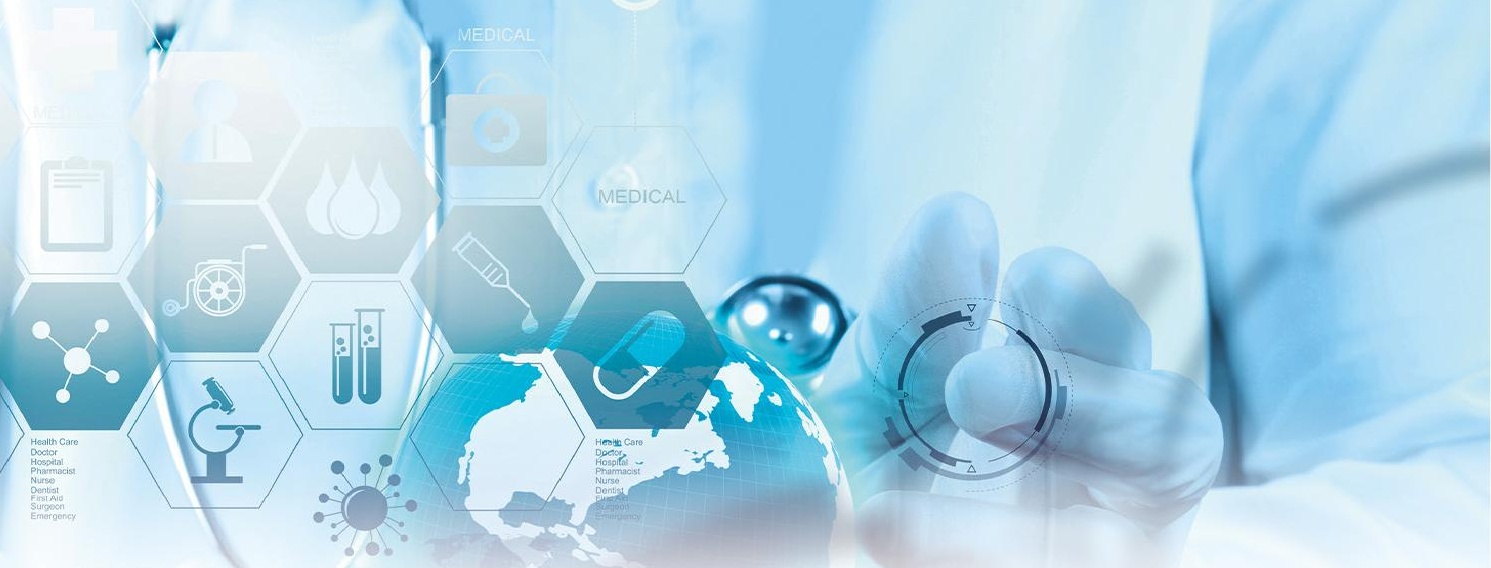

Essays on the Political Economy of Trade

and Regulation:

Biotechnology and Conservation

Qianqian Shao

邵茜茜 


\section{PROPOSITIONS}

1. Strict biotechnology regulations decrease the level of global food security, especially in developing countries.

(this thesis)

2. Second-best conservation policies can still protect the environment in an open economy. (this thesis)

3. Most empirical research supports the truthfulness of existing theories, but empirical research that does not sparks the development of new theories.

4. Crises are necessary triggers to change the political system.

5. The current institutions in the world are far away from the free-market economy.

6. PhD life is a crucial experience for understanding Max Weber's "Science as a Vocation" lecture.

Propositions belonging to the thesis, entitled

'Essays on the Political Economy of Trade and Regulation: Biotechnology and Conservation'

\section{Qianqian Shao}

Wageningen, 29 March 2017. 
Essays on the Political Economy of Trade and Regulation:

Biotechnology and Conservation

Qianqian Shao 


\section{Thesis committee}

\section{Promotor}

Prof. Dr J.H.H. Wesseler

Professor of Agricultural Economics and Rural Policy

Wageningen University \& Research

\section{Co-promotors}

Dr M.J. Punt

Assistant Professor,

Management and Economics of Resources and the Environment (MERE) Group

University of Southern Denmark

Dr D. Drabik

Assistant Professor, Agricultural Economics and Rural Policy Group

Wageningen University \& Research

\section{Other members}

Prof. Dr E.H. Bulte, Wageningen University \& Research

Dr H-P. Weikard, Wageningen University \& Research

Prof. Dr A. Balmann, IAMO, Germany

Prof. Dr V. Beckmann, Ernst-Moritz-Arndt Universität Greifswald, Germany

This research was conducted under the auspices of Wageningen School of Social Science (WASS) 


\title{
Essays on the Political Economy of Trade and Regulation: Biotechnology and Conservation
}

\author{
Qianqian Shao
}

\section{Thesis}

submitted in fulfilment of the requirements for the degree of doctor at Wageningen University

by the authority of the Rector Magnificus,

Prof. Dr A.P.J. Mol, in the presence of the

Thesis Committee appointed by the Academic Board to be defended in public on Wednesday 29 March 2017 at 4 p.m. in the Aula. 
Qianqian Shao

Essays on the Political Economy of Trade and Regulation: Biotechnology and Conservation, 200 pages.

PhD Thesis, Wageningen University, Wageningen, the Netherlands (2017)

With references, with summary in English

ISBN 978-94-6343-050-0

DOI http://dx.doi.org/10.18174/401137 
To my family

献给我的家人 



\section{Contents}

Chapter 1 Introduction $\quad 1$

1.1 Politics and economics 1

1.2 The GM food policy 2

1.2.1 Present and future food supply 3

1.2.2 The agricultural biotechnology debate 4

1.2.3 Current GM food policy regulations and trade $\quad 6$

1.3 The conservation policy and its relation to trade 8

1.4 Objectives

$\begin{array}{ll}1.5 \text { Existing approaches } & 11\end{array}$

1.6 Methodology 13

1.7 Reading guide 16

Chapter 2 GM food policy under food security pressure and lobbying 19

2.1 Introduction 20

2.2 The model 24 
2.4 The political process

the case of South Africa

3.1 Introduction

3.2 The Model 
4.1 Introduction

Chapter 5 The conservation effects of trade with imperfect competition and biased policymakers

5.1 Introduction 
6.5 Relevance

6.6 Limitations and recommendations for further research

Summary

Samenvatting (summary in Dutch)

References

Acknowledgment

Training and supervision plan

199 


\section{Chapter 1}

\section{Introduction}

"The first lesson of economics is scarcity: there is never enough of anything to satisfy all those who want it. The first lesson of politics is to disregard the first lesson of economics."

--- Thomas Sowell

\subsection{Politics and economics}

The design and implementation of public policies are influenced by political and economic factors. Political and economic factors influence the policy instrument choices, the economic rent distribution, and the political power distribution. This is illustrated in Figure 1.1(Rausser et al. 2011). The left-hand side shows the classic economic research domain and the right-hand side the classic political science domain. In the political science box, the governance structures are the constitutional rules which set the voting rules, the rule of law, property rights, and other general rules. These rules determine and divide the general public into different groups depending on their political feedback toward public policies. The implementation of policy connects political science and economics. Economists investigate the economic consequences of policies but also the links between governance structures, policy selection, and the political economy using theoretical and empirical approaches. 
The policy implementation process consists of strategic behavior by the public and private sectors, including studies of the policy mechanism design to improve policy implementation. These include studies of asymmetric information, incentives of interest groups, participation constraints, and other parts of information economics.

One of the central themes of investigation is the link between government policies and international trade. Policies affecting international trade include taxes or subsidies on international transactions, issuing legal limits on particular imports, and more. Many authors (e.g., Grossman and Helpman 1994; Swinnen 1994; Anderson 1995) state that the formation of such trade policy instruments is influenced by political factors. Often, governments choose these policy instruments to protect domestic firms from competition or to support their capacity to compete in international markets. Moreover, bilateral and regional policy relations also influence the implementation of regional or international trade policies, and countries may impose trade barriers or similar policies for strategic reasons.

Lobby groups play an important role in the context of policy formation and trade as they try to influence the results of trade and other policies for their constituencies' benefit.

In this thesis, I discuss the policy-making process under the influence of lobby groups within different scenarios of openness to international trade. I have chosen two specific policies: regulation of biotechnology, more specifically genetically modified (GM) food policies, and forest conservation policy.

\subsection{The GM food policy}

The relationship between GM food technology and food supply is a dilemma for policymakers in many countries. It is not just an issue of a new agricultural technology's application to solve a food 
supply problem, but also a political competition between the suppliers, users, and consumers of the new and alternative technologies at national and international level.

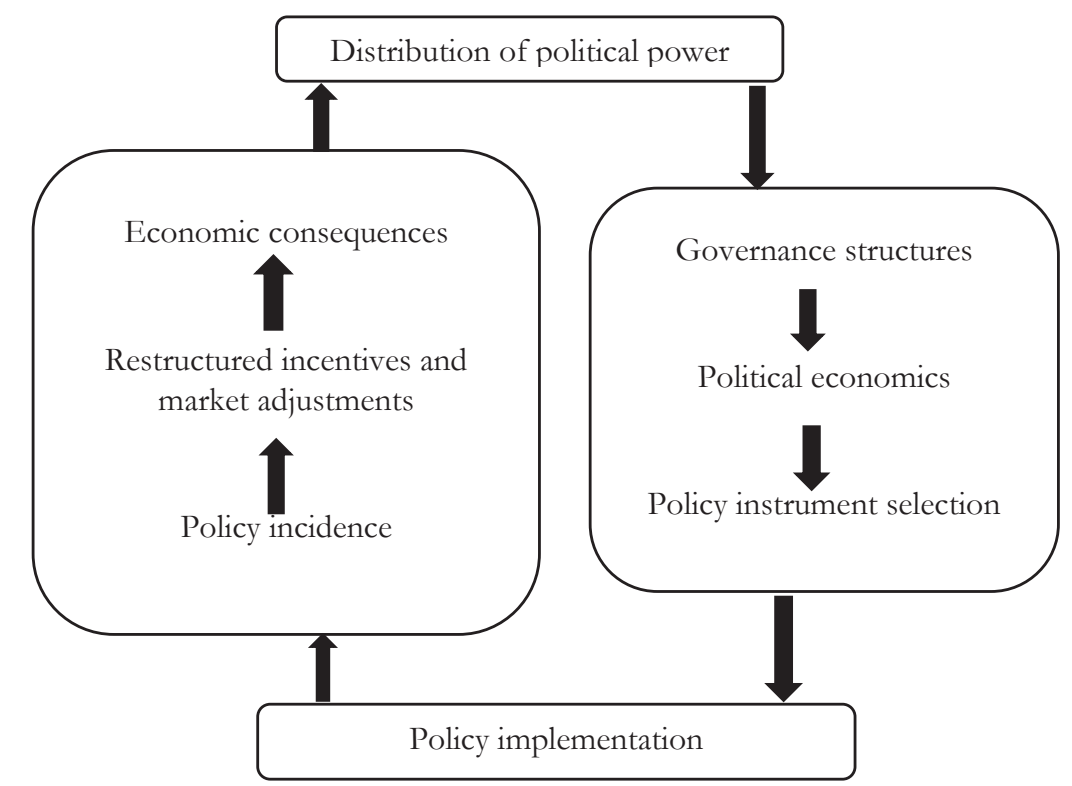

Source: Rausser et al. (2011)

Figure 1.1 The policy-making process and the economic consequences

\subsubsection{Present and future food supply}

According to the United Nations Population Division (2011) and the Food and Agriculture

Organization of the United Nations (FAO 2015) the global population will reach 9 billion by the middle of this century. To feed these people, the world will need to increase food supply by 70 to 100 percent. The FAO (2015) estimates that about 795 million people of the world's 7.3 billion people, meaning one out of nine, already suffer from chronic undernourishment today. Therefore, the International Food Policy Research Institute(IFPRI) (2014) concludes that ending hunger and 
undernutrition must be a top priority of the post-2015 development agenda. However, expanding food production faces major challenges, especially for food production to meet the increase in food demand. Factors such as a smaller rural labor force, changing diets, climate change, and water scarcity exacerbate the production challenge (Ranganathan 2013). Besides the increase in food demand, competition for land with other uses, and the impact of climate change impact global food security (e.g., Tomei and Helliwell 2016; de Gorter et al. 2015).

Governments and international organizations try to address the challenges of an increase in food demand by policy proposals such as increasing crop yields, improving the environment by better land and water management, or providing food aid to the countries and regions experiencing various kinds of food shortages. Moreover, solving the food supply and food distribution issue through agricultural trade will be influenced by uncertainties, such as climate, prices, and political factors. Among the alternatives for addressing changes in food demand and consumption, it is widely believed (e.g., Parry et al. 1999; Godfray et al. 2010; Beddington 2010) that improving agricultural technology is crucial and can be a sustainable way to solve the issues related to food security by increasing crop yields without further negatively affecting the environment.

\subsubsection{The agricultural biotechnology debate}

Agricultural biotechnology is considered to be a breakthrough technology in agriculture not seen since the Green Revolution. It is regarded as a sustainable agricultural production method for feeding the world's growing population in the future. Both theoretical and empirical studies (e.g., Gaisford 2001; Wesseler and Kalaitzandonakes 2011; Qaim 2009) show that GM food technology helps increase crop yields, reduce pesticide and fertilizer use, and bring about economic, environmental, and health benefits. However, despite the potential and already realized benefits of the technology, many consumers are afraid of its potential risks. Public acceptance, for example, is 
low in some countries and regions, and largely influenced by policies (Smart et al. 2015).

Furthermore, consumer perception is influenced by product labels and advertising (Lusk et al. 2014), which in turn are largely determined by specific biotechnology policies (Qaim 2009).

Public attitude towards GM food products is strongly influenced by lobby groups (Tosun and Schaub 2015). Different groups on the production side such as GM food retailers, GM farmers, and suppliers of GM crops share similar interests in supporting GM food technology. Conventional agricultural producers and their input suppliers (e.g., chemical pesticide firms, seed companies) compete with the biotechnology groups for the agricultural commodity market share (Graff et al. 2009). The emergence of new technology creates opportunities for its advocates and challenges for its opponents. Regarding the genetically modified organisms (GMO) issue, there are special interest groups representing both the supporters (henceforth: GM food group) and opponents (henceforth: non-GM food group) of the technology. The GM food group points to the high yields, environmental benefits, and the potential for sustainable agricultural production. The non-GM food group, including conventional farmers, seed and pesticide companies, and retailers of their products, however, emphasizes the unconfirmed potential risks of the technology to human health. Moreover, ethical concerns are often brought up during the GM crops debate, because "genetically modified" is perceived as not "natural" (e.g., Gaisford 2001; Stanziani 2008). Without understanding the technology, led by concerns about the potential food safety, and lack of trust from authorities, consumers are often easily influenced by interest groups and media (Boccia and Sarnacchiaro 2015; Vecchione et al. 2015).

The diverging public attitudes toward GM food technology also influence consumer consumption behavior. Many consumers do not treat GM and non-GM food products as perfect substitutes, but as purely independent products according to their willingness-to-pay for the two product categories (Qaim 2009). This divergence can lead to costly identity preservation and market 
segregation of GM and non-GM food products (Desquilbet and Bullock 2002; Moschini et al. 2005). In some countries (e.g., the EU Member States or Japan), the segregation of GM and non-GM food has become a new type of non-tariff barrier in international agricultural trade (Punt and Wesseler 2016).

\subsubsection{Current GM food regulations and trade}

The public GM crops debate influences the GM food policy-making process. Governments play an important role in ensuring the safety of new technologies and in informing the public about them. However, governments can be influenced by a menagerie of various interest groups. In principle, there are two major GM food policy regimes that have emerged: the EU Member States' policies with very strict GM food regulations, and the US policies with relatively lenient ones. The EU requires labelling for GM food/feed products that contain more than 0.9 percent of GM food ingredients (European Commission 2013). Coexistence regulations are in place that require technical segregation measures, such as minimum distance buffer zones between GM and non-GM farms (Beckmann et al. 2006). In contrast, the US has no mandatory labeling and coexistence is regulated differently. These lenient rules are regarded (Dudek 2015) as a success for the GM food lobby in the US and the strong regulation a win for the non-GM food lobby in the EU (Graff et al. 2014).

Furthermore, the two different regulatory regimes influence other countries' GM food policies. Countries of Latin America follow the US GM food policy more closely and cultivate GM crops. The US, Brazil, and Argentina are the three largest GM crop producers in the world (James et al. 2015). However, African countries primarily follow the EU pattern and many have directly or indirectly banned GM crop production and imports of GM food via their regulatory system. One of the reasons for the bans is EU-Africa bilateral trade (Vigani et al. 2012; Wafula and Gruère 2013). The EU imports about seven billion dollars' worth of agricultural products from Africa every year 
(six times more than the US). African countries, especially the export-oriented economies, are required to follow the EU import standards. Moreover, the EU offers a large amount of foreign aid to African countries each year, three times more than the US funding (Herring and Paarlberg 2016). The EU attitudes toward GM food products and lobby groups dissuade some African countries from adopting GM agricultural technology (Mabaya et al. 2015). Currently, there are only three countries in Africa-South Africa, Burkina Faso, and Sudan—that grow GM crops, and the debate on GM food policy regulations in those countries continues.

GM food policy regulations have different effects on countries with different levels of development. Different GM food policy regulations give rise to different trade standards and differentiated agricultural trade markets. This increases the number of trade disputes on food standards, such as the one on the "quasi-moratorium" on GM crops in the EU (Punt and Wesseler 2016). Different GM food policy regulations generate difficulties for food aid as well. For example, the US provides food aid including GM food products which could only support countries allowing GM food imports. (Zerbe 2004) argues that American food aid to Southern Africa had nothing to do with hunger and development, but was a promotion of GM crops, which in turn accelerated the domestic debate over GMOs. Generally, European donors are more influential in Africa than North-American donors (Paarlberg 2010) and sometimes actively oppose GMOs in Africa (Paarlberg and Pray 2007).

Nevertheless, GMO regulations are changing continuously. Recent examples in the US include GM food labeling (Blake 2016), and in the EU, the recently added opt-out clause for cultivation as well as an opt-out clause currently being discussed for imports (EUR-Lex 2015). In South Africa, the threshold percentage for labeling of GM ingredients has become stricter (de Faria and Wieck 2015). In Kenya, the cultivation of GM maize was officially banned for a number of years, but the ban was recently removed (Wesseler et al. 2016). 
In international trade, many countries seek more cooperation to stimulate international trade. The trade of GM food is included in the Trans-Pacific Partnership and Transatlantic Trade and Investment Partnership negotiations. Even though there have been no substantial outcomes from the two negotiations until now, it is the first time that the GM food issue is being negotiated between different regulatory regimes in trade agreements, rather than in trade disputes at the WTO. The development of GM food regulation in trade talks is difficult to predict, but if countries want international cooperation to grow, collaboration is required and concessions might be necessary.

\subsection{The conservation policy and its relation to trade}

The second policy that I discuss in the thesis is forest conservation policy. The interaction between the economy and the environment can result in conflicts of interest. Environmental policy regulates economic activity to balance those interests. Often, environmental policy is needed for the protection of natural resources, such as old-growth forests, wildlife, and water. Forests constitute 29.6 percent of the world's land area, and 70 percent of the forests produce timber for construction, furniture, and other uses (Hanley et al. 2007). Forest conservation policy faces the challenge of finding the optimal amount of old-growth forest that is left for "amenity services" (e.g. sites for hiking or wildlife habitats). This requires governments to settle the trade-off between the wood industry's profit maximization and the environmental benefit of maintaining parts of the forests. The common instruments that governments use are to specify the rotation length or the remaining stock, or to impose a harvest tax or stumpage fee.

Free trade can increase social welfare through comparative advantages. Environmentalists, however, often believe that trade leads to even more environmental damage and exploitation of resources, through an increase in production and lowering of production standards. Therefore, conflicts of interest arise between the wood processing industry and environmentalists. Moving 
from autarky to trade can induce governments to change environmental policies or to use trade instruments to increase domestic firms' capacity to compete in the world market. Under the influence of lobbying, conservation policy can be distorted from the "first-best solution" (i.e., the socially optimal policy level for environmental protection) and therefore, we have to investigate the effect of "second-best solutions" (Hanley et al. 2007; Bulte and Barbier 2005).

\subsection{Objectives}

Policymakers use policy to regulate the behavior of individuals and organizations, and to contribute to institutional development. However, instead of a policy being aimed at Pareto-efficient improvements, many policies are largely influenced by political power, especially on issues where conflicts of interests exist. The impact of policy on social welfare and the welfare of lobby groups can be very different in a closed versus an open economy.

Relating to the issues that I addressed in Sections 1.2 and 1.3, the central objective of this thesis is, therefore:

To understand the political policy-making process under the influence of lobbying and different openness to trade scenarios by assessing the impact of political intervention on social welfare.

In this thesis, I analyze the formation of two policies: GM food policy, and forest conservation policy. The settings range from autarky to trade in the context of a political economy in which lobby groups try to influence policies and policy makers take contributions by lobby groups into account. More specifically, there are four research questions to be addressed in this thesis:

\section{(1) How does a change in GM food policy affect food security from a global perspective?}


I investigate relationships between food security and GM food policy regulations in Chapter 2. I focus on the effects of GM food policy on three aspects of food security: food availability, food access, and food utilization. Moreover, I investigate the effects on lobbying efforts when the decision makers' aim is to improve overall food security.

\section{(2) How do interest groups influence the food security of a country?}

I discuss food security in South Africa, as measured by the food self-sufficiency rate (SSR), assuming food policy is influenced by lobby groups. Two interest groups, a GM food lobby and a non-GM food lobby, influence policy-making and as a result, the country's food security. I specify the mechanism of the GM food policy effects on welfare and the government's payoffs in a small open economy case. I also include the different sizes of interest groups in the discussion and their effects on the food SSR.

(3) What is the outcome of a GM food trade negotiation between two different policy regimes under lobbying influence?

Given the two-different existing GM food policy regimes discussed under 1.3, and in light of the Trans-Pacific Partnership (TPP) and the Transatlantic Trade and Investment Partnership (TTIP) negotiations, I aim to find the outcome of such a negotiation with both governments receiving contributions from opposing lobby groups.

(4) Should we be more concerned about the environmental effects of trade when the tradeliberalizing governments are industry-biased?

I investigate the forest conservation policy before and after trade, and compare the level of protection when the government is industry-biased. I discuss the effects of trade on welfare in a 
two-country model with Cournot competition in the world market. I also investigate the political bias of the conservation policy before and after trade, and identify the effects of transportation costs on the policy that was chosen.

\subsection{Existing approaches}

The political-economic framework has been applied to many studies, such as public policy, trade policy, monetary policy, and agricultural policy. Numerous strands of literature and many schools of political economy have been developed.

In the early political economy studies, the political framework is built on politician-voter models. The studies of collective actions focus on the interaction between politicians and their voters. For instance, Olson (1971) offers a theoretical investigation of lobby groups and Becker (1983) discusses the strategic competition among pressure groups. Grossman and Helpman (1994) develop a political economy model of trade, which offers a micro-foundation for lobbying. Their model has become a standard for studying the political economy of international trade. The model consists of a two-stage political game, with interest groups announcing their contribution schedules in the first stage, and the government choosing a contribution pair to maximize its payoffs in the second stage. The government maximizes the sum of social welfare and collective contributions income from lobby group. In the standard model, all lobby groups are equally efficient in the lobbying process (Rausser et al. 2011).

Even though the model has been challenged because it yields results that are inconsistent with the empirical evidence, it has been used extensively in the literature because of its intuitive setting. In many subsequent models, weight parameters have been added to distinguish differences in lobbying power over the political policy-making process. For example, Eerola (2004) puts a lobbying efficiency parameter in the lobbying contribution stage, following Laffont and Tirole's 
(1993, Ch. 11) assumption that lobbying is costly. The policy design and outcomes are not only influenced by lobby groups but also by trade. Trade can amplify competition between domestic lobby groups and adds international competition to policy-making. When countries trade, the government pay-off function not only includes welfare from domestic production and consumption, and contributions by domestic lobby groups, but also gains from export and the competition effect of imports.

Political economy models have also been widely applied to studying agricultural policy. Anderson et al. (2013) present a general review of political economy studies of agricultural policies. Two main research themes are the choices of agricultural policy instruments, and investment in public agriculture research. The agricultural political economy studies individual preferences for different varieties of food, the collective action of lobby groups, and preferences of politicians, which is shown as different weights on lobbies. Besides the theoretical models, empirical analysis has focused on consumer preferences (or voting preferences) and lobbying and governmental behavior (see Anderson et al. 2013).

Of politically determined agricultural policies, biotechnology policy is frequently mentioned in the literature. It involves many aspects, such as investment in public research and development, protection of intellectual property rights, labeling regulations, and trade policies. For example, Gruère (2011) provides a three-country model and shows comparative static results of GM food policy for non-GM food producing countries and policy influences on the trade regulations of GM food. Graff et al. (2014) create a voting model to show how voting outcomes are determined by different interest groups. The model follows Downs' (1957) median voter model, showing how a central power government, such as the EU Parliament or US Congress, is influenced by the information provided by interest groups. The government weighs information from different interest groups by the credibility of the groups' voters. 
Many studies also use an empirical analysis to establish the welfare effects of biotechnology. Brookes and Barfoot (2013) conduct a global analysis of GM crops production and show the welfare gains (19.8 billion USD) from GM crop adoption. Studies on consumer behavior cover empirical analysis in different countries regarding GM food consumption (e.g., Paarlberg 2001; Qaim and Traxler 2005), and the consumer willingness to pay to accept or avoid GM food products (Lusk and Coble 2005). These empirical studies show that consumer preferences for GM food products are driven by price effects and information, while the weight of information depends on politics and lobbying.

\subsection{Methodology}

In this thesis, I discuss the effects of a GM food lobby and a non-GM food lobby on GM food policy. I also discuss forest conservation policy that involves an industry-biased policymaker. Based on previous approaches and studies, my political economy analyses follow the Grossman and Helpman $(1994,1995)$ model. A payoff-maximizing government chooses a policy to maximize a weighted sum of social welfare and lobbying contributions. In Chapters 2 through 4, I discuss GM food policy with two lobby groups, a GM food and a non-GM food lobby. In Chapter 5, I analyze how an industry-biased government changes its forest conservation policy when it moves from autarky to trade.

The chapters follow a similar structure. First, I choose the policy instrument. In the forest policy paper, the instrument is a harvest tax. For the GM food policy papers, the GM food policy translates into a policy compliance cost for the GM food producing firm. Since the GM food technology is an input for the GM food producing firm, the GM food policy compliance cost is an additional capital cost for the firm, which is positive and increases the firm's input cost. This follows Beckmann et al. (2006, 2011)'s analysis of the ex ante regulations and expost liability rules on 
coexistence regulations in the European Union. The regulations often impose direct costs on the GM food producing farmers. Previous related studies integrated the GM food policy into either the consumer side or the producer side. For instance, Moschini et al. (2005) segregate GM and non-GM food products in their model. They use a parameter on food consumption to differentiate between consumer preferences for GM and non-GM food products. Swinnen and Vandemoortele (2011) use a GM food standard imposed on producers and a preference indicator on the consumer side to investigate hysteresis of policy standards during trade.

Second, in the GM food policy papers, I categorize all consumers into three groups according to their preference toward the GM food technology: the GM food group, non-GM food group, and the group that is indifferent towards the technology. Consumers in the GM food group believe in the health and environmental benefits of the new technology, support the GM food technology, and only consume GM food products. The non-GM food consumers worry about the potential risks of using the GM food technology. They only purchase non-GM food products. The third group is indifferent towards the technology, and consumers belonging to this group consume both products. They treat GM and non-GM food products as imperfect substitutes.

Third, in the GM food policy papers, I follow Grossman and Helpman's $(1994,1995)$ model of lobbying. I discuss a two-stage lobbying game between interest groups and the government. Interest groups announce their lobbying schedules first and the government chooses policy depending on the lobbying contributions that it selected from the interest groups and on social welfare. Moreover, I use a specific functional form, a logistic function, for the lobbying contributions in the simulations. The curve coincides with a "truthful" contribution schedule demonstrating how groups' contributions always represent the lobbies' policy preferences.

Fourth, I specify the trade conditions. In the GM food policy papers, the settings range from a closed economy to trade. I first consider a closed economy, in a world setting. I then introduce 
trade in a small open economy. In the small open economy, the South Africa case, the price of GM and non-GM food products are exogenous to the economy. In the trade negotiation model, I focus on non-tariff barriers to trade effect as a result of a GM food policy and assume the domestic regulations in each country (GM food regulation for the domestic country and non-GM food regulation for the foreign country) are set before the negotiation. The non-tariff barriers of GM food policy are modeled as tariff equivalents and influence the import prices of GM and non-GM food products. One country has a strict GM food policy and imposes high non-tariff barriers on GM food imports, whereas the other country has a non-tariff barrier for non-GM food imports. The two countries make concessions on their own non-tariff barriers in a bargaining model to increase the joint welfare increments. In the forest conservation policy chapter, I consider a move from autarky to trade. I analyze a two-country model with Cournot competition in the two countries' markets, which is based on Brander and Krugman (1983)'s "reciprocal dumping" model. Both governments are industry-biased when setting the domestic forest harvest tax, but they also aim to increase the total welfare of the country and protect the domestic environment.

Fifth, I solve the model and analyze the equilibrium policy and its effects on welfare. The policies affect welfare through different channels. In the GM food policy papers, the GM food policy compliance costs within the production costs of the GM food-producing firm influences the GM food group's welfare directly, but the non-GM food-producing firm and all other consumers indirectly. The "indirect effects" vary. In the closed economy of Chapter 2, two firms produce GM and non-GM food products, respectively. They sell their products to consumers in their group, but they also compete price-wise for the consumers who are indifferent towards the technology and consume both products. The GM food regulation, therefore, has an impact on the non-GM food price in equilibrium, and affects all consumers as well as both firms. In Chapter 3, the South Africa case, the price of GM and non-GM food products are exogenous to the firms. The GM food policy 
compliance costs influence the economy through the change in consumers' total income. In this model, the transfer payment from the GM food policy cost influences consumers' total food demand and indirectly affects SSR and welfare. In the two-country negotiation model in Chapter 4, the tariff equivalents of the non-tariff barriers influence the markets in each country through GM food and non-GM food price changes. The price changes influence the trade volume and therefore, firms' profit and consumer welfare for all groups. In Chapter 5, the forest conservation policy, that is, the harvest tax, influences the firms' output. The output change influences trade volumes. Therefore, the harvest tax change from autarky to reciprocal dumping influences the aggregate welfare of firms' profit, consumer surplus, and environmental utility. Because firms respond strategically to each other's output in both markets, one country's conservation policy influences the other country's policy as well.

As a last step of the methodology, I conduct simulations for the GM food policy papers and use numerical examples for the forest policy paper to show the effects of lobbying, the resulting policies, and their effect on welfare in more detail.

\subsection{Reading guide}

Chapters 2 through 5 of this thesis each answer one of the four research questions introduced above. The last chapter draws some overall conclusions. The order of chapters is organized by the openness of the economy to trade, in which Chapter 2 is a closed economy, Chapter 3 is a small open economy, Chapter 4 is a two-country model, and Chapter 5 is a change from autarky to open trade. Chapters 2 through 4 discuss GM food policy and Chapter 5 discusses forest conservation policy.

In Chapter 2, I model a closed economy with a partial equilibrium model. Two firms (GM and non-GM) compete in the market, selling their products to their own consumer type, as well as 
to the group that likes both. I show the effects of the GM food policy compliance cost on food security and how interest groups influence the policy and its outcomes, both when the government pays no special attention to food security and when it does.

In Chapter 3, I build a general equilibrium model to investigate the effect of the GM food policy on South Africa's food self-sufficiency level. I show several simulations demonstrating its effects. I also discuss the influence of the non-GM food group's size on the food self-sufficiency rate.

In Chapter 4, I take a three-step approach to finding the outcome of a trade agreement on GM food products in a two-country model. I first develop the theory of the negotiation and then conduct simulations to find the equilibrium tariffs.

Chapter 5 discusses the forest conservation policy under trade. I use a two-country model with Cournot competition to identify the firms' optimal output levels, and optimal conservation policy before and after trade. I then analyze the welfare consequences of the policy change as well as the effect of the model's different parameters.

The last chapter summarizes the results, provides short answers to the research questions, and a general discussion of the topics and policy implications. 


\title{
Chapter $2^{1}$
}

\section{GM Food Policy Under Food Security Pressure and Lobbying}

\begin{abstract}
Different countries have different regulations for the approval and cultivation of genetically modified (GM) crops. In this paper, we investigate the relationship between global food security and the level of GM food policy regulation assuming a World Nation Official (WNO) proposes advice on global GM food policies. We show that a stricter GM food policy regulation reduces food security as measured by food availability, access, and utilization. We also find that political rivalry among interest groups worsens the food security status, by assuming the GM agricultural technology is more productive and the regulatory policy is influenced by lobbying. When the WNO aims to improve food security and weighs the GM food lobby contribution more than the non-GM lobby's in the lobbying game, the total lobbying contributions will be the same for the WNO, and the GM food lobby will be efficient in the political process. The GM food lobby, however, in food-secure countries loses its advantage in the political competition, and this may result in a strict GM food policy. Countries that have food security problems due to implementing stricter GM food policy regulations face welfare losses.
\end{abstract}

\footnotetext{
${ }^{1}$ This chapter is based on the article: Qianqian Shao, Maarten J. Punt, and Justus Wesseler. GM Policy Under Food Security Pressure and Lobbying.
} 


\subsection{Introduction}

After the 2008 food crisis, the potential fragility of the global food system returned as a major topic in the debate on global food security. Politicians and researchers have suggested several solutions, such as reduction in trade barriers, food aid for food insecure regions, and improving productivity through new agricultural technologies. Agricultural biotechnology has been considered one of the main contributors to food security (e.g. Wesseler et al. 2016; Qaim and Kouser 2013; Ruane and Sonnino 2011; Sastry et al. 2011). However, the importance of this technology's contribution to food security is under debate (e.g. Dibden et al. 2013).

The debate illustrates that the application of agricultural biotechnology is not just a scientific problem, but also a political one involving several interest groups (Herring and Paarlberg 2016; Tosun and Schaub 2015; Freedman 2013; Qaim 2009; Graff et al. 2009; Miller and Conko 2004). Biotechnology scientists and companies, such as Monsanto and Pioneer Hi-Bred International, emphasize higher yields and environmental benefits of genetically modified (GM) crops. Anti-GM food organizations, such as Greenpeace and Friends of the Earth, emphasize the potential human health and environmental risks of biotechnology (Tosun and Schaub 2015), even though there is currently no evidence that proves that genetically modified organisms (GMOs) pose higher risks to either human health or the environment (Giller 2016).

International organizations are also involved in the debate. For example, the State of Food and Agriculture report of 2004 on "Agricultural Biotechnology: Meeting the Needs of the Poor?” by the FAO (Food and Agriculture Organization of the United Nations) has been heavily criticized for its "pro-GM" view. Similarly, the report (McIntyre 2009) on the International Assessment of Agricultural Knowledge, Science and Technology for Development (IAASTD) has been criticized for not paying enough attention to the possibilities of modern biotechnology to address food security: "But, partly due to the way in which the authors were selected and the main reports were translated into the 
summaries, the overall message which emerged from the LAASTD was a more restrictive, exclusionary message with an undercurrent against new technology, GMOs, and input-intensive agriculture." (The World Bank 2010, p. 38).

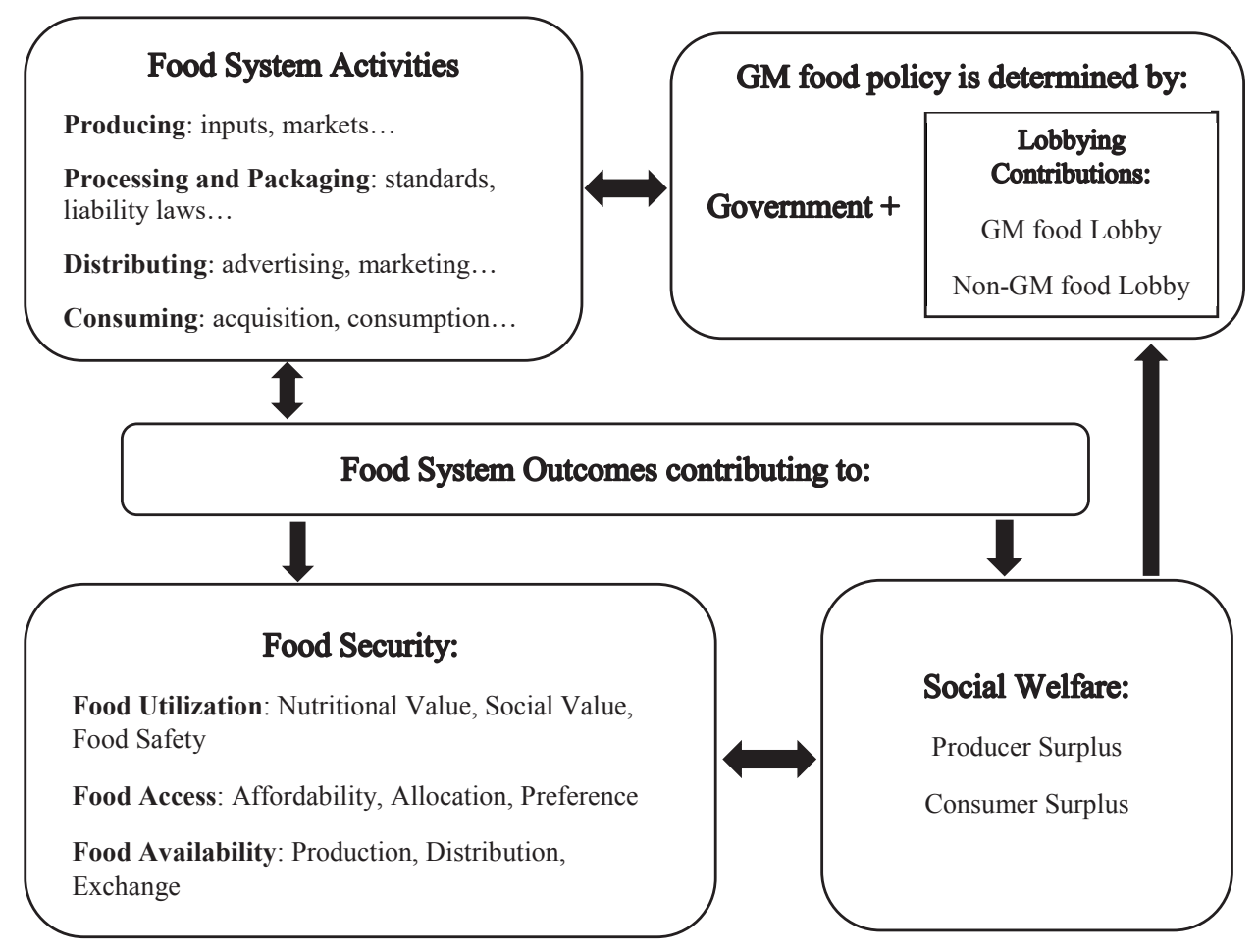

Figure 2.1 Politically influenced main food system (modified from Ericksen 2009)

In Figure 2.1, the importance of food policies is illustrated in the food system framework (Modified from Ericksen 2009, p. 28). The GM food policy will influence the whole food system through production and consumption decisions and will finally result in the changing of prices. The effect will trickle down, affecting food system outcomes. For example, farmers have to comply with GM food policy regulations and their labeling standards (Venus et al. 2016, Gruère et al. 2009), 
coexistence rules (Wesseler and Punt 2016), seed companies with environmental and food safety regulations (Smart et al. 2016), and countries with international trade policies (Punt and Wesseler 2016). In addition, a consumer's preference toward GM and non-GM food products is influenced by labels and advertisements on food products, media reports, and more (Lusk et al. 2014). Food regulations can also influence the acquisition of food products in the market by implementing stringent or lenient sanitary and phytosanitary standards for food imports. All these policies influence the food system outcomes with impacts on food security and social welfare.

Political differences in the use of GMOs widen the productivity gap between developing and developed countries by setting barriers on the application of new agricultural technology. As Shiferaw et al. (2011 p. 321) argue the "hard technology" of genetic modification alone is not enough to improve food security. It needs to be complemented with the "soft technologies" of the development of an appropriate GM food policy and the establishment of proper institutions that ensure that smallholder farmers can use the technology and profit from it. Biotechnology policy not only influences social welfare directly, but also generates environmental benefits and costs. Many positive environmental effects from GM crops have been observed, such as a possible reduction in pressure on habitats and biodiversity through increased productivity (Wesseler et al. 2011). Growing GM crops is also less harmful to the environment and human health than conventional crops because of the lower emissions from herbicide production and field operations and the reduced pesticide use (Bennett et al. 2004).

Several authors applied the political economy theory to study policies on agricultural biotechnology. Apel (2010) claims that there are substantial policy and financial benefits that GMO opponents gain from their opposition to GM food technology, i.e., donations, membership fees, and WNO funded policy programs. Some donors provide financial support to NGOs that campaign against GMOs in developing countries (Paarlberg and Pray 2007). At the same time, the GM food 
R\&D institutes and some seed companies lobby for less strict regulations of biotechnology across countries. The strict GM food policy regulation in the EU is regarded as a lobbying success of antiGM food lobby groups (Qaim 2009; Graff et al. 2009). These conflicting public attitudes and interests in biotechnology manifest in the GM food policy of each country. Therefore, a political economy analysis can offer important insights into the policy formation (Josling et al. 2004).

In this paper, we discuss GM food policies that influence the food system, and thereby the three aspects of food security (food utilization, food access and food availability) from a globally political perspective. The three pillars of food security follow the World Food Summit (1996)'s definition, and the FAO added stability as the fourth pillar in 2001(Thomas and Morrison 2006), which refers to the first three aspects over time. Since our model is static, we only focus on the first three pillars. We quantify food availability by food production, food access by food prices, wages and food demand, and food utilization by consumer surplus from food consumption. The political economy model follows the classic model of Grossman and Helpman (1994) and investigates the GM food policy effects on food security in a global context. We follow Weitzman (2001) and model the World Nation Official's (WNO, such as FAO) advice on global GM crop policies. The crucial assumption is that GM food policy regulations are supplementary to the regulations on non-GM food products and do not generate additional social benefits, such as higher levels of food or environmental safety. The WNO maximizes the sum of a weighted social welfare function and contributions from two lobby groups, a GM and a non-GM food group, who have contradictory interests toward the GM food technology. Some consumers have strong preferences for or against GMOs, while many other consumers are indifferent to either GM or non-GM food products or demand variety. Consequently, in the model we divide consumers into three groups (for, against, and indifferent). This helps us to integrate consumer preferences into the conflict of interest analysis. The WNO, finally, balances different social aspects in its proposed GM food policy. 
We find that a stricter GM food policy regulation has negative effects on all three aspects of the global food security. We also show how the GM food policy influences the three aspects. This influence gets more negative when interests groups get involved. If the GM food technology is argued to be more efficient in production than the conventional technology, then the GM food lobby is more efficient in the lobbying process when the WNO aims to improve food security status. But if the non-GM food lobby group is very large, the GM food policy would stay strict. Therefore, a more powerful food lobby group, whether the GM or the non-GM, in the policy-making process makes international organizations, which depend on contributions from many sources, have difficulties in providing clear statements in favor of or against GMOs. The politically influenced policy results also apply at the country level. For example, African countries who are food-insecure still implement strict GM food policies for both domestic production and imports. One of the important reasons is that the lobbying effort of groups opposed to GMOs is powerful.

\subsection{The model}

We model the world as a closed economy. There are two sectors in the economy, an agricultural food sector and a numeraire sector $(z)$. Even though there are many farmers for GM and non-GM food production, we assume there are only two firms in the food sector in our model, a firm producing GM food $x_{G}$ (henceforth: GM food firm, subscript $G$ ) and a firm producing non-GM food $x_{N}$ (henceforth: non-GM food firm, subscript $N$ ). Labor $(L)$ and capital $(K)$ are the inputs for production ${ }^{2}$. The GM food firm uses the GM food technology as an additional input in its production process and receives benefits such as improved yield and/or reduced production costs, whereas the non-GM food firm only uses conventional agricultural technology for its production.

\footnotetext{
${ }^{2}$ We only focus on the agricultural sector and take the labor and capital price exogenous.
} 
The WNO, however, implements restrictions on the use of GM food technology to regulate GM ingredients, such as specific regulations for GMO approval, regulations on cultivation, and private sector policies on GM-free food products. The coexistence policies, for instance, require minimum distance, buffer zones, and/or rotation intervals when planting GM crops with reference to the conventional farming. Such regulations raise the cost of using GM food technology (Beckmann et al. $2006,2011)$. We translate these policies into a single variable $\theta(\theta \geq 0)$, which represents an additional cost for the firm using the GM food technology ${ }^{3}$; a stricter GM food policy means a higher GM food policy compliance cost.

We normalize the overall population $(L)$ to one and classify consumers into three types, denoted by superscripts $\alpha, \beta, \gamma$, depending on their preferences. Fraction $\alpha$ of the population owns the GM food firm and shares the GM food profits. For example, GM R\&D researchers, producers, and retailers belong to this group. Consumers in this group have a strong preference for GM food and only consume GM food products. They are in favor of innovative technology and are convinced of its environmental and health benefits. Fraction $\beta$ of the population belongs to the non-GM food group. It consists of people who own the non-GM food firm and earn the non-GM food profits. The anti-GM food organizations, conventional and organic farmers, and anti-GM food consumers belong to this group. Consumers belonging to this group have a strong preference for non-GM food products and only purchase non-GM food products. They worry about the potential risks of the GM food technology. The rest of consumers belong to fraction $\gamma(=1-\alpha-\beta)$. This group considers GM and non-GM food products as imperfect substitutes and demands both. Its

\footnotetext{
${ }^{3}$ Beckmann et al. (2006) investigate the ex ante regulations and expost liability rules on coexistence regulations in the European Union, which pose costs on the GM farmer. For example, the coexistence regulations impose costs on the GM food firm directly, but they also influence the non-GM food production by possibilities of admixture. Since there is no direct input cost from the GM food policy regulation to the non-GM food firm, we only model the GM food policy compliance cost for the GM food firm and the non-GM food firm is influenced indirectly by the GM food policy regulation.
} 
members do not worry much about the potential risks of the GM food technology; therefore, we label them henceforth as "indifferent". The two food firms, GM and non-GM, engage in Bertrand competition, that is, they compete for the $\gamma$ consumers by setting a lower food price.

Consumers in the different groups purchase food products and numeraire goods subject to their income. Following Singh and Vives (1984), the quasi-linear utility functions of three groups $\operatorname{are}^{5}$ :

$$
\begin{aligned}
& U^{\alpha}=z^{\alpha}+a x_{G}^{\alpha}-\frac{1}{2} b\left(x_{G}^{\alpha}\right)^{2} \\
& U^{\beta}=z^{\beta}+a x_{N}^{\beta}-\frac{1}{2} b\left(x_{N}^{\beta}\right)^{2} \\
& U^{\gamma}\left(x_{G}^{\gamma}, x_{N}^{\gamma}\right)=z^{\gamma}+a x_{G}^{\gamma}+a x_{N}^{\gamma}-\frac{1}{2}\left[b\left(x_{G}^{\gamma}\right)^{2}+2 h x_{G}^{\gamma} x_{N}^{\gamma}+b\left(x_{N}^{\gamma}\right)^{2}\right] \\
& \text { s.t. } \quad I^{i}=z^{i}+\sum_{j} p_{j} x_{j}^{i} \text { for } i=\alpha, \beta, \gamma \text { and } j=G, N
\end{aligned}
$$

where $z^{i}$ is the utility from consuming the numeraire product with a price of one and $p_{j}$ is the price of the food product. Given that $b$ is positive, we assume $b^{2}-h^{2}>0, a b-a h>0$ and $h>0$. For the indifferent consumers, GM and non-GM food are substitutes, i.e., $h=0$ as they are perfect substitutes. The price change of GM food has an effect on the demand for the non-GM food products by $\gamma$ consumers. For $\alpha$ and $\beta$ consumers, the total income consists of wage and a share of either GM or non-GM food profits. Consumers belonging to group $\gamma$ only have income from their wages.

From equation (2.1), we can see that GM food consumers only consume GM food products and non-GM food consumers only consume non-GM food products, but the indifferent consumers

\footnotetext{
${ }^{4} \gamma$ consumers are indifferent to the GM food technology, not the GM or the non-GM food products.

${ }^{5}$ We assume the same parameters $a$ and $b$ for three groups, because i) all consumers demand for food products, no matter GM food or non-GM, ii) we want to simplify the analytical calculation and sign the policy effects.
} 
consume both. Thus, the total demand for GM food products is $x_{G}^{\alpha}+x_{G}^{\gamma}$, and the total demand for non-GM food products is $x_{N}^{\beta}+x_{N}^{\gamma}$.

The GM food policy influence on the food market is modeled as a two-stage game. First, the WNO sets the GM food policy level, and second the firms choose their prices. The GM and nonGM food firms have monopolies on their production. We use backward induction to find the policy compliance cost. The firms' profits are:

$$
\begin{gathered}
\pi_{G}=p_{G} x_{G}-[w+(1+\theta) r] x_{G} \\
\pi_{N}=p_{N} x_{N}-(w+r) x_{N}
\end{gathered}
$$

where $p_{i}(i=G, N)$ is the price of either the GM or non-GM food product, $w$ is the unit labor cost (wage rate) , and $r$ is the unit capital cost. The unit costs for the GM and non-GM food firms are assumed to be independent of the level of output and are given by $w+(1+\theta) r$ and $w+r$. In equilibrium, the GM food firm produces a sufficient quantity to meet the GM food demand, that is, $x_{G}=x_{G}^{\alpha}+x_{G}^{\gamma}$, and the non-GM firm food produces $x_{N}=x_{N}^{\beta}+x_{N}^{\gamma}$. The demand functions for both products are derived from consumers' maximization problems. These demand functions are (Appendix section 2.A.1):

$$
\begin{aligned}
& x_{G}=x_{G}^{\alpha}+x_{G}^{\gamma}=\frac{a-p_{G}}{b}+m-n p_{G}+\delta p_{N}=\frac{a}{b}+m-\left(\frac{1}{b}+n\right) p_{G}+\delta p_{N}, \\
& x_{N}=x_{N}^{\beta}+x_{N}^{\gamma}=\frac{a-p_{N}}{b}+c+\delta p_{G}-d p_{N}=\frac{a}{b}+c-\left(\frac{1}{b}+d\right) p_{N}+\delta p_{G} .
\end{aligned}
$$

where $m=(a b-a h) /\left(b^{2}-h^{2}\right), n=b_{2} /\left(b^{2}-h^{2}\right), \delta=h /\left(b^{2}-h^{2}\right)$. Using the demand functions, we can solve for the reaction functions of the firms (see Appendix section 2.A.2): 


$$
p_{G}=\frac{\frac{a}{b}+m+\delta p_{N}+\left(\frac{1}{b}+n\right)[w+(1+\theta) r]}{2\left(\frac{1}{b}+n\right)} \text { and } p_{N}=\frac{\frac{a}{b}+m+\delta p_{G}+\left(\frac{1}{b}+n\right)(w+r)}{2\left(\frac{1}{b}+d\right)} \text {. }
$$

Using these can solve for the equilibrium price for the GM food product:

$$
p_{G}^{*}=\frac{1}{b^{2} \delta^{2}-4 b^{2} n^{2}-8 n b-4}\left(\begin{array}{l}
-2(1+b n)^{2}(w+(1+\theta) r) \\
-b \delta((1+b n)(w+r)+(b m+a)) \\
-2(a+b m)(1+b n)
\end{array}\right)
$$

where $\partial p_{G}^{*} / \partial \theta>0$. The GM food policy compliance cost influences the GM food price directly, and the non-GM food price indirectly. The GM and non-GM food firms have a price-based competition to capture indifferent consumers. We solve for the equilibrium non-GM food price from the reaction function and find $\partial p_{N}^{*} / \partial \theta>0$, but $\partial p_{G}^{*} / \partial \theta>\partial p_{N}^{*} / \partial \theta$. The GM food firm prefers a low GM food policy cost and more GM food technology, whereas the non-GM food firm prefers a high GM food price to attract more $\gamma$ consumers to purchase non-GM food products.

The inverse demand functions for food products are: $p_{G}^{\alpha}=a-b x_{G}^{\alpha}$ for the GM food consumers, $p_{N}^{\beta}=a-b x_{N}^{\beta}$ for the non-GM food consumers, and $p_{G}^{\gamma}=a-b x_{G}^{\gamma}-h x_{N}^{\gamma}$ and $p_{N}^{\gamma}=a-h x_{G}^{\gamma}-b x_{N}^{\gamma}$ for $\gamma$ consumers. In the equilibrium, the consumer surplus is $c s_{G}^{\alpha}=\int_{0}^{x_{G}^{\alpha^{*}}} p\left(x_{G}^{\alpha}\right) d x_{G}^{\alpha}-p_{G}^{*} x_{G}^{\alpha^{*}}$ for $\alpha$ consumers and $c s_{N}^{\beta}=\int_{0}^{x_{N}^{\beta^{*}}} p\left(x_{N}^{\beta}\right) d x_{N}^{\beta}-p_{N}^{*} x_{N}^{\beta^{*}}$ for $\beta$ consumers. $\gamma$ consumers demand both GM and non-GM food products, so $c s^{\gamma}=c s_{G}^{\gamma}+c s_{N}^{\gamma}=\int_{0}^{x_{G}^{\gamma^{*}}} p\left(x_{G}^{\gamma}\right) d x_{G}^{\gamma}-p_{G}^{*} x_{G}^{\gamma^{*}}+\int_{0}^{x_{N}^{\gamma^{*}}} p\left(x_{N}^{\gamma}\right) d x_{N}^{\gamma}-p_{N}^{*} x_{N}^{\gamma^{*}}$. The aggregate social welfare of each group is given by: 


$$
\begin{aligned}
& W^{\alpha}=\pi_{G}(\theta)+c s_{G}^{\alpha}(\theta) \\
& W^{\beta}=\pi_{N}(\theta)+c s_{N}^{\gamma}(\theta) \\
& W^{\gamma}=c s_{G}^{\gamma}(\theta)+c s_{N}^{\gamma}
\end{aligned}
$$

Aggregate welfare is the sum of the three groups' welfare in equation (2.4):

$$
W(\theta)=\pi_{G}(\theta)+\pi_{N}(\theta)+c s_{G}(\theta)+c s_{N}(\theta)
$$

Thus, we can find the socially optimal GM food policy regulation by letting

$$
\frac{\partial W(\theta)}{\partial \theta}=\frac{\partial W^{\alpha}(\theta)}{\partial \theta}+\frac{\partial W^{\beta}(\theta)}{\partial \theta}+\frac{\partial W^{\gamma}(\theta)}{\partial \theta}=0
$$

\subsection{GM food policy effects on food security}

We investigate the GM food policy regulation effects on availability, access and utilization of food security. Food security is a multi-aspects issue. To obtain specific results, we interpreted in economic terms the three dimensions of food security in our model. As we stated earlier, the change of GM food policy regulation influences the GM food group directly and the non-GM food group

\begin{tabular}{|c|c|c|c|c|c|c|}
\hline & \multirow{2}{*}{$\begin{array}{l}\text { Availability } \\
\text { Production }\end{array}$} & \multicolumn{3}{|c|}{ Access } & \multicolumn{2}{|c|}{ Utilization } \\
\hline & & Price & Total income* & Demand & $\begin{array}{l}\text { Total } \\
\text { Utility }\end{array}$ & $\begin{array}{c}\text { Consumer } \\
\text { surplus }\end{array}$ \\
\hline GM & - & + & - & - & - & - \\
\hline Non-GM & + & + & + & + & + & + \\
\hline Indifferent & $\mathrm{N} / \mathrm{A}$ & $\mathrm{N} / \mathrm{A}$ & $\mathrm{N} / \mathrm{A}$ & - & $-/+$ & $-/+$ \\
\hline Total & - & + & $-/+$ & - & & \\
\hline
\end{tabular}
indirectly. In addition, it influences the consumption distribution across GM and non-GM food products for the indifferent consumers. The marginal effects in Table 2.1 (derivation: Appendix section 2.A.3) shows the GM food policy effects.

Table 2.1. Marginal policy effects due to an increase in regulation on food security 
In Table 2.1, food availability is the production of food in the economy, i.e. $x_{G}+x_{N}$. A stricter GM policy will reduce the production of GM food products because a higher GM food policy regulation compliance cost increases the price of capital input for the GM food firm. The price of GM food products is then higher, so the GM food demand from the $\alpha$ and $\gamma$ group decreases. The non-GM food demand from the $\beta$ group is not influenced by the GM food policy change, but if the demand for GM food products from the indifferent group decreases, the demand for non-GM food products will increase. So, a change of the GM food policy level has a positive effect on the non-GM food demand. There are two contradicting policy effects on both the GM and non-GM food production, but the policy effect on the overall food production is negative. The reason is that a higher GM food policy cost directly decreases the demand of both the GM food consumers and a portion of the indifferent consumers, which outweighs the positive effect on the non-GM food production that affected only a part of the indifferent consumers.

The GM food policy regulation influences food access, which includes food affordability, food allocation, and consumer choices. We quantify the food access by food prices, the total income of consumers, and their food demand. We divided all consumers into three groups according to their preference for food varieties, i.e., GM, non-GM, and indifferent. The GM food consumers are directly influenced by the change of GM food price and income. If the GM food policy compliance cost increases, the GM food price increases, hence more indifferent consumers choose non-GM food. The increasing demand for non-GM food drives the non-GM food price upwards. The GM food firm's profit decreases under a stricter GM policy defined in equation (2.2), but the non-GM food profit increases from a higher demand and the resulting higher equilibrium price of non-GM food products. Wage rate does not change, so the total income is smaller for the GM food group, larger for the non-GM food group and the same for the indifferent group. Therefore, both the GM 
and non-GM food prices go up. This price change decreases the average households' affordability and allocation of food.

Food utilization comprises nutritional value, social value, and food safety. We measure this by total food demand and consumer surplus from food consumption. Consumers choose food products according to their preferences (see equation 2.1); furthermore, they believe the food they choose is of higher value. A higher GM food policy regulation cost decreases the GM food production and total income of the GM food group and the demand for GM food products, hence nutrient intake decreases. If the GM food policy becomes stricter, consumer surplus of the GM food group will be reduced. The non-GM food consumers also lose from a higher non-GM food price induced by a higher demand from the indifferent group. Since the policy effect on the GM food price is larger than the non-GM food price and the effect on the GM food production is contradictory to the non-GM food production, the policy effect on the total consumer surplus is ambiguous. But indifferent consumers who purchase both GM and non-GM food products are compensated by the non-GM gain from the negative policy effect on the GM food products.

Thus, we conclude that

Proposition 2.1 A more stringent GM food policy regulation has a negative impact on global food security measured by its influence on food availability, accessibility and utilization.

\subsection{The Political Process}

We endogenize the GM food policy in the policy-making process. The GM and non-GM food groups have contradictory interests toward the level of GM food policy. The GM food group lobbies for lower GM food policy regulation costs in order to reduce the GM food firm's production costs, whereas the non-GM food group lobbies for a stricter GM food policy regulation. The indifferent group does not make any contribution to the WNO. They choose the GM and/or 
non-GM food products available in the market. Lobby groups influence the regulation in several ways. For example, they can make contributions, endorsements and committed votes to the WNO (or governments) so as to influence the policy outcome. For simplicity, we model these contributions as monetary equivalents from the interest groups. We follow Grossman and Helpman (1994)'s model and define the WNO payoff function as a maximization of a weighted sum of aggregate social welfare plus contributions from the lobbies. The WNO payoff is given by:

$$
G\left(\theta ; C^{\alpha}, C^{\beta}\right)=q W(\theta)+(1-q)\left[C^{\alpha}(\theta)+C^{\beta}(\theta)\right],
$$

where $q$ is the weight parameter, $0<q<1$, that the WNO attaches to the social welfare. $C^{\alpha}(\theta)$ and $C^{\beta}(\theta)$ are the differentiable truthful contribution schedules of the two lobbying groups like in Grossman and Helpman (1994), which means the GM food policy effects on the groups' contribution always represent the lobbies' policy preferences. We show this with two levels (high and low) of GM food policy regulations in Figure 2.2. For example, the negative effects resulting from higher GM food policy regulation costs induce the GM food lobby to contribute less. The non-GM food group contribution reaches the maximum at a high level of GM food policy regulation. The maximum contribution that any lobby can make is its gross income, which include wages and firms' profits. 


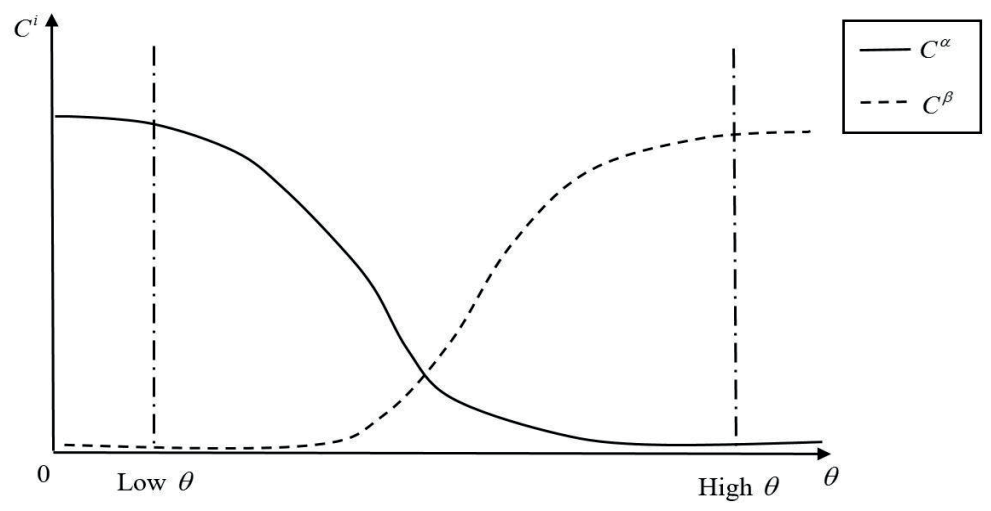

Figure 2.2 Truthful Contribution Schedules and the level of GM Regulations

The political process is a three-stage non-cooperative game. Two lobbies simultaneously announce their contribution schedules to the WNO in the first stage, and the WNO decides the GM food policy that maximizes its payoff in the second stage. In the third stage, firms choose prices and pay their contributions.

The GM and non-GM food groups make the total contribution $B^{i}(\theta)$ from their income for lobbying. The amount of the contribution from each group depends on the number of consumers and the share of their donations. The net income of each group is the net gross income of lobbying contributions:

$$
\begin{aligned}
& I_{P}^{\alpha}=\alpha w L+\pi_{G}(\theta)-B^{\alpha}(\theta) \\
& I_{P}^{\beta}=\beta w L+\pi_{N}(\theta)-B^{\beta}(\theta) \\
& I^{\gamma}=\gamma w L
\end{aligned}
$$

where $I_{P}^{i}(i=\alpha, \beta)$ denotes the group's net income in the political game. The indifferent group does not lobby, they only choose the food product available in the market, so their net income does not change. We assume that lobbying is costly (Laffont and Tirole 1993, Eerola 2004) and that a one dollar contribution costs $\left(1+\lambda^{i}\right)$ dollars in donations for lobby $i$. That is, $B^{i}(\theta)=\left(1+\lambda^{i}\right) C^{i}(\theta)$, 
where $\lambda^{i}$ is nonnegative and represents the efficiency of lobbying. $B^{i}$ is the total money collected for lobbying from group members. A group with a large membership collects a higher sun of contributions. But the lobbying efficiency also matters for the political outcomes. A higher $\lambda^{i}$ implies less efficient lobbying or, equivalently, higher lobbying cost. The WNO may have different preferences for interest groups. One group may have a higher efficiency and hence lower costs than the other group in the lobbying process. Lemma 2.2 of Grossman and Helpman (1994) provides the micro-foundations for lobbying and implies the optimal contribution level $C^{i^{*}}(\theta)$ for each group, which is determined by:

$$
\frac{\partial W^{i}(\theta)}{\partial \theta}=\left(1+\lambda^{i}\right) \frac{\partial C^{i^{*}}(\theta)}{\partial \theta} \text { for } i=\alpha, \beta
$$

In the above equation, we can see that due to lobbying costs $\left(\lambda^{i}\right)$, the marginal effect of GM food policy on the contribution is smaller than the marginal effect of GM food policy on welfare. It is, therefore, costly to lobby. The optimal political GM food policy is determined by:

$$
\frac{\partial G(\theta)}{\partial \theta}=q \frac{\partial W(\theta)}{\partial \theta}+(1-q)\left[\frac{\partial C^{\alpha}(\theta)}{\partial \theta}+\frac{\partial C^{\beta}(\theta)}{\partial \theta}\right]=0
$$

We substitute equation (2.9) into (2.10), and find that the first order condition for GM food policy can be expressed as:

$$
\frac{\partial G(\theta)}{\partial \theta}=\left(\frac{1-q}{1+\lambda^{\alpha}}+q\right) \frac{\partial W^{\alpha}(\theta)}{\partial \theta}+\left(\frac{1-q}{1+\lambda^{\beta}}+q\right) \frac{\partial W^{\beta}(\theta)}{\partial \theta}+q \frac{\partial W^{\gamma}(\theta)}{\partial \theta}=0
$$

Equation (2.11) is different from equation (2.6), which means that the politically determined GM food policy is a deviation from the social optimum, unless $\lambda^{i}$ is extremely high or $q=1$. We can see that lobby groups will not make contributions if the lobbying is extremely costly (i.e., $\lambda^{i}$ is high). 
Similarly, the WNO will not consider the contribution from groups if it only considers welfare (i.e, $q=1)$

Lobbying influences GM food policy and the food security status because the lobby contribution is taken from the income, according to equation (2.8). The two groups spend $B^{i}$ for lobbying, so the budget constraint shifts inward, which decreases the demand for both GM and non-GM food products as well as numeraire goods. Inward budget constraint shifting directly influences food security due to food access. The reduction in food demand decreases the amount of food consumed in equilibrium. More lobbying efforts from the GM food lobby may push the GM food policy compliance cost down and benefit the overall food security, but food security will be improved only when the benefits from lower policy costs compensate the lobbying costs of the two groups. On the other hand, if the policy is stricter with the lobbying influence, the food security will be worse. To summarize,

Lemma 2.1 The politically determined GM food policy regulation is a deviation from the socially optimal GM food policy due to the unbalanced lobbying power of interest groups. Political rivaly among interest groups worsens the food security status unless the benefit from a lenient GM food policy compensates the lobbying costs.

\subsection{Food security as a policy target}

GM food technology is a possible solution to improve food productivity and security (e.g. Paarlberg 2010, Vigani and Olper 2013). In this section, we discuss the political rivalry concerning GM food policy formation if the WNO wants to improve the food security level. We aggregate the three food security aspects (availability, access, and utilization) into a single variable $s$, which denotes the world's food security status.

Suppose the world has a target food security level to reach and allows GM food technology to be used in the agricultural food production. If the food security level is below the target level, the 
WNO would like to increase its food output by using more of the productive technology. Therefore, we define $\mu=\bar{s} / s$, where $\bar{s}$ is the target food security level and $s$ is the current level. $0<\bar{s}<1$ and $0<s<1$. We use $\mu$ to indicate the inverse of the current progress towards the food security goal of the world, $\bar{s}$. The non-GM food consumers constitute a significant part of social welfare, but an increase of $s$ through more GMO input does not increase their welfare directly. Therefore, we use an indirect way of including food security in the WNO's objective function, namely by changing the weights of the different lobbying contributions based on progress towards food security. Although $\mu$ is an exogenous variable for the lobbying groups and does not depend on the groups' lobbying efforts, it will influence the lobbies' contribution behaviors in the political process. In this case, the WNO payoff function becomes

$$
G_{s}=q W+(1-q)\left(\mu C^{\alpha}+C^{\beta}\right)
$$

We can use backward induction to find the optimal lobbying schedule for the two lobby groups. If the GM food lobby group knows that the WNO will try to increase the food security level in the second stage, it will change its optimal lobbying schedule in the first stage. That is,

$$
\frac{\partial W^{\alpha}}{\partial \theta}=\left(\frac{1+\lambda^{\alpha}}{\mu}\right) \frac{\partial C_{s}^{\alpha}}{\partial \theta}
$$

The GM food group spend $B_{s}^{\alpha}=\left(\left(1+\lambda^{\alpha}\right) / \mu\right) C_{s}^{\alpha}$ for lobbying, which is smaller than a target of no food security improvement (section 2.4). The GM group's contribution weighs more in the policymaking process when $\mu>1$ (i.e. food insecure). GM food consumers spend less of their income, which improves food affordability under a constant GM food price of food consumption.

Comparing equation (2.13) with (2.9), we can see that the GM food group is more efficient in the political process. One unit of welfare gain in the lobbying process needs $\left(1+\lambda^{\alpha}\right) / \mu$ units of 
contribution instead of $\left(1+\lambda^{\alpha}\right)$. From the WNO perspective, the income from lobby groups stays constant because one unit of GM group's contribution counts for more in the WNO payoff function. Lobby groups would spend less than when food security is not a policy issue for a lenient GM food policy regulation, according to equation (2.13).

From the above discussion, we determine that

Lemma 2.2 When the food security status is an important part of a WNO policy, the GM food group will be more efficient in the political game, but the WNO will not be worse off by having the same total contribution income.

When the domestic production level reaches its target food security level, the WNO resorts to its old weights. In this case, the WNO does not weigh the GM food lobby heavier than the nonGM food lobby; lobbies compete equally in the policy game. However, many low food security countries implement strict GM food policies. Possible reasons could be that the GM food policy does not always aim to improve the food security. Also, if the non-GM food lobby has a large membership and is more powerful in the political process than the GM food lobby, the non-GM group's contribution will be high, and finally the GM food policy regulation will be strict. In this case, the WNO could also weight the non-GM food lobby heavier than the GM food lobby without decreasing its payoff.

Many countries in Africa, for instance, continue to ban the GM crop traits regardless of its significant yield gains (Paarlberg 2009, Qaim and Zilberman 2003). Other reasons for the ban are exports worries, the non-GM food group successfully lobbying the government in those countries, and/or the GM food lobby's benefits are small in relation to the lobbying costs, i.e. the lobbying costs are relatively high.

\subsection{Discussion and Conclusion}


Agricultural biotechnology is an advanced technology to improve agricultural production. It is regarded as one of the options for improving global food security. The dispute about the effects of the technology on humans and nature impeded its application (Wesseler and Zilberman 2014). This debate has made the level of GM food policy regulation a political game.

This paper develops a standard political economy model of GMO regulations, modeling the GM food policy as the outcome of a GM and non-GM food group lobbying game. We find that a stricter GM food policy has negative effects on three aspects of the food security: availability, access, and utilization. The politically determined GM food policy worsens the food security situation under the costly lobbying assumption. We also discuss when the WNO weighs the GM and non-GM food lobbies' contributions differently depending on the food security status. The GM food lobby becomes more efficient in the political game than the non-GM food group when the country commits to improving its food security. If the non-GM food lobby is large and strong, it will make large lobbying contributions for a stricter GM food policy, even when the country is food insecure. The pro-GM food lobby group will be more effective if the ruling WNO is concerned about food security. Linking the results to international debates on GMOs in the case where the opposition to the GM food technology is more successful, either the opposition has more financial resources available for lobbying or the governing bodies are less concerned about food security. What in this case is the most dominating factor will be an empirical question. Considering the importance of the issue, this warrants further research.

High-income countries, such as some European countries, can afford to implement a strict GM food policy without worsening the food security condition, but for more than two-thirds of low-middle-income countries, the food security issue remains (Economist Intelligent Unit 2015). The GM food policy in many developing countries, such as Southern Asian and African countries, is strict, whereas many of them experience food shortages and malnutrition. The various countries 
could have tailored GM food policies according to each of their domestic food supply and demand, but they also need to take food security into consideration while making food policies, especially for developing countries. The food security issue is international, and becoming more and more important. Food security status is low in many low-middle-income countries. Governments in each country have a responsibility to find more ways of improving sustainable agricultural production and food security in their country and globally.

The model provides an economic explanation for the observed lobbying activities. For many, it is obvious that the input supply sector of the technology will gain from lobbying for less strict regulations. On the other hand, there are also some private gains from lobbying against the technology, as claimed explicitly by Apel (2010) and more indirectly by Paarlberg (2009), when referring to projects funding biotechnology regulations in Africa. The political rivalry between contradictory interest groups offers an additional explanation why new technologies often have faced resistance, not only GMOs (Moses 2016; Juma 2016). Our model explains the market competition of the GM and non-GM food products and the driving force of lobbying competition that drives opposition to new technologies. The challenge is to identify what are the private economic gains of lobby groups that oppose new technologies. One obvious benefit is reducing losses from being displaced by the new technologies. In the case of GM food technologies, environmental and other non-governmental organizations are more vocal within the European Union. Within the European Union, the group for non-GM food products is much larger than the group supporting the GM food technology (Tosun and Schaub 2015). Again, this raises the question of what do they gain? Or do EU policy makers care less about food security? 


\section{A Appendix}

\section{A.1 Derivation of demand functions of the three types of consumers:}

GM food consumers maximize: $U^{\alpha}=z^{\alpha}+a x_{G}^{\alpha}-\frac{1}{2} b\left(x_{G}^{\alpha}\right)^{2}$

Non-GM food consumers maximize: $U^{\beta}=z^{\beta}+a x_{N}^{\beta}-\frac{1}{2} b\left(x_{N}^{\beta}\right)^{2}$

Indifferent consumers maximize: $U^{\gamma}\left(x_{G}^{\gamma}, x_{N}^{\gamma}\right)=z^{\gamma}+a x_{G}^{\gamma}+a x_{N}^{\gamma}-\frac{1}{2}\left[b\left(x_{G}^{\gamma}\right)^{2}+2 h x_{G}^{\gamma} x_{N}^{\gamma}+b\left(x_{N}^{\gamma}\right)^{2}\right]$

Subject to their respective incomes:

$$
\begin{aligned}
& I^{\alpha}=w \alpha L+\pi_{G} \\
& I^{\beta}=w \beta L+\pi_{N} \\
& I^{\gamma}=w \gamma L
\end{aligned}
$$

where $b$ is positive, $b^{2}-h^{2}>0$ and $a b-a h>0$ given that $h>0$, GM and non-GM food are imperfect substitutes. A price change of GM food products has effects on the total demand for the non-GM food products.

Setting up the maximization problems subject to the budget constraints we can solve for the demand functions of the different groups:

$$
\begin{aligned}
x_{G}^{\alpha} & =\frac{a-p_{G}}{b} \\
x_{N}^{\beta} & =\frac{a-p_{N}}{b}
\end{aligned}
$$

For the indifferent consumers: 
From the first-order condition for the utility function of the $\gamma$ consumers, we find:

$$
\begin{aligned}
& p_{G}=a-b x_{G}^{\gamma}-h x_{N}^{\gamma} \\
& p_{N}=a-h x_{G}^{\gamma}-b x_{N}^{\gamma}
\end{aligned}
$$

and solving these for the direct demand gives:

$$
\begin{aligned}
& x_{G}^{\gamma}=m-n p_{G}+\delta p_{N} \\
& x_{N}^{\gamma}=m+\delta p_{G}-n p_{N}
\end{aligned}
$$

where

$m=\frac{a b-a h}{b^{2}-h^{2}}, n=\frac{b}{b^{2}-h^{2}}, \delta=\frac{h}{b^{2}-h^{2}}$, given our earlier assumptions about parameters, these imply that: $n>0, \delta>0, n>\delta, n^{2}>\delta^{2}$.

From the direct demand functions, we can see there are cross-price effects.

Total demand for both products are then respectively:

$$
\begin{aligned}
& x_{G}=x_{G}^{\alpha}+x_{G}^{\gamma}=\frac{a-p_{G}}{b}+m-n p_{G}+\delta p_{N}=\frac{a}{b}+m-\left(\frac{1}{b}+n\right) p_{G}+\delta p_{N} \\
& x_{N}=x_{N}^{\beta}+x_{N}^{\gamma}=\frac{a-p_{N}}{b}+m+\delta p_{G}-n p_{N}=\frac{a}{b}+m-\left(\frac{1}{b}+n\right) p_{N}+\delta p_{G} .
\end{aligned}
$$

\section{A.2 Solving for the equilibrium prices:}

Profit function of the GM food firm:

$$
\pi_{G}=p_{G} x_{G}-[w+(1+\theta) r] x_{G}
$$


Inserting the total demand function for GM food products and taking the first derivative, and solving for $p_{G}$ gives the reaction function of the GM food firm:

$$
\begin{aligned}
& \frac{\partial \pi_{G}}{\partial p_{G}}=\frac{a}{b}+m-2\left(\frac{1}{b}+n\right) p_{G}+\delta p_{N}+\left(\frac{1}{b}+n\right)[w+(1+\theta) r]=0 \\
& p_{G}=\frac{\frac{a}{b}+m+\delta p_{N}+\left(\frac{1}{b}+n\right)[w+(1+\theta) r]}{2\left(\frac{1}{b}+n\right)}
\end{aligned}
$$

Similarly, the profit function of the non-GM food firm:

$$
\pi_{N}=p_{N} x_{N}-(w+r) x_{N}
$$

Inserting the total demand function for non-GM food products and taking the first derivative, and solving for $p_{N}$ gives the reaction function of the non-GM food firm:

$$
\begin{gathered}
\frac{\partial \pi_{N}}{\partial p_{N}}=\frac{a}{b}+m-2\left(\frac{1}{b}+n\right) p_{N}+\delta p_{G}+\left(\frac{1}{b}+n\right)(w+r)=0 \\
p_{N}=\frac{\frac{a}{b}+m+\delta p_{G}+\left(\frac{1}{b_{2}}+n\right)(w+r)}{2\left(\frac{1}{b}+n\right)}
\end{gathered}
$$

By inserting the reaction function of the non-GM food firm in the function of the GM food firm, we can solve for the equilibrium price $p_{G}^{*}$

$$
p_{G}^{*}=\frac{1}{b^{2} \delta^{2}-4 b^{2} n^{2}-8 n b-4}\left(\begin{array}{l}
-2(1+b n)^{2}(w+(1+\theta) r) \\
-b \delta((1+b n)(w+r)+(b m+a)) \\
-2(a+b m)(1+b n)
\end{array}\right)
$$


So, $\frac{\partial p_{G}^{*}}{\partial \theta}=\underbrace{\frac{\overbrace{-2(1+b n)^{2}}^{<0}}{b^{2}\left(\delta^{2}-4 n^{2}\right)-8 n b-4}}_{<0}>0$, for $n>\delta$.

Using the reaction function of the non-GM food firm we find for the equilibrium non-GM food price:

$\frac{\partial p_{N}^{*}}{\partial \theta}=\frac{\delta}{2\left(\frac{1}{b}+n\right)} \frac{\partial p_{G}}{\partial \theta}>0$. We find $\frac{\delta}{2\left(\frac{1}{b}+n\right)}<1$, for $n>\delta$, so $\frac{\partial p_{G}^{*}}{\partial \theta}>\frac{\partial p_{N}^{*}}{\partial \theta}$.

\section{A.3 The marginal effects of the GM food policy on food security:}

Food availability: quantity (production):

Given that in equilibrium the quantity on the market is solely determined by equilibrium prices we can use the demand functions to establish the effects on production:

$$
\begin{aligned}
& \frac{\partial x_{G}^{*}}{\partial \theta}=-\left(\frac{1}{b}+n\right) \frac{\partial p_{G}}{\partial \theta}+\delta \frac{\partial p_{N}}{\partial \theta}=-\left(\frac{1}{b}+n\right) \frac{\partial p_{G}}{\partial \theta}+\delta \frac{\partial p_{N}}{\partial p_{G}} \frac{\partial p_{G}}{\partial \theta} \\
& =-\left(\left(\frac{1}{b}+n\right)-\frac{\delta^{2}}{2\left(\frac{1}{b}+n\right)}\right) \frac{\partial p_{G}}{\partial \theta}=-\underbrace{(\overbrace{\left.\frac{2\left(\frac{1}{b}+n\right)^{2}-\delta^{2}}{2\left(\frac{1}{b}+n\right)}\right)}^{\left(\frac{1}{b}\right)})}_{<0} \frac{\partial p_{G}}{\partial \theta}<0
\end{aligned}
$$

There is no direct influence on the price and quantity of non-GM food products from the GM food policy, but given that the two are imperfect substitutes we have $x_{N}\left(p_{G}(\theta), p_{N}\left(p_{G}(\theta)\right)\right)$, and $\frac{\partial x_{N}}{\partial p_{G}}>0$ 


$$
\begin{aligned}
& \frac{\partial x_{N}^{*}}{\partial \theta}=-\left(\frac{1}{b}+n\right) \frac{\partial p_{N}}{\partial \theta}+\delta \frac{\partial p_{G}}{\partial \theta}=-\left(\frac{1}{b}+n\right) \frac{\partial p_{N}}{\partial p_{G}} \frac{\partial p_{G}}{\partial \theta}+\delta \frac{\partial p_{G}}{\partial \theta} \\
& =-\left(\left(\frac{1}{b}+n\right) \frac{\delta}{2\left(\frac{1}{b}+n\right)}-\delta\right) \frac{\partial p_{G}}{\partial \theta}=-\underbrace{\left(\frac{\delta}{2}-\delta\right)}_{>0} \frac{\partial p_{G}}{\partial \theta}>0
\end{aligned}
$$

For the policy effect on the total food supply:

$$
\begin{aligned}
& \frac{\partial x_{G}^{*}}{\partial \theta}+\frac{\partial x_{N}^{*}}{\partial \theta}=-\left(\frac{2\left(\frac{1}{b}+n\right)^{2}-\delta^{2}}{2\left(\frac{1}{b}+n\right)}\right) \frac{\partial p_{G}}{\partial \theta}-\left(\frac{\delta}{2}-\delta\right) \frac{\partial p_{G}}{\partial \theta}=\left(\frac{-2\left(\frac{1}{b}+n\right)^{2}+\delta^{2}+\delta\left(\frac{1}{b}+n\right)}{2\left(\frac{1}{b}+n\right)}\right) \frac{\partial p_{G}}{\partial \theta}
\end{aligned}
$$

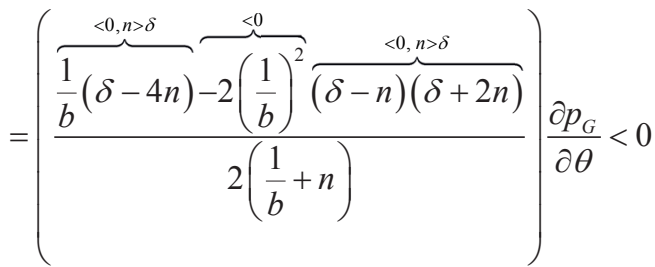

Food access: food prices, income, and demand:

GM food price: $\frac{\partial p_{G}^{*}}{\partial \theta}>0$

Non-GM food price has no direct effects, but from the reaction function, $\frac{\partial p_{N}^{*}}{\partial \theta}=\frac{\partial p_{N}^{*}}{\partial p_{G}^{*}} \frac{\partial p_{G}^{*}}{\partial \theta}>0$.

Wage income is determined by the whole economy, the labor supply, and the demand from the food market and the numeraire market, so we assume it is exogenous and constant.

However, the GM and non-GM food profits are influenced.

$$
\frac{\partial \pi_{G}^{*}}{\partial \theta}=-r x_{G}^{*}<0,
$$


$\frac{\partial \pi_{N}^{*}}{\partial \theta}=\frac{\partial p_{N}^{*}}{\partial \theta} x_{N}^{*}+\underbrace{\left(p_{N}-w-r\right)}_{>0} \frac{\partial x_{N}^{*}}{\partial \theta}>0$.

The profit effects depend on both the GM and non-GM food productions, so the sign it hard to say.

Marginal effects on demands:

$$
\begin{aligned}
& \frac{\partial x_{G}^{\alpha}}{\partial \theta}=-\frac{1}{b} \frac{\partial p_{G}}{\partial \theta}<0 \\
& \frac{\partial x_{N}^{\beta}}{\partial \theta}=-\frac{1}{b} \frac{\partial p_{N}}{\partial \theta}<0 \\
& \frac{\partial x_{G}^{\gamma}}{\partial \theta}=-n \frac{\partial p_{G}}{\partial \theta}+\delta \frac{\partial p_{N}}{\partial \theta}=-n \frac{\partial p_{G}}{\partial \theta}+\delta \frac{\partial p_{N}}{\partial p_{G}} \frac{\partial p_{G}}{\partial \theta}=-n \frac{\partial p_{G}}{\partial \theta}+\frac{b \delta^{2}}{2(1+b n)} \frac{\partial p_{G}}{\partial \theta} \\
& =\left(-n+\frac{\delta^{2}}{2\left(\frac{1}{b}+n\right)}\right) \frac{\partial p_{G}}{\partial \theta}=\underbrace{\left(\frac{-2 n \frac{1}{b}-2 n^{2}+\delta^{2}}{2\left(\frac{1}{b}+n\right)}\right)}_{<0} \frac{\partial p_{G}}{\partial \theta}<0
\end{aligned}
$$

for $b^{2}-h^{2}>0$

$$
\frac{\partial x_{N}^{\gamma}}{\partial \theta}=\delta \frac{\partial p_{G}}{\partial \theta}-n \frac{\partial p_{N}}{\partial p_{G}} \frac{\partial p_{G}}{\partial \theta}=\left(\delta-n \frac{\delta}{2\left(\frac{1}{b}+n\right)}\right) \frac{\partial p_{G}}{\partial \theta}=\left(\frac{2 \delta \frac{1}{b}+\delta n}{2\left(\frac{1}{b}+n\right)}\right) \frac{\partial p_{G}}{\partial \theta}>0 .
$$


$\frac{\partial x_{G}^{\gamma}}{\partial \theta}+\frac{\partial x_{N}^{\gamma}}{\partial \theta}=\left(\frac{-2 n \frac{1}{b}-2 n^{2}+\delta^{2}}{2\left(\frac{1}{b}+n\right)}\right) \frac{\partial p_{G}}{\partial \theta}+\left(\frac{2 \delta \frac{1}{b}+\delta n}{2\left(\frac{1}{b}+n\right)}\right) \frac{\partial p_{G}}{\partial \theta}=\left(\frac{-2 n \frac{1}{b}+2 \delta \frac{1}{b}-2 n^{2}+\delta^{2}+\delta n}{\left.2 \frac{2 \delta \frac{1}{b}+\delta n}{2\left(\frac{1}{b}+n\right)}\right) \frac{\partial p_{G}}{\partial \theta}}\right) \frac{\partial p_{G}}{\partial \theta}<0$

Food utilization: utility from food consumption.

Consumer surplus:

$$
\begin{aligned}
& c s^{\alpha}=\int_{0}^{x_{G}^{\alpha^{*}}}\left(a-b x_{G}^{\alpha}\right) d x_{G}^{\alpha}-p_{G}^{*} x_{G}^{\alpha^{*}}=a x_{G}^{\alpha}-b \frac{\left(x_{G}^{\alpha}\right)^{2}}{2}-p_{G} x_{G}^{\alpha}=\left(a-p_{G}\right) x_{G}^{\alpha}-\frac{b}{2}\left(x_{G}^{\alpha}\right)^{2} \\
& c s^{\beta}=\int_{0}^{x_{G}^{\beta^{*}}}\left(a-b x_{N}^{\beta}\right) d x_{N}^{\beta}-p_{N}^{*} x_{N}^{\beta^{*}}=a x_{N}^{\beta}-b \frac{\left(x_{N}^{\beta}\right)^{2}}{2}-p_{N} x_{N}^{\beta}=\left(a-p_{N}\right) x_{N}^{\beta}-\frac{b}{2}\left(x_{N}^{\beta}\right)^{2} \\
& c s^{\gamma}=\int_{0}^{x_{G}^{\gamma^{*}}}\left(a-b x_{G}^{\gamma}-h x_{N}^{\gamma}\right) d x_{G}^{\gamma}-p_{G}^{*} x_{G}^{\gamma^{*}}+\int_{0}^{x_{N}^{\gamma^{*}}}\left(a-h x_{G}^{\gamma}-b x_{N}^{\gamma}\right) d x_{N}^{\gamma}-p_{N}^{*} x_{N}^{\gamma^{*}} \\
& =\left(a-p_{G}\right) x_{G}^{\gamma}-\frac{b}{2}\left(x_{G}^{\gamma}\right)^{2}-2 h x_{G}^{\gamma} x_{N}^{\gamma}+\left(a-p_{N}\right) x_{N}^{\gamma}-\frac{b}{2}\left(x_{N}^{\gamma}\right)^{2}
\end{aligned}
$$

The marginal effects:

$$
\begin{aligned}
& \frac{\partial c s^{\alpha}}{\partial \theta}=-\frac{\partial p_{G}}{\partial \theta} x_{G}^{\alpha}+\left(a-p_{G}\right) \frac{\partial x_{G}^{\alpha}}{\partial \theta}-b x_{G}^{\alpha} \frac{\partial x_{G}^{\alpha}}{\partial \theta}=-\frac{\partial p_{G}}{\partial \theta} x_{G}^{\alpha}+\left(a-p_{G}\right) \frac{\partial x_{G}^{\alpha}}{\partial \theta}+x_{G}^{\alpha} \frac{\partial p_{G}}{\partial \theta} \\
& =-\frac{\partial p_{G}}{\partial \theta} x_{G}^{\alpha}+\left(a-p_{G}\right) \frac{\partial x_{G}^{\alpha}}{\partial \theta}+x_{G}^{\alpha} \frac{\partial p_{G}}{\partial \theta}=\underbrace{\left(a-p_{G}\right)}_{>0} \frac{\partial x_{G}^{\alpha}}{\partial \theta}<0 \\
& <0 \\
& \frac{\partial c s^{\beta}}{\partial \theta}=-\frac{\partial p_{N}}{\partial \theta} x_{N}^{\beta}+\left(a-p_{N}\right) \frac{\partial x_{N}^{\beta}}{\partial \theta}-b x_{N}^{\beta} \frac{\partial x_{N}^{\beta}}{\partial \theta}=-\frac{\partial p_{N}}{\partial \theta} x_{N}^{\beta}+\left(a-p_{N}\right) \frac{\partial x_{N}^{\beta}}{\partial \theta}+x_{N}^{\beta} \frac{\partial p_{N}}{\partial \theta}=\left(a-p_{N}\right) \frac{\partial x_{N}^{\beta}}{\partial \theta}>0
\end{aligned}
$$




$$
\begin{aligned}
& \frac{\partial c s^{\gamma}}{\partial \theta}=-\frac{\partial p_{G}}{\partial \theta} x_{G}^{\gamma}+\left(a-p_{G}\right) \frac{\partial x_{G}^{\gamma}}{\partial \theta}-b x_{G}^{\gamma} \frac{\partial x_{G}^{\gamma}}{\partial \theta}-2 h x_{N}^{\gamma} \frac{\partial x_{G}^{\gamma}}{\partial \theta}-2 h x_{G}^{\gamma} \frac{\partial x_{N}^{\gamma}}{\partial \theta}-\frac{\partial p_{N}}{\partial \theta} x_{N}^{\gamma}+\left(a-p_{N}\right) \frac{\partial x_{N}^{\gamma}}{\partial \theta}-b x_{N}^{\gamma} \frac{\partial x_{N}^{\gamma}}{\partial \theta} \\
& =\underbrace{\left(a-p_{G}\right) \frac{\partial x_{G}^{\gamma}}{\partial \theta}}_{<0} \underbrace{-2 h x_{N}^{\gamma} \frac{\partial x_{G}^{\gamma}}{\partial \theta}}_{>0} \underbrace{-2 h x_{G}^{\gamma} \frac{\partial x_{N}^{\gamma}}{\partial \theta}}_{<0} \underbrace{+\left(a-p_{N}\right) \frac{\partial x_{N}^{\gamma}}{\partial \theta}}_{>0} \underbrace{-\frac{\partial p_{G}}{\partial \theta} x_{G}^{\gamma}-\frac{\partial p_{N}}{\partial \theta} x_{N}^{\gamma}}_{<0} \underbrace{-b x_{G}^{\gamma} \frac{\partial x_{G}^{\gamma}}{\partial \theta}}_{>0} \underbrace{-b x_{N}^{\gamma} \frac{\partial x_{N}^{\gamma}}{\partial \theta}}_{<0}
\end{aligned}
$$

It is ambiguous. 


\title{
Chapter $3^{6}$
}

\section{Food Self-sufficiency Under a Conflict of Interest: The Case of Maize in South Africa}

\begin{abstract}
Food sufficiency is an important aspect of the food security issue, especially after the 2008 food crisis. One of the potential solutions to this problem is agricultural biotechnology. We study the relationship between the GM food policy and the food self-sufficiency rate under the condition of a conflict of different interests, with the example of maize production in South Africa. In our model, the government sets the GM food policy to maximize the weighted sum of social welfare and contributions from interest groups. We show that a strict GM food policy can lead to food selfinsufficiency. We also find that the food self-sufficiency rate is a biased measure of food availability when both the production and consumption are changed.
\end{abstract}

\footnotetext{
${ }^{6}$ This chapter is based on the article: Qianqian Shao, Dusan Drabik, and Justus Wesseler. Food Self-sufficiency Under a Conflict of Interest: The Case of Maize in South Africa.
} 


\subsection{Introduction}

Food security is a complex development issue that involves health, economic development, the environment, and trade. The Food and Agriculture Organization of the United Nations defines food security as "the access for all people at all times to enough food for a healthy, active life" (FAO, 1996). The food crisis in 2008 and the ensuing price spikes in early 2011 and 2012 drew attention to the vulnerability of the global food supply.

Climate change and competition of resources (e.g., land, water, and energy) due to the biofuels production were listed as the most important causes of volatile food prices and factors affecting food availability (e.g., Royal Society of London 2009; Godfray et al. 2010; Oxfam 2012; and de Gorter et al. 2015). Moreover, the global population is projected to reach 9 billion by the middle of the twenty-first century. As a result, it is expected that the world will need 70 to 100 percent more food by then compared to what is needed now (World Bank 2008; Royal Society of London 2009; von Braun 2010).

Agricultural science and technological innovations are promising contributors to the hunger reduction and could help developing countries improve their food security (von Braun 2010; Ruane and Sonnino 2011; Qaim and Kouser 2013; Dibden et al. 2013). Qaim and Kouser (2013) conducted an expost analysis of the relation between food security and GM crops at the micro level and found that the GM food technology improvs food security, but by itself it will not solve the hunger problem. Agricultural biotechnology could be embraced in the national food policy as an option to increase food availability in a sustainable way.

The application of agricultural biotechnology is controversial in many countries. Many consumers worry about the potential risks of the GM food technology and are reluctant to purchase GM food products. The divergence of consumers' attitudes influences the GM food policy regulations of a country. For example, the United States assesses the food and environmental safety, 
allowing voluntary labeling, while the European Union applies mandatory labeling and traceability rules.

Even though the GM food technology offers potential benefits to address a number of food security related issues, many developing countries are reluctant to use the technology and do not have a complete GMO regulatory framework (FAO 2000, 2003). However, an intensive public debate takes place also in countries that allow the cultivation of GM crops (e.g., China, South Africa, and the United States). The GM food issue is not only a scientific problem but also a political one, where different interest groups compete to influence policy outcomes (Graff et al. 2014; Apel 2010; Qaim 2009; Paarlberg and Pray 2007; Josling et al. 2004). These outcomes influence food production and food security in a country.

The food self-sufficiency rate (SSR) is defined as a ratio of domestic food production to food consumption (FAO, 2015). A higher SSR was set as an agricultural policy goal in many countries during the 1970s' food crisis, especially in developing countries (O’Hagan 1976, Barker and Hayami et al. 1976, Clapp 2015). A greater reliance on the domestic food market is regarded as a less risky strategy to avoid the volatility of food prices and the uncertainty of food import. However, the opposing views argue that the SSR is misleading because of its inefficient loss of comparative advantage for countries in the world market, and introduction of trade distortion (Naylor and Falcon 2010). Even though the SSR is debatable for its measurement, many countries (e.g., Japan and South Korea) still emphasize food self-sufficiency with in their food policies for staple foods (Honma 2015, Beghin and Bureau 2015).

The 2007-2008 food crisis brought the focus back to the SSR again. Despite its debatable effectiveness, a growing number of developing countries are now including food self-sufficiency into their food policies to avoid the uncertainty of world food markets (Clapp 2015). In this paper, we analyze the situation in one such a country-South Africa. We use South Africa as an example for 
three reasons. First, the country has both GM and non-GM food production, and the GM maize production occupies $72 \%$ of its total maize production. Second, the use of GM crops is controversial and the policy has become more stringent after the mandatory labeling regulation, which was issued in 2011. Third, South Africa is self-sufficient in maize, but the SSR is unstable due to the fluctuation of the food production and supply system (Luan et al. 2013).

In this paper, we use a political economy model to investigate the GMO food policy effects on the food SSR in a small open economy. Our political economy framework follows Grossman and Helpman's (1994) model that has been applied to a number of similar problems. Graff et al. (2009) developed a conceptual political economy framework to analyze the formation of agricultural biotechnology policies. They consider multiple interest groups that have different weights in influencing regulators. Graff et al. (2009) conclude that the ban on GM food in Europe is not simply due to the consumers' rejection, but rather due to the convergence of the influence of multiple interest groups. Gruère et al. (2009) show that interests related to production are important in explaining GM food policy regulations both theoretically and empirically.

We study the relationship between the GM food policy and the food self-sufficiency rate under a conflict of different interests. The government maximizes a weighted sum of social welfare and lobby contributions. Two lobby groups, a GM and a non-GM food lobby, compete in the policy-making process for their own interests. GM food policy regulations directly influence the GM food production.

Our results show that when the GM food policy cost is low, the government maximizes its payoff regardless of the political bias from the lobbying contributions. The food self-sufficiency rate is high when the GM food policy cost is low. Two lobby groups need to make contributions for their favorable regulation levels. The GM food lobby benefits more from a lenient GM food policy; however, the non-GM food lobby gains from a stricter GM food policy. We also point out to the 
limitation of using the SSR as a food sufficiency measure when the food demand is not constant in the country.

\subsection{The Model}

\subsubsection{Production}

We consider a small open economy with two sectors. One sector produces agricultural food products, and the other produces a numeraire good $(z)$. There are two representative competitive firms in the food sector: a GM food firm that uses a GM technology to produce GM food $\left(x_{G}\right)$ and a non-GM food firm producing conventional food $\left(x_{N}\right)$. We assume the GM food firm is more productive than the non-GM food firm due to the technology (e.g., less labor input). There are biotechnology regulations in food production (e.g., approval, labeling, and coexistence policies) that generate additional costs for using GM food technology. We regard the regulation compliance cost $(\theta, 0 \leq \theta \leq 1)$ as a part of the GM food firm's capital input. This representation of the compliance cost is in line with the argument of Beckmann et al. (2011), which says that there is an additional cost to the GM food firm due to the property rights regimes. A stricter GM policy induces a higher GM compliance cost for the GM food firm.

The wage rate of labor $(L)$ is denoted by $w$ and the cost of capital $(K)$ by $r$. The total labor and capital endowment $(\bar{L}, \bar{K})$ is used in GM $\left(L_{G}, K_{G}\right)$, non-GM $\left(L_{N}, K_{N}\right)$ and numeraire $\left(L_{z}, K_{z}\right)$ goods production. The Cobb-Douglas production function of a $z$ good exhibits constant returns to scale $z=a L_{z}^{\mu} K_{z}^{1-\mu}$, where $0 \leq \mu \leq 1$. The production functions for GM and non-GM goods are $x_{G}=A L_{G}^{\varepsilon_{L}} K_{G}^{\varepsilon_{K}}$ and $x_{N}=B L_{N}^{\eta_{L}} K_{N}^{\eta_{K}}$. They exhibit decreasing returns to scale (i.e., 
$\varepsilon_{L}+\varepsilon_{K}<1$ and $\left.\eta_{L}+\eta_{K}<1\right)$. The profits made by the GM and non-GM food firms can be written as

$$
\begin{gathered}
\pi_{G}=p_{G} x_{G}-w L_{G}-(1+\theta) r K_{G} \\
\pi_{N}=p_{N} x_{N}-w L_{N}-r K_{N},
\end{gathered}
$$

where $p_{G}$ and $p_{N}$ are the world prices of GM and non-GM food products, respectively.

\subsubsection{Consumers}

We normalize the overall population to one and divide it into three groups, depending on their preferences regarding GM food technology. A fraction $\alpha$ of the population owns the GM food firm and shares the GM food profits. This group includes, among others, GM R\&D researchers, producers, and retailers. Consumers in this group have a strong preference for GM food technology and only consume GM food products. They are in favor of GM food technology and are convinced of its environmental and health benefits. A fraction $\beta$ of the population belongs to the non-GM food group. It consists of people who own the non-GM food firm and earn the non-GM food profits. The conventional farmers and anti-GM organizations belong to this group. Some of these organizations play an integral role in the policy formation, and their revenue comes from non-GM donors that align with their interests (Graff et al. 2009). Consumers belonging to this group have a strong preference for the non-GM food products and only purchase non-GM food products. They worry about the potential risks of GM food technology. The rest of consumers belong to the $\gamma$ fraction $(\gamma=1-\alpha-\beta)$. They do not have a strict preference for either product and consume both.

All consumers earn wage income and a lump-sum transfer from the government, corresponding to the GM food policy regulation $\left(\theta r K_{G}\right)$; each group receives a share of the 
transfer equal to its population share. $\alpha$ and $\beta$ groups also obtain profits from the GM and nonGM food firm.

Consumers who belong to either the GM or non-GM food group need to make donations to their lobby organizations in order for them to make contributions in the political process. These contributions are used to lobby the government for a favorable GM food policy. We assume there is an incumbent government and two lobbies make monetary equivalent ${ }^{7}$ contributions to influence policies. We denote the total contribution made by each group for lobbying by $T^{i}, i=\alpha, \beta$. The total contribution depends on the policy cost $\theta$ (more details on $T$ in the section on the political process). Lobby groups make contributions from their income, so the net income of each group can be given as

$$
\begin{aligned}
& Y^{\alpha}=\alpha w \bar{L}+\alpha \theta r K_{G}+\pi_{G}-T^{\alpha} \\
& Y^{\beta}=\beta w \bar{L}+\beta \theta r K_{G}+\pi_{N}-T^{\beta} \\
& Y^{\gamma}=\gamma w \bar{L}+\gamma \theta r K_{G}
\end{aligned}
$$

Group $\gamma$ is not involved in the political game and its income is influenced by the GM food policy cost directly.

Consumers purchase food products and numeraire goods to maximize their constant elasticity of substitution (CES) utility subject to their net income

$$
\begin{gathered}
\max U^{i}=\left[\phi\left(x_{j}^{i}\right)^{\rho^{i}}+(1-\phi)\left(z^{i}\right)^{\rho^{i}}\right]^{\frac{1}{\rho^{i}}} \\
\text { s.t. } z^{i}+p_{G} x_{G}^{i}+p_{N} x_{N}^{i}=Y^{i} \text { for } i=\alpha, \beta, \gamma, j=G, N, F \text { and } \phi=m, n, s,
\end{gathered}
$$

where $z^{i}$ is the utility from consuming the numeraire products. $\phi$ is the calibrating parameter. $m, n$ and $s$ stand for the food consumption shares of the GM, non-GM, and indifferent consumers,

\footnotetext{
${ }^{7}$ Lobby groups influence the regulator in several ways. For example, they can make contributions, endorsements and committed votes. For simplicity, we model these contributions as monetary equivalents.
} 
respectively. We denote $x_{G}^{i}$ and $x_{N}^{i}$ as the demand for GM and non-GM food products by group $i$. The GM and non-GM food groups only consume either GM or non-GM food products, so the food consumption for GM food consumers is $x_{G}^{\alpha}$ and $x_{N}^{\beta}$ for non-GM food consumers. $\gamma$ consumers consume both GM and non-GM food products. We define an aggregate food product $(F)$ for $\gamma$ consumers, where $F$ is a composite consumption of GM and non-GM food products $\left(x_{G}^{\gamma}+x_{N}^{\gamma}\right)$. Thus, the total demand for GM food products is $\left(x_{G}^{\alpha}+x_{G}^{\gamma}\right)$ and $\left(x_{N}^{\beta}+x_{N}^{\gamma}\right)$ for non-GM food products (Appendix 3.A.1).

The trade volume of GM food products is $M_{G}=x_{G}^{\alpha}+x_{G}^{\gamma}-x_{G}$. It can be either positive or negative, depending on the domestic consumption and production. Similarly, the trade volume of non-GM food products is $M_{N}=x_{N}^{\beta}+x_{N}^{\gamma}-x_{N}$. Numeraire goods $z^{i}$ are tradable, and the excess demand is $M_{z}=z^{\alpha}+z^{\beta}+z^{\gamma}-z$.

\subsubsection{Social welfare of the economy}

We measure the consumer welfare by calculating the equivalent variation (Appendix 3.A.2) and the total social welfare as the sum of the consumer welfare of the three groups and the profits of the two firms. Thus, the aggregate social welfare can be written as

$$
W=\sum_{i} W^{i}=\sum_{i} c s^{i}+\sum_{i} \pi_{j} \quad i=\alpha, \beta, \gamma ; j=G, N
$$

The level of GM food policy regulation $(\theta)$ influences the welfare of the different types of consumers. $\alpha$ consumers prefer a low $\theta$ for less costly production, whereas the $\beta$ group prefers a high regulation cost to receive a higher transfer payment from the regulation and more consumption of non-GM food products from the indifferent consumers. For $\gamma$ consumers, the welfare loss of 
consuming GM food products under a stricter GM food policy will partly be compensated for by the welfare benefit from consuming non-GM food products. The $\alpha$ and $\beta$ groups, however, have competing interests regarding the GM food policy. This conflict of interest causes them to lobby during the political process.

\subsubsection{The Political Process}

Following Grossman and Helpman (1994), the government's objective function is a combination of social welfare and lobby contributions. The government maximizes

$$
G=b W+(1-b)\left(T^{\alpha}+T^{\beta}\right)
$$

where $0 \leq b \leq 1$ is the weight of social welfare in the government payoffs. The government payoff is less than the total social welfare under the political framework, even though the welfare carries a strong weight in the government payoffs (Goldberg and Maggi 1999).

From equation (3.3), we know that the level of GM food policy regulation matters for all consumers. For the lobbying groups, however, there are possible contradictory interests between firms and consumers. The GM food firm prefers a lower GM food policy cost. GM food consumers receive lower transfer payment from a low GM food policy cost and a low GM food price for their consumption. The GM food group supports a lower GM food policy compliance cost if the total gain from the policy is greater than the loss. However, for the non-GM food group, consumers prefer a high GM food policy cost for a higher income. Even though there is no direct influence from the GM food policy change on the non-GM food firm's profit, more indifferent consumers purchase the non-GM food products under a strict GM food policy regulation and a low GM food output. Therefore, $\alpha$ and $\beta$ groups lobby for a different GM food policy regulation cost. 
The political process is a three-stage non-cooperative game. Two lobbies simultaneously announce their contribution schedules to the government in the first stage. The government decides on the GM food policy that maximizes its payoff in the second stage. In the third stage, firms choose their output levels and pay the contribution. The GM food group prefers lower GM food regulations and makes contributions to maximize its own welfare. In contrast, the non-GM food group lobbies for a higher GM food regulation. The incumbent government knows that the GM and non-GM food lobbies have opposing interests and knows how they behave in the lobbying process for different GM food policies. We assume that each lobbying contribution is nonnegative but has an upper bound amount. We also assume that the lobbying is equally efficient for both groups, which means the lobbying efforts only depend on the amount of money contributed. The contributions also follow the truthful contribution schedule assumption in Grossman and Helpman (1994), which means the GM food policy effects on the groups' contributions always represent the lobbies' policy preferences.

For both groups, we model the above properties of each contribution as a logistic function, depending on the GM food policy $\theta$

$$
T^{i}=\frac{N^{i}}{1+B^{i} e^{-C^{i} \theta}}+D^{i} i=\alpha, \beta,
$$

where $N^{i}$ is the maximum value of the contribution. The GM food group lobbies for a lower GM food regulation, and likewise, the non-GM food group for a higher one. $B^{i}$ is a shape parameter and $C^{i}$ is the growth rate of contribution. $D^{i}$ is a shifting parameter.

\subsection{Maize self-sufficiency rate in South Africa}

South Africa is the top GMO producer in Africa, and the debate on GMOs in the country has been going on for many years. Some farmers worry about the pest resistance and are reluctant to plant 
GM maize, but some believe pest resistance to all pesticides will ultimately occur. The government admits higher yields and lower herbicide use due to GM food technology, but is also concerned about the potential risks to human and animal health (Stieber 2013). Thus, the GM food policy regulation could either be stricter or lenient in the future.

In this section, we use maize production of South Africa to illustrate the GM food policy effects on lobbying, government payoff, and the SSR. The SSR is measured as (FAO 2012),

$$
\text { SSR }=\frac{\text { Production }}{\text { Production+Imports-Exports }} \times 100,
$$

We calibrate a stylized small open economy model for South Africa relying on data from 2014 (Appendix 3.A.4). We first discuss the effects of the GM food policy regulation on the social welfare, lobbying behavior, government payoffs, and maize sufficiency, to explain the transmission of the GM food policy effects. Then, we demonstrate the relations among different GM food policy regulation costs and lobbying, government payoffs, and the SSR level. The government payoffs are influenced by both the level of the GM food policy and the weight parameter. The GM food policy influences domestic maize production, the trade position of the country, and the SSR.

\subsubsection{GM food policy effects on the economy}

We first explain the GM food policy effects on the economy by changing the baseline value of $\theta=0.586$ by $+/-10 \%$ (in Table 3.1).

Table 3.1 GM food policy effects as compared to the baseline $(\theta=0.586)$

\begin{tabular}{cccccc}
\hline & \multicolumn{2}{c}{$\theta(+10 \%)$} & & \multicolumn{2}{c}{$\theta(-10 \%)$} \\
\cline { 2 - 3 } \cline { 5 - 6 } Variables & level & $\%$ & & level & $\%$ \\
\hline GM food production: & & & & & \\
Labor use $\left(\mathrm{MP}^{\mathrm{a}}\right)$ & 3.6182 & -10.45 & & 4.5312 & 12.14 \\
Capital use $\left(\mathrm{MM}^{\mathrm{b}}\right)$ & 12473 & -13.64 & & 16818 & 16.44 \\
Output $\left(\mathrm{MT}^{\mathrm{c}}\right)$ & 9.6594 & -10.45 & & 12.096 & 12.14
\end{tabular}


Food security status: (MT)

$\begin{array}{ccccc}\alpha \text { GM consumption } & 0.2874 & -8.76 & 0.3470 & 10.17 \\ \gamma \text { GM consumption } & 4.6698 & -0.12 & 4.6806 & 0.11 \\ \text { GM export } & -4.7023 & -18.88 & -7.0689 & 21.95 \\ \beta \text { non-GM consumption } & 0.1727 & -0.59 & 0.1740 & 0.16 \\ \gamma \text { non-GM consumption } & 7.7476 & 0.12 & 7.7656 & 0.11 \\ \text { Non-GM import } & 3.7253 & -0.27 & 3.7446 & 0.24 \\ \text { SSR } & 1.0759 & -7.22 & 1.2564 & 8.35\end{array}$

\section{Social Welfare: (MM)}

Net income of $\alpha$ group

8206.9

$-8.76$

9910.2

10.17

Net income of $\beta$ group

4931.4

$-0.59$

4968.7

0.16

Net income of $\gamma$ group

354631

0.12

355453

0.11

GM profit

6739.1

$-10.45$

8439.4

12.14

Consumer surplus of $\alpha$ group

8206.9

$-8.76$

9910.2

10.17

Consumer surplus of $\beta$ group

4931.4

$-0.59$

4968.7

0.16

377855

$-0.42$

381296

0.48

\section{Political Process: (MM)}

\begin{tabular}{ccccc}
$\alpha$ group contribution & 0.0178 & -79.96 & 0.4457 & 400.81 \\
$\beta$ group contribution & 34.020 & 381.51 & 1.4611 & -79.32 \\
Total contribution & 34.038 & 375.77 & 1.9067 & -73.35 \\
Government payoff & 340073 & -0.42 & 343167 & 0.48 \\
\hline
\end{tabular}

Note: a.MP $=$ million people; b.MM=million US Dollars; c.MT $=$ million tons.

The change in GM food policy cost directly influences the GM food production cost. When the GM food policy increases by 10\% (=0.6446), the non-GM lobby is more powerful in the political game. From Table 3.1, we can see the GM food output decreases by $10 \%$ due to the higher input cost. The GM food profit and consumer surplus decrease. The non-GM food consumption for the non-GM food consumers also decreases because they have to spend more money from their income to make lobbying contributions. Both GM food exports and non-GM food imports 
decrease. The SSR reduces largely because of the reduction in the GM food output. The total social welfare reduction occurs mainly due to the GM food group loss. In the political process, the nonGM food group contributes more to the government than the GM food group for a higher GM food policy. But the GM food group stays profitable even if the GM food policy is 10\% stricter, so the group does not have a strong incentive to contribute more. The SSR decreases by $7 \%$ because the stricter GM food policy reduces the total domestic production.

If the GM food group spends more on lobbying and makes the GM food policy $10 \%$ less than the baseline value (=0.5274), the GM food production cost decreases and the GM food output increases. The GM food group gains a lot from profits, gross income, and welfare. Higher GM food output also increases the GM food export by $22 \%$ compared the baseline due to the lower production cost. The SSR in the country increases by $8 \%$ due to a higher total output. The total welfare increases by $0.4 \%$ when the GM food policy is less strict. Even though the GM food regulation is neither too high for the GM food firm nor too low for the non-GM food firm, the incentive of lobbying for the GM food group is higher than the non-GM food group. However, the total contribution amount is much less than it would be under a stricter GM food regulation, and the total contribution from the lobby groups decreases by $73 \%$. The contribution schedules of the two groups can be shown in the following two figures.

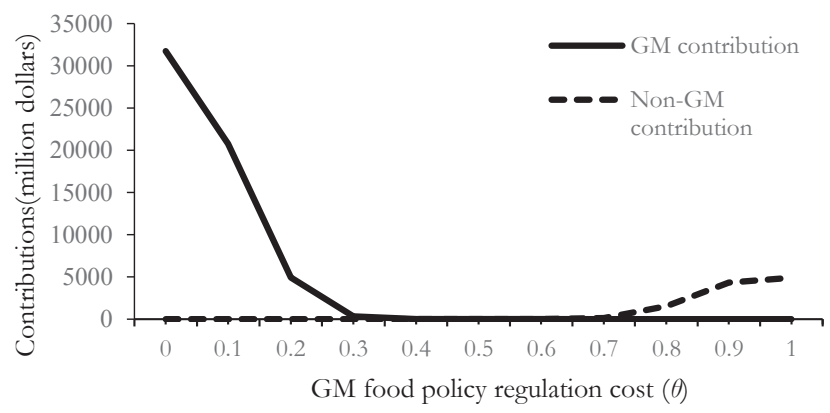

Figure 3.1 Contribution from lobbying groups when GM/Non-GM groups are small. 
Figure 3.1, depicts the simulated contribution curves of GM and non-GM food groups as per equation (3.7), where the regulation $\operatorname{cost} \theta$ is on the horizontal axis and the contributions $T^{i}$ are on the vertical axis. Apparently, the GM food lobby is more powerful in our simulations. The lobbying contribution for the GM food group will increase by a large amount when $\theta<0.3$, whereas the non-GM food lobby would spend more when $\theta>0.7$. We exemplify the $+/-10 \%$ change in the GM food policy regulation cost to see the effects on lobbying in Figure 3.2.

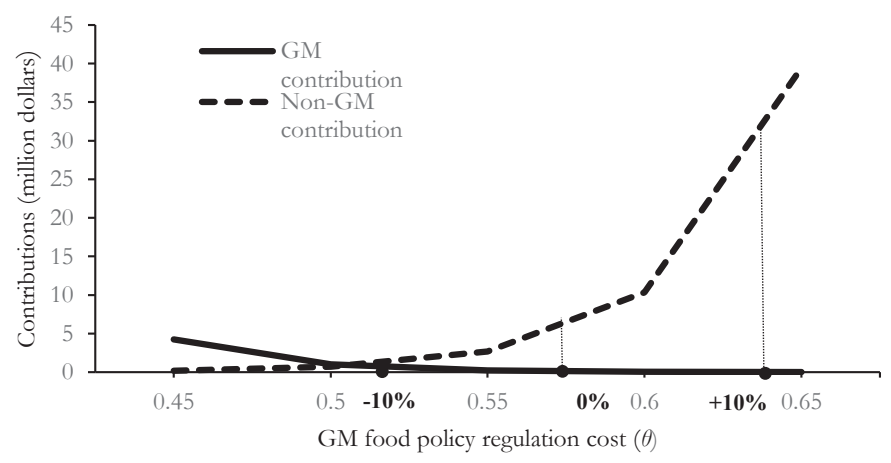

Figure 3.2 Contributions when $0.45 \leq \theta \leq 0.65$ and $+/-10 \%$

In Figure 3.2, the non-GM food lobby would spend a large amount for a $10 \%$ stricter GM food policy, while the GM food lobby spends less than the non-GM food lobby for a lower GM food policy cost. The GM contribution curve is flatter than the non-GM curve. The non-GM food lobby is more sensitive to the $10 \%$ increase in the GM food policy cost than the GM lobby to the $10 \%$ reduction in the GM food policy cost. A higher GM food policy cost will increase the lobbying contribution from the GM food lobby but decrease the total welfare, such that the government needs to balance the contribution income and welfare gain of the society.

\subsubsection{The balance between social welfare and lobbying income}


The government has two instruments, $b$ and $\theta$, to maximize its payoff. It aims to get an increment payoff relative to the baseline by changing the GM food policy. We calculate the government payoffs under different GM food policies and weight parameters from 0.1 to 0.9 . Then we compare the calculated values with the baseline value under different weight parameters. The baseline value of the regulation cost is $\theta=0.5859$, so we calculate the payoff change relative to the baseline. The changes in the government payoffs are shown in Figure 3.3. We can see the government payoff gain is monotonically decreasing with an increase in the GM food policy regulation cost if the government weighs social welfare equal or greater than 0.4 . The government will still get a negative payoff change when $b=0.3$. The baseline GM food policy regulation cost is $\theta=0.585859$. The government can either increase the regulation cost up to $\theta \geq 0.9$ or reduce it to $\theta \leq 0.5$ for $b=0.2$. If the government weights social welfare by 0.1 and contributions by 0.9 , the total payoffs are largely dependent on the revenue from lobby groups. In this case, the government can either set a high $\theta=1$ or a low $\theta=0.2$ to get similar payoff gains. But the government in our model maximizes its payoff when regulation cost equals zero, regardless of the welfare weights. This suggests that a lenient GM food policy regulation in South Africa maximizes the government objective function.

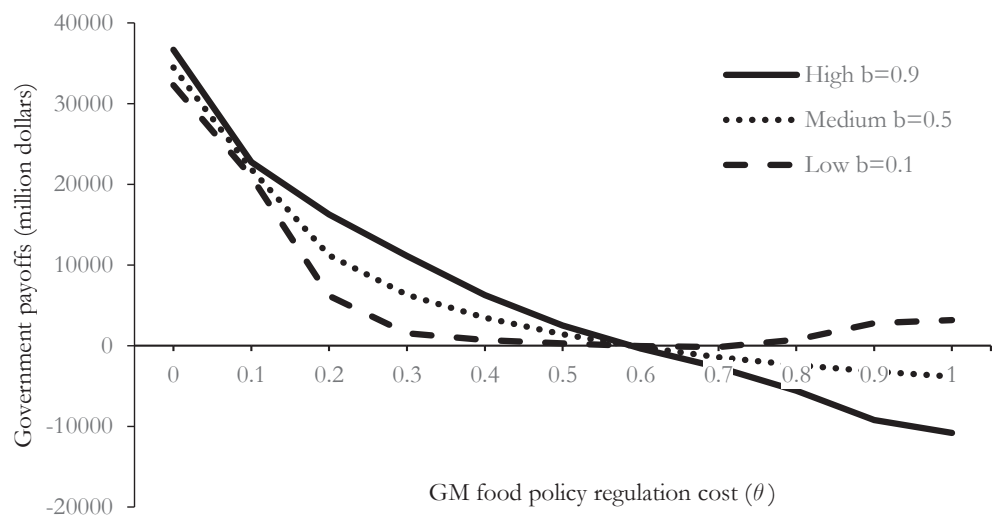

Figure 3.3 Relative government payoff change under different weight parameters 
The payoff is maximized when the GM food policy is very low because a lower GM food policy will increase the social welfare and the GM food group will contribute the most. From Figure 3.1, we know the maximum contribution level of the GM food group is higher than the non-GM food group. The GM food group could make a higher contribution towards achieving the lowest GM food policy than the non-GM food group could spend on obtaining the highest GM food policy. The government payoff is also influenced by the weight parameter on the social welfare. We show the weight parameter effects on the government payoffs in Figure 3.3 for three levels: high (0.9), medium (0.5), and low (0.1). Higher welfare and higher overall contribution make the government choose a lower GM food policy regulation cost. We also find that the government will have a high loss from a strict GM food policy regulation when it weighs social welfare high (for example when $b=0.9)$. The government payoffs are similar when the GM food policy regulation cost is low, but the payoffs are very different under a strict GM food policy regulation because a stricter GM food policy regulation will reduce both the GM food firm's profits and consumer surplus. On the other hand, if the government weighs the social welfare at a 0.1 level, the government could compensate its welfare loss via the contribution gain.

\subsubsection{The GM food policy regulation and the SSR}

The level of GM food policy regulation directly influences the GM food input cost. A higher GM food policy cost will decrease the firm's profits and reduce the production. The domestic supply is influenced by the area and quality of arable land, agricultural climate, and efficiency of production, among other things. The population of the country primarily influences the demand.

In the simulation, we find that the SSR is decreasing with a higher GM food policy regulation cost (Figure 3.4). The change in the GM food policy regulation influences the GM food production directly but not the non-GM food production (see Appendix 3.A.6 for details). The GM 
maize production and consumption decline with the increase in strictness for the GM food policy. A stricter GM food policy regulation cost increases the production cost for the GM food firm and reduces its output such that more $\gamma$ consumers buy non-GM maize compared to when the GM food policy regulation is not as strict (i.e. $\theta \leq 0.4$ in this case). But when the GM food policy regulation becomes stricter $(\theta \geq 0.5)$, the total consumption of the non-GM maize decreases: the total consumption reduces slightly, while the total maize production decreases largely due to stricter GM food policies $(72 \%$ of the total maize production in South Africa is GM maize). Thus, the SSR decreases if the GM food policy cost increases. The country could be self-insufficient when the GM food policy is very strict $(\theta \geq 0.8)$, and part of the food supply relies on food import. The SSR can be an indicator of the domestic food availability when the domestic consumption remains stable.

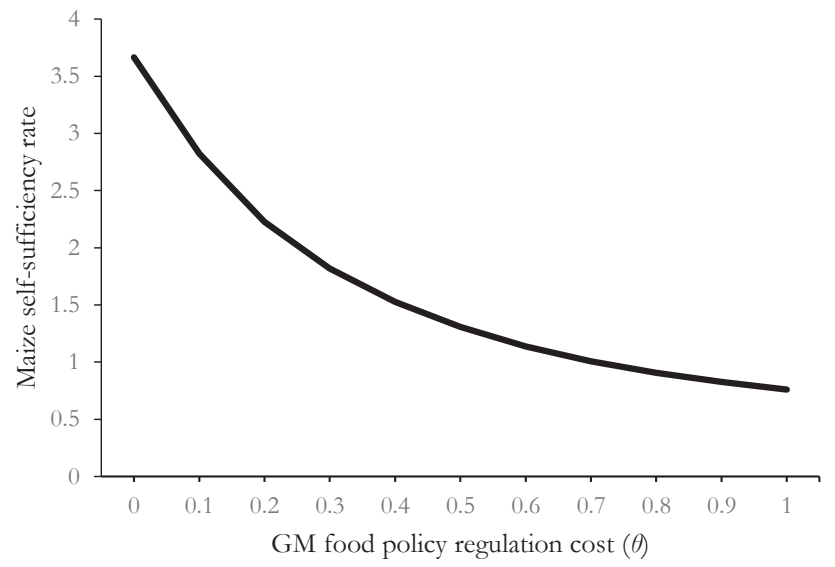

Figure 3.4 The SSR and GM policy

\subsection{GM food policy and the SSR under a large anti-GM group assumption}

The population fractions of GM and non-GM food consumers are modeled to be very small in the case of South Africa. The consumer preferences influence the group size, lobbying power, and the GM food policy regulation in a significant way. We show a special case to study the population 
effects on GM food policy and the SSR, that is, when the weight parameter $b=0.1$ and the nonGM food group takes 95 percent of the total population. In the simulation, we keep the GM food group fraction as before, and the indifferent group takes the rest of consumers.

First, the contribution curves of the GM and non-GM food groups are changed during the lobbying process (Figure 3.5).

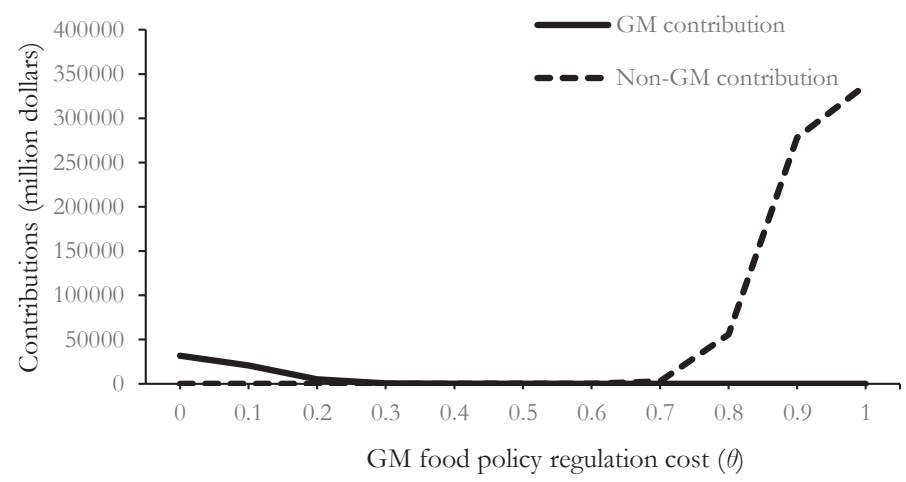

Figure 3.5 Contributions when the non-GM group takes 95\% of the total population

Since the non-GM food group has 95 percent of all consumers, Figure 3.5 shows different lobbying power than Figure 3.1. The non-GM food group's income is much higher than the GM food group. In this case, the non-GM food group could spend more for a strict GM food policy regulation. In contrast, the GM food lobby only takes 0.4 percent of the total population and will lose the political competition on influencing GM food regulations. The lobbying power also influences the government payoffs for different regulations. Depending on the weights, the government payoffs are different under a large non-GM food group. 


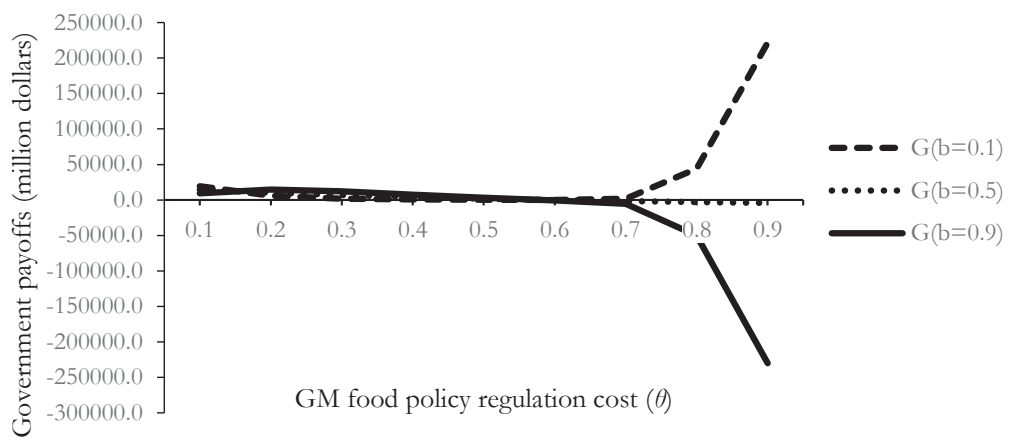

Figure 3.6 Relative government payoffs change under a large nonGM $(95 \%)$ group

The relative government payoffs are also changed. In Figure 3.6, we can see the government payoffs are very different under different weights when the non-GM food group is large compared to Figure 3.3. The politically determined GM food policy will be the lowest GM food policy regulation cost under a low or a medium weight. However, the GM food policy will be strict if the government places a high weight on the contributions. In this case, the non-GM food group spends a large amount of money on a very strict policy. This could happen when the politicians need more political support from the voters (e.g., elections). However, the weight parameter on social welfare heavily influences the government payoff. If the government wants a higher payoff, it needs to be less politically biased during the policy making process because the political rivalry between interest groups greatly reduces the government payoffs.

Moreover, the GM food policy affects the SSR differently when the non-GM food group is large in comparison to the results displayed in Figure 3.4. 


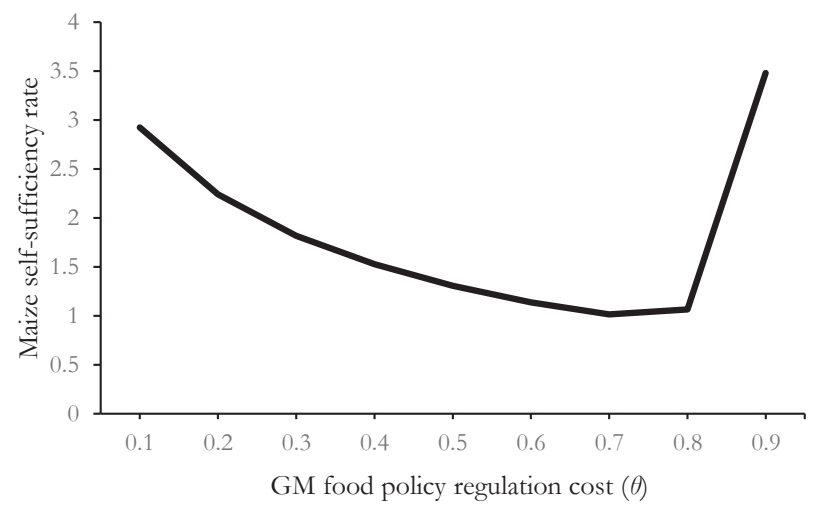

Figure 3.7 the SSR and the GM regulation (beta $=0.95, \mathrm{~b}=0.1$ )

Figure 3.7 shows a special case when the government weights contribution higher than social welfare. The SSR is decreasing with a higher cost of GM food policy until 0.7 , but surprisingly, the SSR increases dramatically after that. This development occurs because the demand for non-GM food products from the non-GM food group decreases largely when $\theta \geq 0.8$ (Appendix 3.A.5). The group needs to contribute a lot for a strict GM food regulation, and the money is collected from the group's income. The disposable income for purchasing food products is largely decreased under a high GM food policy cost. The SSR is a ratio of food supply to food demand. Consumers cannot afford more food under a high contribution, so it does not mean a higher food security level in the country. This outcome also shows the deficiency of the SSR measure.

To summarize our discussion, Sections 3.3 and 3.4 imply that

(i) The GM food lobby has a higher power than the non-GM group when the GM and non-GM food groups together make up a small fraction of the total number of consumers, but the non-GM contribution becomes larger when the non-GM food lobby is large. 
(ii) The government maximizes its payoff by choosing a low GM food policy cost, but it gets a high payoff from a strict GM food policy regulation when the non-GM food group is very large. The government gets high payoffs when it weights social welfare more than the contributions in the political process.

(iii) The politically determined GM food policy cost is low under the assumption of a small GM and a small non-GM food group, but the policy can be strict if there is a large nonGM food group in the country.

(iv) The food self-sufficiency rate is low under a strict GM food regulation, but it could be high under a strict GM food policy and a large non-GM food group assumption. The SSR can measure the food availability when the domestic food consumption is stable, but it is biased when both the production and consumption are changed.

\subsection{Discussion and Conclusion}

Food self-sufficiency rate can be improved by the increase in the domestic food production. Agricultural biotechnology adoption can reduce pesticide use and increase crop yields. The debate between pro-GM and anti-GM food lobbies influences the level of the GM food policy in a country. The level of the GM food policy then influences the GM food production and the SSR.

This paper studies the relationship between the politically determined GM food policy and domestic food self-sufficiency. We first develop a theoretical model of a small-open economy and investigate the GM food policy as the outcome of a GM and a non-GM food groups' lobbying game that follows the model of Grossman and Helpman (1994). The government maximizes its payoff by considering the weighted sum of social welfare and contributions from interest groups. We take the maize production in South Africa as an example to quantify the politically influenced self-sufficiency rate. Later, we simulate an extreme case when the non-GM food group in the country is large, as is 
the case in the European Union and Japan, and investigate the policy effects on lobbying, government payoffs, and the SSR.

We find that the SSR will decrease with an increase in the GM food policy regulation cost. This occurs because a higher GM food policy regulation cost decreases the GM maize production by a large amount; however, the domestic maize consumption does not change a great deal. We find that the government payoff does not monotonically decrease when the government weighs social welfare at a low level in the political process. The important factor is whether the marginal loss of the non-GM food firm from increasing the SSR is less than the gain for the rest of the economy. A strict GM food policy will reduce the social welfare by more than the gain of the non-GM food group.

However, even if the government weighs social welfare not very high, it still maximizes the payoff by implementing a very low GM policy cost. This outcome suggests that the government could set lenient GM food policy regulations to maximize its payoffs. However, in the case where the non-GM food group is large, the GM food policy effects are different on lobbying, government payoffs, and the SSR. Most importantly, this case demonstrates that the SSR is only practical as a measure of food security if food consumption is stable.

Our study shows the incentives and reasons why lobby groups solicit governments for a favorable agricultural biotechnology policy. Both lobbies are reluctant to make contributions when the GM food policy regulation is not too strict or lenient regarding their interests. They would like to contribute more for their own favorable policies. Our results also offer potential reasons why a country that has a low SSR still has a strict GM food policy regulation: a) the non-GM group is large and has more money for lobbying than the GM food group even though the lobbying is costly and b) the government cares less about the social welfare than contributions from interest groups, or at least an increase in social welfare is not its priority. 
According to a 2004 FAO report, the GM agricultural technology may work for the poor. Our analysis suggests that a lower GM food regulation supports domestic agricultural production. Since the weight parameter plays an important role in the government payoff function, the government can help to improve the domestic food sufficiency without decreasing its payoff by weighing social welfare higher. 


\section{A Appendix}

\section{A.1 Calculation of GM, non-GM and numeraire good demands for three groups}

From equation (3.4), we can write the utility function of $\alpha$ consumers:

$\max U^{\alpha}=\left[m\left(x_{G}^{\alpha}\right)^{\rho^{\alpha}}+(1-m)\left(z^{\alpha}\right)^{\rho^{\alpha}}\right]^{\frac{1}{\rho^{\alpha}}}$

s.t. $p_{G} x_{G}^{\alpha}+p_{z} z^{\alpha}=Y^{\alpha}$

so we can get:

$$
\begin{aligned}
& x_{G}^{\alpha}=\left(\frac{m}{p_{G}}\right)^{\sigma^{\alpha}} \frac{Y^{\alpha}}{m^{\sigma^{\alpha}} p_{G}{ }^{1-\sigma^{\alpha}}+(1-m)^{\sigma^{\alpha}} p_{z}{ }^{1-\sigma^{\alpha}}} \\
& z^{\alpha}=\left(\frac{1-m}{p_{z}}\right)^{\sigma^{\alpha}} \frac{Y^{\alpha}}{m^{\sigma^{\alpha}} p_{G}{ }^{1-\sigma^{\alpha}}+(1-m)^{\sigma^{\alpha}} p_{z}{ }^{1-\sigma^{\alpha}}}
\end{aligned}
$$

where $\sigma^{\alpha}=\frac{1}{1-\rho^{\alpha}}, m=\frac{\varphi_{G}^{\frac{1}{\sigma^{\alpha}}}}{\left(1-\varphi_{G}\right)^{\frac{1}{\sigma^{\alpha}}}\left(\frac{p_{z}}{p_{G}}\right)^{\frac{\sigma^{\alpha}-1}{\sigma^{\alpha}}}+\varphi_{G}^{\frac{1}{\sigma^{\alpha}}}}$, and $\varphi_{G}$ is the expenditure share of

consuming food for $\alpha$ group.

Similarly, we can find demand functions of $\beta$ consumers:

$$
\begin{aligned}
& x_{N}^{\beta}=\left(\frac{n}{p_{N}}\right)^{\sigma^{\beta}} \frac{Y^{\beta}}{n^{\sigma^{\beta}} p_{N}{ }^{1-\sigma^{\beta}}+(1-n)^{\sigma^{\beta}} p_{z}^{1-\sigma^{\beta}}} \\
& z^{\beta}=\left(\frac{1-n}{p_{z}}\right)^{\sigma^{\beta}} \frac{Y^{\beta}}{n^{\sigma^{\beta}} p_{N}{ }^{1-\sigma^{\beta}}+(1-n)^{\sigma^{\beta}} p_{z}{ }^{1-\sigma^{\beta}}}
\end{aligned}
$$


where $\sigma^{\beta}=\frac{1}{1-\rho^{\beta}}, n=\frac{\varphi_{N}^{\frac{1}{\sigma^{\beta}}}}{\left(1-\varphi_{N}\right)^{\frac{1}{\sigma^{\beta}}}\left(\frac{p_{z}}{p_{N}}\right)^{\frac{\sigma^{\beta}-1}{\sigma^{\beta}}}+\varphi_{N}^{\frac{1}{\sigma^{\beta}}}}$, and $\varphi_{N}$ is the expenditure share of

consuming $x_{N}$.

For $\gamma$ people, they demand both GM and non-GM food products. We assume they

consume the aggregate food product $F$ which price is $p_{F} . F=x_{G}^{\gamma}+x_{N}^{\gamma}$, and $p_{F}=b_{G}^{\gamma} p_{G}+b_{N}^{\gamma} p_{N}$,

where $b_{G}^{\gamma}$ is the consumption share of GM food products for $\gamma$ consumers from the aggregate food purchase and $b_{N}^{\gamma}$ is the non-GM food product share. $\gamma$ consumers first minimize their total food expenditure:

$\min p_{G} x_{G}^{\gamma}+p_{N} x_{N}^{\gamma}$

s.t. $\sigma_{F}\left[a_{G}\left(x_{G}^{\gamma}\right)^{\frac{\delta_{x}-1}{\delta_{x}}}+\left(1-a_{G}\right)\left(x_{N}^{\gamma}\right)^{\frac{\delta_{x}-1}{\delta_{x}}}\right]^{\frac{\delta_{x}}{\delta_{x}-1}}=1$

where $a_{G}$ is the GM food policy cost share of reaching one unit of utility from the aggregate food product. We solve for the consumption of GM and non-GM food products:

$$
\begin{aligned}
& x_{G}^{\gamma}=\left(a_{G}+\left(1-a_{G}\right)\left(\frac{a_{G} p_{N}}{\left(1-a_{G}\right) p_{G}}\right)^{1-\delta_{x}}\right)^{\frac{\delta_{x}}{1-\delta_{x}}} \frac{1}{\sigma_{F}} \\
& x_{N}^{\gamma}=\left(1-a_{G}+a_{G}\left[\frac{\left(1-a_{G}\right) p_{G}}{a_{G} p_{N}}\right]^{1-\delta_{x}}\right)^{\frac{\delta_{x}}{1-\delta_{x}}} \frac{1}{\sigma_{F}}
\end{aligned}
$$

We have $b_{G}^{\gamma}=x_{G}^{\gamma} / F$ and $b_{N}^{\gamma}=x_{N}^{\gamma} / F$ from the definition. So, $\gamma$ consumers maximize their utility from consuming the aggregate food product and numeraire: 
$\max U^{\gamma}=\left[s F^{\rho^{\gamma}}+(1-s)\left(z^{\gamma}\right)^{\rho^{\gamma}}\right]^{\frac{1}{\rho^{\gamma}}}$

s.t. $\quad p_{F} F+p_{z} z^{\gamma}=Y^{\gamma}$

The Marshallian demand function corresponding to this utility maximization problem is:

$$
\begin{aligned}
& F=\left(\frac{s}{p_{F}}\right)^{\sigma^{\gamma}} \frac{Y^{\gamma}}{s^{\sigma^{\gamma}} p_{F}{ }^{1-\sigma^{\gamma}}+(1-s)^{\sigma^{\gamma}} p_{z}{ }^{1-\sigma^{\gamma}}} \\
& z^{\gamma}=\left(\frac{1-s}{p_{z}}\right)^{\sigma^{\gamma}} \frac{Y^{\gamma}}{s^{\sigma^{\gamma}} p_{F}{ }^{1-\sigma^{\gamma}}+(1-s)^{\sigma^{\gamma}} p_{z}{ }^{1-\sigma^{\gamma}}}
\end{aligned}
$$

where $\sigma^{\gamma}=\frac{1}{1-\rho^{\gamma}}, s=\frac{\varphi_{F}^{\frac{1}{\sigma^{\gamma}}}}{\left(1-\varphi_{F}\right)^{\frac{1}{\sigma^{\gamma}}}\left(\frac{p_{z}}{p_{F}}\right)^{\frac{\sigma^{\gamma}-1}{\sigma^{\gamma}}}+\varphi_{F}^{\frac{1}{\sigma^{\gamma}}}}$, and $\varphi_{F}$ is the expenditure share of consuming F.

\section{A.2 Calculation of consumer surplus}

From the discussion of production and consumption, the indirect utility functions of each of the three groups of consumers are:

$$
\begin{aligned}
& V^{\alpha}=\frac{Y^{\alpha}}{\left(m^{\sigma^{\alpha}} p_{G}^{1-\sigma^{\alpha}}+(1-m)^{\sigma^{\alpha}} p_{z}^{1-\sigma^{\alpha}}\right)^{\frac{1}{1-\sigma^{\alpha}}}} \\
& V^{\beta}=\frac{Y^{\beta}}{\left(n^{\sigma^{\beta}} p_{N}^{1-\sigma^{\beta}}+(1-n)^{\sigma^{\beta}} p_{z}^{1-\sigma^{\beta}}\right)^{\frac{1}{1-\sigma^{\beta}}}} \\
& V^{\gamma}=\frac{Y^{\gamma}}{\left(s^{\sigma^{\gamma}} p_{F}{ }^{1-\sigma^{\gamma}}+(1-s)^{\sigma^{\gamma}} p_{z}^{1-\sigma^{\gamma}}\right)^{\frac{1}{1-\sigma^{\gamma}}}}
\end{aligned}
$$

The expenditure functions for each group of consumers are: 


$$
\begin{aligned}
& e^{\alpha}=u_{0}^{\alpha}\left(m^{\sigma^{\alpha}} p_{G}^{1-\sigma^{\alpha}}+(1-m)^{\sigma^{\alpha}} p_{z}^{1-\sigma^{\alpha}}\right)^{\frac{1}{1-\sigma^{\alpha}}} \\
& e^{\beta}=u_{0}^{\beta}\left(n^{\sigma^{\beta}} p_{N}{ }^{1-\sigma^{\beta}}+(1-n)^{\sigma^{\beta}} p_{z}^{1-\sigma^{\beta}}\right)^{\frac{1}{1-\sigma^{\beta}}} \\
& e^{\gamma}=u_{0}^{\gamma}\left(s^{\sigma^{\gamma}} p_{F}{ }^{1-\sigma^{\gamma}}+(1-s)^{\sigma^{\gamma}} p_{z}^{1-\sigma^{\gamma}}\right)^{\frac{1}{1-\sigma^{\gamma}}}
\end{aligned}
$$

where $u_{0}^{i}$ is the utility that a consumer would get with the new price of $p_{j}(j=G, N, F)$ and $p_{z}$. In this case, $u_{0}^{i}$ equals to the value of $V^{i}$ in equation (3.A1).

\section{A.3 Calibration of the lobbying logistic functions}

The GM and non-GM food groups make contributions to the government and influence the GM food policy outcome. The contribution curves follow equation (3.7), and the calibration results are shown in Table 3.A1. We assume the minimum contribution for both groups is near zero and the maximum is the gross income of each group, which is the income before subtracting lobbying contribution from equation (3.3) because the groups will not make contributions if it generates negative income. For the GM food group, a higher GM food policy cost means the contribution is low, whereas a very low policy cost shows the group contributed a lot in the lobbying process. For the non-GM food group, the situation is opposite. We define the policy compliance cost is $\mathrm{Ad}$ Valorem, so $\theta \in[0,1]$. Thus, the GM food group lobbies for zero policy cost, and the non-GM food lobby contributes for the stringent policy towards GM food technology.

Calibration:

(1) GM food $\operatorname{group}(\alpha)$ :

The contribution function of the group is: 


$$
T^{\alpha}=\frac{N^{\alpha}}{1+B^{\alpha} e^{-C^{\alpha} \theta}}+D^{\alpha}
$$

There are four cases for shaping the logistic curve of (3.A3):

(i) when $\theta$ approaches positive infinity, we find the minimum contribution $T_{L}^{\alpha}$ is: $T_{L}^{\alpha}=N^{\alpha}+D^{\alpha}$;

(ii) when $\theta$ approaches negative infinity, we find the maximum contribution $T_{U}^{\alpha}$ is: $T_{U}^{\alpha}=D^{\alpha}$;

(iii) when $\theta=0$, we have $(1-\chi) T_{U}^{\alpha}=\frac{N^{\alpha}}{1+B^{\alpha}}+D^{\alpha}$, where $\chi$ is the "precision" parameter, which is very small;

(iv) when $\theta=1$, equation (3.A3) becomes $(1+\chi) T_{L}^{\alpha}=\frac{N^{\alpha}}{1+B^{\alpha} e^{-C^{\alpha}}}+D^{\alpha}$.

Thus, we can solve for:

$$
\begin{aligned}
& N^{\alpha}=T_{L}^{\alpha}-T_{U}^{\alpha} \\
& B^{\alpha}=\frac{T_{U}^{\alpha}-T_{L}^{\alpha}}{\chi T_{U}^{\alpha}}-1 \\
& C^{\alpha}=-\ln \frac{\frac{T_{L}^{\alpha}-T_{U}^{\alpha}}{(1+\chi) T_{L}^{\alpha}-T_{U}^{\alpha}}-1}{B^{\alpha}} \\
& D^{\alpha}=T_{U}^{\alpha}
\end{aligned}
$$

Non-GM food group $(\beta)$ :

The contribution function from equation (3.7) can be written as:

$$
T^{\beta}=\frac{N^{\beta}}{1+B^{\beta} e^{-C^{\beta} \theta}}+D^{\beta}
$$

There are four cases for shaping the logistic curve of (3.A4): 
(i) when $\theta$ approaches positive infinity, we find the minimum contribution $T_{U}^{\beta}$ is: $T_{U}^{\beta}=N^{\beta}+D^{\beta}$;

(ii) when $\theta$ approaches negative infinity, we find the maximum contribution $T_{L}^{\beta}$ is: $T_{L}^{\beta}=D^{\beta}$;

(iii) when $\theta=0$, we have $(1-\chi) T_{L}^{\beta}=\frac{N^{\beta}}{1+B^{\beta}}+D^{\beta}$;

(iv) when $\theta=1$, equation (3.A4) equals to $(1+\chi) T_{U}^{\beta}=\frac{N^{\beta}}{1+B^{\beta} e^{-C^{\beta}}}+D^{\beta}$.

Thus, we can solve for:

$$
\begin{aligned}
& N^{\beta}=T_{U}^{\beta}-T_{L}^{\beta} \\
& B^{\beta}=\frac{T_{U}^{\beta}-T_{L}^{\beta}}{\chi T_{L}^{\beta}}-1 \\
& C^{\beta}=-\ln \frac{\frac{T_{U}^{\beta}-T_{L}^{\beta}}{(1-\chi) T_{U}^{\beta}-T_{L}^{\beta}}-1}{B^{\beta}} \\
& D^{\beta}=T_{L}^{\beta}
\end{aligned}
$$

Calibration results:

Table 3.A1 Calibration of lobbying contribution

Description Value

Variable

$\begin{array}{llc}T_{U}^{\alpha} & \text { Maximum contribution of } \alpha \text { group } & 8995.4^{\mathrm{m}} \\ T_{L}^{\alpha} & \text { Minimum contribution of } \alpha \text { group } & 0.0001^{\mathrm{m}} \\ T_{U}^{\beta} & \text { Maximum contribution of } \beta \text { group } & 4967.82^{\mathrm{m}} \\ T_{L}^{\beta} & \text { Minimum contribution of } \beta \text { group } & 0.0001^{\mathrm{m}}\end{array}$

Assumed and calibrated

$\begin{array}{llc}\chi & \text { "precision” parameter } & 0.01 \\ N^{\alpha} & \text { Maximum value of } \alpha \text { group contribution curve } & 8995.40^{\mathrm{m}} \\ N^{\beta} & \text { Maximum value of } \beta \text { group contribution curve } & 4967.82^{\mathrm{m}}\end{array}$




\begin{tabular}{llc}
$B^{\alpha}$ & Shape parameter of $\alpha$ group & 98.99 \\
$B^{\beta}$ & Shape parameter of $\beta$ group & 496782 \\
$C^{\alpha}$ & Growth rate of $\alpha$ group contribution & 27.5151 \\
$C^{\beta}$ & Growth rate of $\beta$ group contribution & 26.9214 \\
$D^{\alpha}$ & Shift of the $\alpha$ contribution curve & $8995.40^{\mathrm{m}}$ \\
$D^{\beta}$ & Shift of the $\beta$ contribution curve & $0.0001^{\mathrm{m}}$ \\
\hline
\end{tabular}

Note: $\mathrm{m}=$ million dollars.

\section{A.4 Data and Calibration}

We present the data of the variables and parameters in Table 3.A2, which refer to the year 2014. We assume full employment in the economy, so the total labor supply is the number of employed people. The gross labor earning in 2014 is 27,289 million US Dollars from the Statistics South Africa (StatsSA) and the total employment in the economy is 15.32 million people. One unit of labor gets one unit of wage, so the annual wage per person is 1781.27 US Dollars. Due to the small fraction of GM and non-GM land use in the total production, the value of the total capital is the GDP net of the total labor supply. The total maize supply is 15 million tons (FAO 2014), and the trade balance of maize is 2.06 million tons in 2014 from International Trade Centre, so the maize SSR in 2014 is 1.16. We choose the maize price in our model such that the SSR equals 1.16. We assume the GM, non-GM, and the composite maize products have a uniform price in the baseline and that the world price of maize is the same. Since the country is a small open economy, the domestic maize market is the same as world maize price despite the variety (GM or non-GM) of maize. We know $72 \%$ of the total maize production is GM maize in the country (van de Walt 2011), so there is a supply of GM and non-GM maize. If a firm implements the GM food technology in their production, it spends more on the capital and less on the labor input (Regier and Dalton 2014). The GM food policy regulation cost can be expressed as the excess cost of the GM capital input, which is higher than the conventional, as we model the regulation cost as an additional capital cost for the GM food firm. We 
calculate the GM food policy regulation cost by using data from Regier and Dalton (2014) on the input cost of GM and non-GM maize production in South Africa.

Table 3.A2 Parameters and variables implemented in the baseline

\begin{tabular}{|c|c|c|c|}
\hline & Description & Baseline Value & Source \\
\hline \multicolumn{4}{|c|}{ Variables } \\
\hline $\bar{L}$ & Total Labor & $15.32 \mathrm{MP}^{\mathrm{a}}$ & UN Data \\
\hline $\bar{K}$ & Total capital & $322811 \mathrm{MM}^{\mathrm{b}}$ & StatsSA \\
\hline$x_{G}$ & GM food supply & $10.787 \mathrm{MT}^{\mathrm{c}}$ & Calculated \\
\hline$x_{N}$ & Non-GM food supply & $4 \mathrm{MT}$ & Calculated \\
\hline$w$ & Annual wage & 1781.27 USD & Calculated \\
\hline$\theta$ & GM food policy cost & 0.58586 & Calculated \\
\hline$T_{U}^{\alpha}$ & Maximum contribution of $\alpha$ group & 8995.4MM & Calculated \\
\hline$T_{U}^{\beta}$ & Maximum contribution of $\beta$ group & $4976.8 \mathrm{MM}$ & Calculated \\
\hline \multicolumn{4}{|c|}{ Parameters } \\
\hline$\alpha$ & GM food group fraction & 0.00409 & StatsSA \\
\hline$\beta$ & Non-GM food group fraction & 0.00569 & StatsSA \\
\hline$\xi^{i}$ & $\begin{array}{l}\text { Own-price elasticity of demand of } \\
\text { individual group }\end{array}$ & -0.3 & $\begin{array}{l}\text { Kostandini et al. } \\
(2009)\end{array}$ \\
\hline$\varphi$ & $\begin{array}{l}\text { Share of maize consumption in total } \\
\text { expenditure }\end{array}$ & 0.12214 & $\begin{array}{l}\text { Vermeulen et al. } \\
(2009)\end{array}$ \\
\hline$\varepsilon_{L}$ & $\begin{array}{l}\text { Share of labor costs in GM food } \\
\text { production }\end{array}$ & 0.19128 & $\begin{array}{l}\text { Regier and Dalton } \\
\text { (2014) and adjustment }\end{array}$ \\
\hline$\varepsilon_{K}$ & $\begin{array}{l}\text { Share of capital costs in GM food } \\
\text { production }\end{array}$ & 0.60872 & $\begin{array}{l}\text { Regier and Dalton } \\
\text { (2014) and adjustment }\end{array}$ \\
\hline$\eta_{L}$ & $\begin{array}{l}\text { Share of labor costs in non-GM food } \\
\text { production }\end{array}$ & 0.42405 & $\begin{array}{l}\text { Regier and Dalton } \\
\text { (2014) and adjustment }\end{array}$ \\
\hline$\eta_{K}$ & $\begin{array}{l}\text { Share of capital costs in non-GM food } \\
\text { production }\end{array}$ & 0.37595 & $\begin{array}{l}\text { Regier and Dalton } \\
\text { (2014) and adjustment }\end{array}$ \\
\hline$\mu$ & Share of labor costs in ₹ production & 0.04126 & World bank \\
\hline \multicolumn{4}{|c|}{ 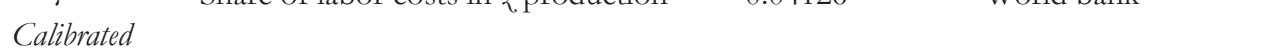 } \\
\hline$A$ & $\begin{array}{l}\text { Total factor productivity of GM food } \\
\text { products }\end{array}$ & 0.02426 & \\
\hline$B$ & $\begin{array}{l}\text { Total factor productivity of non-GM } \\
\text { food products }\end{array}$ & 0.09697 & \\
\hline$a$ & Total factor productivity of other & 1.61727 & \\
\hline
\end{tabular}

Note: a. $\mathrm{MP}=$ million people; $\mathrm{b}$. MM=million US Dollars; c. MT=million tons.

We know maize production employs about 0.15 million people (the Department of Agriculture, Forestry and Fisheries 2012), and GM food technology saves about 28\% of labor input 
in comparison to the non-GM food production, so for the GM maize labor, the $\alpha$ fraction of people in the model occupy about $0.4 \%$ of the total population. $\beta$ and $\gamma$ persons are $0.6 \%$ and $99 \%$ of the total labor supply, respectively. $\alpha$ and $\beta$ make up only a small portion of the total society because we only consider people involved in maize production. A study about various policies on household food security in South Africa from Vermeulen et al. (2009) offers the expenditure share of maize products in the total household income. The average expenditure share of maize is about $12 \%$, showing maize is an important food consumption item. Regier et al. (2014) study GM and non-GM maize input costs without considering land and machinery depreciation cost. So, we consider the fixed cost takes $20 \%$ of the total maize production cost according to the corn production in Iowa (Plastina 2016). So, labor and capital take $80 \%$ of the total production costs. According to the StatsSA, we find the non-agricultural employment is 7.92 million and earns 14,108 million USD in wages, and GDP from the non-agricultural sector is 341,940 million USD. We calculate that the labor cost fraction in the $z$ production equals to the wage over GDP of the non-agricultural sector in 2014.

\section{A.5 Baseline values of the model}

The baseline scenario results in Table 3.A3 are calculated from the model.

Table 3.A3 Baseline Values

\begin{tabular}{cllc}
\hline \multicolumn{1}{c}{ Variables } & Description & Unit & Values \\
\hline Food Security Status: & & & \\
$x_{G}^{\alpha}$ & Maize consumption of the GM foodgroup & MT $^{\text {a }}$ & 0.315 \\
$x_{N}^{\beta}$ & Maize consumption of the non-GM food group & MT & 0.195 \\
$x_{G}^{\gamma}$ & GM maize consumption of the indifferent group & MT & 4.632 \\
$x_{N}^{\gamma}$ & Non-GM maize consumption of the indifferent & MT & 7.685 \\
$M_{G}$ & group & MT & -5.80 \\
$M_{N}$ & GM food export & MT & 3.736 \\
SSR & Son-GM food import & & 1.16
\end{tabular}


Social Welfare:

$\begin{array}{llcc}\pi_{G} & \text { GM food firm's profit } & \mathrm{MM}^{\mathrm{b}} & 7526 \\ \pi_{N} & \text { Non-GM food firm's profit } & \mathrm{MM} & 2927 \\ c s^{\alpha} & \text { Consumer surplus of the GM food group } & \mathrm{MM} & 8995 \\ c s^{\beta} & \text { Consumer surplus of the non-GM food group } & \mathrm{MM} & 4961 \\ c s^{\gamma} & \text { Consumer surplus of the indifferent group } & \mathrm{MM} & 355051 \\ W & \text { Social welfare } & \mathrm{MM} & 379460\end{array}$

Political Process:

$\begin{array}{clcc}b & \text { Weight parameter } & & 0.9 \\ T^{\alpha} & \text { GM food lobby contribution } & \mathrm{MM} & 0.089 \\ T^{\beta} & \text { Non-GM food lobby contribution } & \mathrm{MM} & 7.065 \\ T^{\alpha}+T^{\beta} & \text { Total contribution } & \mathrm{MM} & 7.154 \\ G & \text { Government payoff } & \mathrm{MM} & 341514\end{array}$

Note: a. MT=million tons; b. MM=million US Dollars.

\section{A.6 The GM food policy and the SSR}

Table 3.A4 Maize production and consumption under the change of GM food policy regulations

\begin{tabular}{|c|c|c|c|c|c|c|c|}
\hline \multirow[t]{2}{*}{$\theta$} & \multicolumn{2}{|c|}{ GM food market } & \multicolumn{2}{|c|}{ Non-GM food market } & \multicolumn{2}{|c|}{ Total } & \multirow[t]{2}{*}{ SSR } \\
\hline & Production & Consumption & Production & Consumption & Production & Consumption & \\
\hline 0.0 & 43.8966 & 5.37571 & 4.19496 & 7.74599 & 48.0916 & 13.12170 & 3.67 \\
\hline 0.1 & 32.8433 & 5.22915 & 4.19496 & 7.88441 & 37.0383 & 13.11356 & 2.82 \\
\hline 0.2 & 25.2019 & 5.25788 & 4.19496 & 7.94072 & 29.3968 & 13.19860 & 2.23 \\
\hline 0.3 & 19.7529 & 5.21742 & 4.19496 & 7.95731 & 23.9479 & 13.17473 & 1.82 \\
\hline 0.4 & 15.7642 & 5.12585 & 4.19496 & 7.95480 & 19.9592 & 13.0806 & 1.53 \\
\hline 0.5 & 12.7784 & 5.04655 & 4.19496 & 7.94343 & 16.9734 & 12.99 & 1.31 \\
\hline 0.6 & 10.4995 & 4.98189 & 4.19496 & 7.92816 & 14.6944 & 12.91 & 1.14 \\
\hline 0.7 & 8.73036 & 4.93909 & 4.19496 & 7.90745 & 12.9253 & 12.8365 & 1.01 \\
\hline 0.8 & 7.33633 & 4.88568 & 4.19496 & 7.84282 & 11.5313 & 12.7285 & 0.91 \\
\hline 0.9 & 6.22316 & 4.84973 & 4.19496 & 7.73128 & 10.4181 & 12.581 & 0.83 \\
\hline 1.0 & 5.32366 & 4.81975 & 4.19496 & 7.69718 & 9.51862 & 12.5169 & 0.76 \\
\hline
\end{tabular}




\title{
Chapter $4^{8}$
}

\section{A Political Economy Model of A GMO Trade Agreement}

\begin{abstract}
Motivated by the emerging topic of harmonization of the regulation of genetically modified organisms (GMOs) in trade agreement negotiations, such as the Trans-Pacific Partnership and the Transatlantic Trade and Investment Partnership, we discuss a trade agreement of agricultural products between two countries with different GM food policy regulatory regimes from a political economy perspective. We identify the negotiation equilibrium of such an agreement by simulating a reduction of the GM food non-tariff barrier from the side of the domestic country and a reduction of the non-GM food non-tariff barrier from the side of the foreign country. The government in each country prefers either a high or low non-tariff barrier that is influenced by interest groups during the negotiation. Due to the different consumer acceptance of GM and non-GM food products, the country that has high GM food trade barriers has the right of initiative for a successful trade negotiation, while the country that has lower trade barriers is reluctant to make concessions. Simulation results show that the equilibrium lies between the optimal unilateral stances of the two countries, which implies that certain agricultural protection benefits a country when political rivalries are involved.
\end{abstract}

\footnotetext{
${ }^{8}$ This Chapter is based on the article: Qianqian Shao, Maarten Punt, Rong-Gang Cong, and Justus Wesseler. A Political Economy Model of A GMO Trade Agreement.
} 


\subsection{Introduction}

After the subprime mortgage crisis and the Euro crisis, many countries are now willing to develop new economic policies. Trade agreements offer possibilities to revive stagnant economies. The WTO negotiations and the Doha Round, however, have hardly progressed. Therefore, some countries have launched regional bilateral or multilateral trade agreements. The largest ones are the Trans-Pacific Partnership (TPP) and the Transatlantic Trade and Investment Partnership (TTIP). The TPP is an agreement between the United States (US) and 11 other countries in the Pacific region that concluded on October 5, 2015. It accounts for nearly 40 percent of global GDP. The TTIP is an agreement between the European Union (EU) and the US. The two parties launched the negotiations in July 2013. Given the low tariff between trade partners, the elimination of non-tariff barriers (NTBs) is the key focus of the trade negotiations. According to a report from the Center for Economic Policy Research (Francois et al. 2013), for example, the elimination of the NTBs as a result of the TTIP will bring significant economic gains as a whole for the EU (€119 billion a year) and the US (€95 billion a year). Agricultural trade plays a significant role in trade agreements, but it is also a difficult part of the negotiations due to strong domestic protection. Agricultural NTBs comprise different regulations and standards on agricultural commodities, such as sanitary, phytosanitary, and agricultural biotechnology policies. Agricultural biotechnology is a particularly sensitive topic within the negotiating terms. The TPP marks the first time that agricultural biotechnology is mentioned in the trade agreement. Similarly, the TTIP includes negotiable terms under which the EU would import more Genetically Modified (GM) products and loosen its labeling regulations on GM Organisms (GMOs) (Hansen-Kuhn and Suppan 2013).

All 12 TPP countries are either a GM crops grower or importer, but their regulations are asymmetric. For example, Japan highly protects its domestic agricultural trade as well as has strict GM food policy regulations, while the US is the leading exporter of soybeans, grains and feeds and 
applies lenient GM food policy regulations. The difference between the EU and the US GMO food policy regimes is an example of a hindrance in the TTIP negotiation. The EU has strict regulations on GMOs, such as labeling and coexistence, while the US does not require labels nor has specific coexistence rules (Wesseler and Kalaitzandonakes 2011). Even though these two large economies have a divergence in their GM food policies, they are important trade partners for each other. EUUS trade climbed to $\$ 787$ billion in 2013, double the level in 2000 (Hamilton and Quinlan 2014). After 2011, EU agricultural product sales on the US market kept on growing to over $€ 15$ billion in 2012, which is a 13\% increase compared to 2011 (Eurostat 2016). However, the EU imports about 30 million tons of GM crops per year, most of which are soybeans and maize for animal consumption (European Commission 2016). The total trade volume in agricultural products from the US to the EU is only 4.8 percent of the total bilateral trade volume (World Trade Organization, W'TO 2015).

In the US, the largest GM food commercial producer, 88 percent of corn, 94 percent of cotton, and 93 percent of soybeans are GM crops (United States Department of Agriculture, Economic Research Service 2013). The US imports only 2.1 percent of its total amount of agricultural products from the EU (WTO 2015). Even though there are no substantial achievements on GM food policy regulation coherence from the previous trade negotiations (e.g., the TPP agreement), the tackling of NTBs in agricultural biotechnology has a large economic potential in future negotiations. In this paper, we discuss trade negotiations between two large countries over tariff equivalent NTBs of agricultural commodities, GM and non-GM, where two countries have different domestic regulations on their GM and non-GM food products.

The GMO attitude is believed to be politically influenced. The GMO food regulation approval process is a result of political rivalry between different interest groups, according to many scientists (Anderson et al. 2013; Graff et al. 2009; Qaim 2009). Some interest groups (such as 
biotech R\&D firms, GM farmers, and retailers) would be in favor of lenient GM food policy regulations, whereas the interest groups who represent conventional agriculture (e.g. conventional farmers and chemical producers) and environmentalists would prefer stringent GM food policy regulations. This debate could influence the GMO Trade Agreement (GTA) negotiation, and the GTA negotiation may intensify the current GMO debate within the member countries.

In this paper, we model the negotiation between two governments that are politically influenced by their domestic interest groups, a GM food group and a non-GM food group. This political economy approach has been discussed in many previous free trade agreement (FTA) negotiations studies. For example, Grossman and Helpman (1995) described a bilateral FTA negotiation and discuss the economic terms and conditions of an FTA equilibrium outcome. Levy (1997) studied the interaction between multi and bilateral FTA negotiations. He finds that bilateral negotiations can undermine political support for multilateral free trade because a bilateral FTA offers larger gains than the multilateral FTA. Many of these studies focus on aggregate welfare and simplify the context by assuming a single traded good. Later, Fajgelbaum et al. (2011) developed a framework to study the trade of differentiated products. They provided a tool for studying welfare consequences of the trade and trade policy by differentiating consumers by income and preferences towards the quality and variety of goods. We depart from previous literature and discuss the coherence of two different trade standards on differentiated agricultural products that are categorized based on consumer preferences. We assume there are three kinds of food consumers: GM, non-GM, and indifferent. GM and non-GM food consumers have strong preferences for one of the products, but indifferent consumers purchase both GM and non-GM food products and treat them as imperfect substitutes.

Our discussion focuses on bilateral GTA negotiations by assuming a strict GM food policy regulation in the domestic country and a lenient regulation in the foreign country. Two countries 
trade both GM and non-GM food products, but exports from the foreign country to the domestic market face a high GM food NTB, and the domestic country faces a high non-GM food NTB regarding its exports to the foreign market. The negotiation between two countries aims to mitigate the NTBs for both products. The governments' stances in the negotiation are influenced by their domestic interest lobbies. We simulate the negotiation process and find the equilibrium NTB. Countries benefit from lower NTBs; however, free trade (zero tariff or NTBs) is not always beneficial to all consumers because a low GM food NTB will hurt the domestic non-GM food consumers, especially when the non-GM food group is large in the country, and a low non-GM food NTB will make the foreign non-GM food firm lose profits. Moreover, the initiation of the GTA negotiation could intensify domestic debates. Governments need to balance the NTB reduction and the domestic interests within the heterogeneous regulations negotiation. We also demonstrate that welfare and lobbying contribution change during the negotiation and the Nash bargaining solution of the NTBs reduction in the simulation.

\subsection{The Two-country Model}

We formulate a two-country model, a domestic country and a foreign country. The domestic country has strict GM food policy regulations, and the consumer acceptance of GM food products in the domestic country is low. A stricter GM food policy regulation can be interpreted as a high compliance cost for the GM food producer (Beckmann et al. 2011), which includes higher production costs. Here firms have increasing return to scale farm level production by using GM food policy technology versus conventional farming. In contrast, the GM food policy regulation is less strict in the foreign country. We assume there is a less strict GM food policy or even subsidization on the GM food production in the country. Instead of subtracting the subsidy from the foreign GM food production cost, we impose a similar regulation compliance cost to the non- 
GM food firm in the foreign country for symmetry. However, this cost may not be as high as the GM food policy cost in the domestic country because the non-GM food products are acceptable for all consumers. Thus, we have a high GM food policy regulation cost in the domestic country and a lower non-GM food policy regulation cost in the foreign country in our initial setting. The foreign country applies more GM food technology in agricultural production, while the domestic country produces mainly conventional agricultural goods. Except for the difference in the regulation and acceptance of GM food technology, the two countries are symmetric in terms of economic structure.

In the world market, both countries trade agriculture products and numeraire goods with each other. The domestic country exports non-GM food products to and imports GM food products from the foreign country, but the trade volume is influenced by the asymmetric GM food policy regulations between the two countries. Tariffs in the bilateral trade are very low, but regulations of import products, such as GM food labeling regulations for the domestic GM food imports (Kreipe 2010), are non-tariff barriers that mainly impede the free trade. Given the minimal tariff on GM food products in the bilateral trade, we assume the GM food trade tariff is zero and only models the NTBs. We model it as tariff equivalents in the bilateral trade as in previous trade literature (Linkins and Arce 2002; Ferrantino 2006; Winchester 2009). $t_{G}$ is the tariff equivalent of the GM food NTB set by the domestic government, and $t_{N}$ is the tariff equivalent of the non-GM food NTB set by the foreign government. The purpose of the GTA negotiation is to reduce the NTBs on GM and non-GM food products in the bilateral trade. We focus our discussion on the negotiation, so we assume the GM food policy regulations in each country: strict in the domestic country and lenient in the foreign country before the negotiation. 
In the following discussion, we describe the symmetric economic structure of the two countries. Notations with and without an asterisk are variables of the foreign country and the domestic country, respectively. Due to the symmetry, we discuss the domestic economy first.

There are two sectors in the domestic country, an agricultural food sector and a numeraire $\operatorname{good}(z)$ sector. There are two representative firms in the food sector in the domestic agriculture market, a conventional food and a GM one. The GM food firm in the domestic country has to pay a GM food policy regulation compliance cost $(\theta, \theta>0)$ for using the GM food technology. Stricter GM food policy regulation induces a higher production cost for the firm. Total labor $(\bar{L})$ is sufficient for both sectors with a wage rate of $w$ in both sectors. Two sectors also have capital input with the unit price of $r$. Input factors are not tradable, so $\bar{L}=L_{G}+L_{N}+L_{z}$ and $\bar{K}=K_{G}+K_{N}+K_{z}$ in the domestic market. We denote the output of the GM food products as $x_{G}$, and $x_{N}$ is the output of the conventional food products, where $x_{G}=A L_{G}^{\varepsilon_{L}} K_{G}^{\varepsilon_{K}}$ and $x_{N}=B L_{N}^{\eta_{L}} K_{N}^{\eta_{K}}$. We assume decreasing returns to scale for both types of production (i.e., $\varepsilon_{L}+\varepsilon_{K}<1$ and $\left.\eta_{L}+\eta_{K}<1\right)$ in order to ensure positive profits for the two firms. The distribution of labor and capital in the production due to the application of GM food technology influences the output of the GM and non-GM food firms. The domestic non-GM food firm exports the excess supply of nonGM food products $\left(X_{N}\right)$ to the foreign country. The profit functions of the two firms in the domestic country are:

$$
\begin{gathered}
\pi_{G}=p_{G} x_{G}-w L_{G}-(1+\theta) r K_{G} \\
\pi_{N}=p_{N}\left(x_{N}-X_{N}\right)+p_{N}^{*} X_{N}-w L_{N}-r K_{N}
\end{gathered}
$$


where $p_{G}$ and $p_{N}$ are the prices of the GM and non-GM food product, respectively, where $p_{G}=p_{G}^{*}+t_{G}$ and $p_{N}^{*}=p_{N}+t_{N}$ in the world market. Stricter GM food policy regulations generate a higher compliance cost for the firm and decrease the firm's profit in the country. But we focus on the negotiation of NTBs and take the domestic GM food policy as an exogenous variable in the model. The non-GM food firm earns foreign profits from the non-GM food exports $\left(X_{N}\right)$ with the non-GM food price $\left(p_{N}^{*}\right)$ in the foreign market, and the NTBs influence its foreign profits.

Following Eerola (2004), we normalize the overall population to one and divide them into three groups. Fraction $\alpha$ of the population owns the GM food firm and shares the GM food firm's profits. For example, GM R\&D researchers, producers, and retailers belong to this group.

Consumers in this group have a strong preference for GM food and only consume GM food products. They are in favor of innovative technology and are convinced of its environmental and health benefits. Fraction $\beta$ of the population is the non-GM food group. Consumers in this group have a strong preference for the non-GM food products and only consume non-GM food products. They own the non-GM food firm and earn the non-GM profits. The anti-GM organizations, conventional and organic farmers, and anti-GM food consumers belong to this group. They worry about the potential risks of the GM food technology. The rest of consumers belong to fraction $\gamma(=1-\alpha-\beta)$, and they do not have profit income. This group considers GM and non-GM food products imperfect substitutes and demands both. They do not worry much about the potential risks of the GM food technology, and therefore we label them henceforth as "indifferent." Consumers belonging to either fraction $\alpha$ or $\beta$ make donations to their lobby groups from their income for the lobbying contributions. $\gamma$ consumers do not make donations and stay passive in the political game. The government collects policy income and redistributes it into the society, so all consumers 
earn a share of payment from the GM food policy regulation $\left(\theta r K_{G}\right)^{9}$. Interest groups make

contributions from their income to influence the trade policy, and we assume the groups only lobby within their own governments. The net income of each group is:

$$
\begin{aligned}
& I^{\alpha}=\alpha w \bar{L}+\pi_{G}+\alpha \theta r K_{G}-C^{\alpha}\left(t_{G}\right) \\
& I^{\beta}=\beta w \bar{L}+\pi_{N}+\beta \theta r K_{G}-C^{\beta}\left(t_{G}\right) \\
& I^{\gamma}=\gamma w \bar{L}+\gamma \theta r K_{G}
\end{aligned}
$$

where $C^{i}(i=\alpha, \beta)$ is the lobbying contribution of each group to the government. Individuals consume both numeraire goods and food products subject to their net income $I^{i}(i=\alpha, \beta, \gamma)$. Consumers maximize their utility

$$
\begin{gathered}
\max U^{i}=\left[\phi\left(x_{j}^{i}\right)^{\rho^{i}}+(1-\phi)\left(z^{i}\right)^{\rho^{i}}\right]^{\frac{1}{\rho^{i}}} \\
\text { s.t. } I^{i}=p_{z} z^{i}+p_{G} x_{G}^{i}+p_{N} x_{N}^{i} \text { for } i=\alpha, \beta, \gamma, j=G, N, F \text { and } \phi=m, n, s,
\end{gathered}
$$

where $z^{i}$ is the utility from consuming the numeraire product, $\phi$ is the share of consumed food products. $m, n$, and $s$ stand for the food consumption shares of GM, non-GM, and indifferent consumers. We denote $x_{G}^{i}$ and $x_{N}^{i}$ as the demand for GM and non-GM food products by group $i$. The total demand of GM food products is $\left(x_{G}^{\alpha}+x_{G}^{\gamma}\right)$, and the total demand of non-GM food products is $\left(x_{N}^{\beta}+x_{N}^{\gamma}\right)$ (see Appendix 4.A1 for the calculation).

The domestic excess demand for GM food products is $M_{G}=\left(x_{G}^{\alpha}+x_{G}^{\gamma}\right)-x_{G}$, and the excess GM food supply for the foreign country is $X_{G}=x_{G}^{*}-\left(x_{G}^{\alpha^{*}}+x_{G}^{\gamma^{*}}\right) . M_{G}=X_{G}$ for the world market equilibrium. Similarly, the domestic country exports the excess non-GM food products

\footnotetext{
9 Since we assume the domestic GM food policy $(\theta)$ is exogenous, the total amount of transfer payment for each group will not be changed during the trade negotiation. But of course, large group gets higher income for its consumption and lobbying.
} 
$X_{N}=x_{N}-\left(x_{N}^{\alpha}+x_{N}^{\gamma}\right)$, which equals the excess demand in the foreign country,

$M_{N}=\left(x_{N}^{\alpha^{*}}+x_{N}^{\gamma^{*}}\right)-x_{N}^{*} \cdot M_{N}=X_{N}$ for the world market equilibrium.

The aggregate welfare of the country is the sum of the producer surplus and the consumer surplus. Consumer surplus is measured by equivalent variation of consuming either GM or non-GM food products or both (see Appendix 4.A.2). We can write the aggregate welfare of each country as

$$
W_{e}\left(t_{G}, t_{N}\right)=\pi_{G}+\pi_{N}+c s^{\alpha}+c s^{\beta}+c s^{\gamma} \text { where } e=D, F
$$

where $\operatorname{cs}^{i}(i=\alpha, \beta, \gamma)$ is the consumer surplus for each group, $D$ denotes the domestic country, and $F$ denotes the foreign country. The social welfare is influenced by both the GM and non-GM food NTBs.

\subsection{The Bilateral GTA Negotiation}

We follow Winters (1987)'s declaration that the costs and benefits of NTB reduction can be analyzed with the techniques of a tariff negotiation. He defines the costs and benefits from an NTB negotiation as follows: the domestic country's "benefits" of a concession in TE is equal to the reduction of regulation costs of the foreign country. Similarly, the reduction of the domestic NTBs also benefits the foreign country. This relation especially applies in a two-country model. Countries value their negotiation stances subject to the gains from regulatory change. NTBs have a direct effect on the trade volume and an indirect effect on the price (Herberg 1990). Thus, we assume that the rents from the NTB reduction equal to the benefits from lower regulation costs, which is included in the consumer surplus.

The two countries negotiate two trade policies, the GM food NTB and the non-GM food NTB, in the negotiation concurrently. The incumbent domestic government has set an initial GM food trade policy $\left(t_{G}^{0}\right)$, which is high for the foreign GM food exports. The initial foreign non-GM NTB $\left(t_{N}^{0}\right)$ is 
also high for the domestic non-GM food exports. The reduction of both import NTBs is beneficial for the welfare in both countries. We denote the new NTB for the GM food import as $t_{G}$ and the new

NTB for the non-GM food import as $t_{N}$, if both countries reach an agreement. So, the superscript " $A$ " denotes the condition of continuing the status quo, and the superscript " $B$ " denotes the condition of realizing a GTA. Then, the TE rents from the NTB reduction is: $t_{j} M_{j}^{B}-t_{j}^{0} M_{j}^{A}$, where $j=G, N$. The rents are influenced by food prices in the world market, as well as the consumer surplus. Producer profits in each country are influenced directly by a change in the NTB. Therefore, the change of social welfare is $\Delta W_{e}=W_{e}^{B}-W_{e}^{A}\left(W_{e}\right.$ is defined in equation (4.5)).

As we mentioned before, the governments' negotiation behaviors are influenced by the lobbying groups in each country. There are two lobby groups in each country, the GM and the nonGM food group. Lobby groups influence the regulations in several ways. For example, they can make contributions, endorsements, and committed votes to the government in order to influence the policy outcome. For simplicity, we model these contributions as monetary equivalents from the interest groups. The government's payoff constitutes the general interests and contributions from the two interest groups (Grossman and Helpman 1995). The timing of the political game in both countries is as follows: the two interest groups announce their contribution schedules simultaneously to the government at the first stage. The government then chooses a GM food policy that maximizes its payoff at the second stage. The government maximizes the monetary equivalent of weighted general interests and special interests in the negotiation process

$$
G_{e}\left(t_{e}\right)=a_{e} W_{e}+\left(1-a_{e}\right)\left(C_{e}^{\alpha}+C_{e}^{\beta}\right)
$$

where $a_{e}$ is the weight parameter indicating the relative importance of general interests in the policy-making process. We assume lobbying is equally efficient for each interest group. Following Grossman and Helpman (1994), lobbies' contribution schedules are truthful, which means the 
change of contribution induced by the policy change reflects the lobbies true preferences for the policy in the lobbying game. In other words, for example, a high GM food NTB represents a high non-GM group's contribution and a low GM group's contribution in the lobbying occurring within the domestic country. In this way, the lobbying income from interest groups is reflected in the government payoff during the negotiation. This is illustrated in the simulation (see Figure 4.4).

There are only two outcomes of the negotiation: signed and failed. For the domestic country, the GM food lobby, who is currently relatively worse-off in the domestic country before the negotiation, takes it as an opportunity to change its domestic status in the GTA game. More GM food imports will increase the competition in the domestic GM food market, but if the domestic GM food firm occupies a very small fraction of the food market, the domestic GM food consumers benefit from a lower GM food price. The consumers gain compensates the firm's loss of the GM food group, under a lower $t_{G}$. In contrast, the better-off non-GM food lobby in the domestic country would like to lobby for a strict GM food import regulation for the country. A higher $t_{G}$ induces a higher domestic GM food price, so more indifferent consumers would choose non-GM food products. However, the domestic government needs to make concessions on the GM food import NTB for getting a lower non-GM food exports NTB, so it needs to take both the loss due to more GM food imports and the gain due to more non-GM food exports into account when announcing its contribution schedule. Similarly, in the foreign country, the non-GM food group lobbies for a lower non-GM food NTB for cheaper non-GM food products in order to increase non-GM food consumer surplus. The GM food lobby in the foreign country is supported by the government and takes a large market share in the country. The GM food group wants to export more, so it needs to take the loss by cause of more nonGM food imports in the domestic country and the gain from more GM food exports into consideration 
in the negotiation. The above argument is supported by the optimal contribution schedule of Grossman and Helpman (1994), which is determined by $\partial W_{e}^{i}\left(t_{j}\right) / \partial t_{j}=\partial C_{e}^{i}\left(t_{j}\right) / \partial t_{j}$.

The governments in the two countries maximize their payoffs by choosing a pair of contributions from lobby groups after entering the negotiation. In each country, the government pursues the GTA only if the change of its payoff after the GTA is positive:

$$
\Delta G_{e}\left(t_{G}, t_{N}\right)=a_{e} \Delta W_{e}+\left(1-a_{e}\right) \Delta\left(C_{e}^{\alpha}+C_{e}^{\beta}\right) \geq 0
$$

The government payoff changes depending on the welfare change, the change in contributions from the lobbying groups, and the weights of these different aspects.

In the negotiation, we define unilateral stances as a set of positions that the government will choose in response to the domestic interest groups' equilibrium behavior. We follow Grossman and Helpman (1995) and denote the set of unilateral stances for the domestic country $\left\{t_{G}\right\}$ and the foreign country $\left\{t_{N}\right\}$, which are selected according to the sets of contributions for the interest groups before the negotiation in each country. The set of positions $\left\{t_{j}\right\}$ for the two governments in the GTA negotiation guarantees a positive payoff increase. The contribution schedules of lobbying groups are unique and maximize their welfare in the political game. Among the unilateral stances, we can find the optimal unilateral regime $\bar{t}_{j e}$ from the government payoff functions, which gives the highest government payoff. It is determined by

$$
\frac{\partial \Delta G_{e}}{\partial t_{j}}=a_{e} \frac{\partial \Delta W_{e}\left(\bar{t}_{j}\right)}{\partial t_{j}}+\left(1-a_{e}\right)\left[\frac{\partial \Delta C_{e}^{i}\left(\bar{t}_{j}\right)}{\partial t_{j}}+\frac{\partial \Delta C_{e}^{i}\left(\bar{t}_{j}\right)}{\partial t_{j}}\right]=0
$$

Our definition describes the unilateral stances as a range of choices that constitute a positive $\Delta G_{e}$. Each point in the possibility set gives the two governments a different payoff pair. The government payoff is maximized at the optimal unilateral stance. Each government would prefer the 
equilibrium agreement to be located as close to its own optimal unilateral stance as is possible. For example, when two governments negotiate about the GM food NTB while keeping the non-GM food NTB constant, the GTA solution is shown in Figure 4.1. In the example, we suppose that the two governments are roughly the same, and their payoff functions are quadratic.

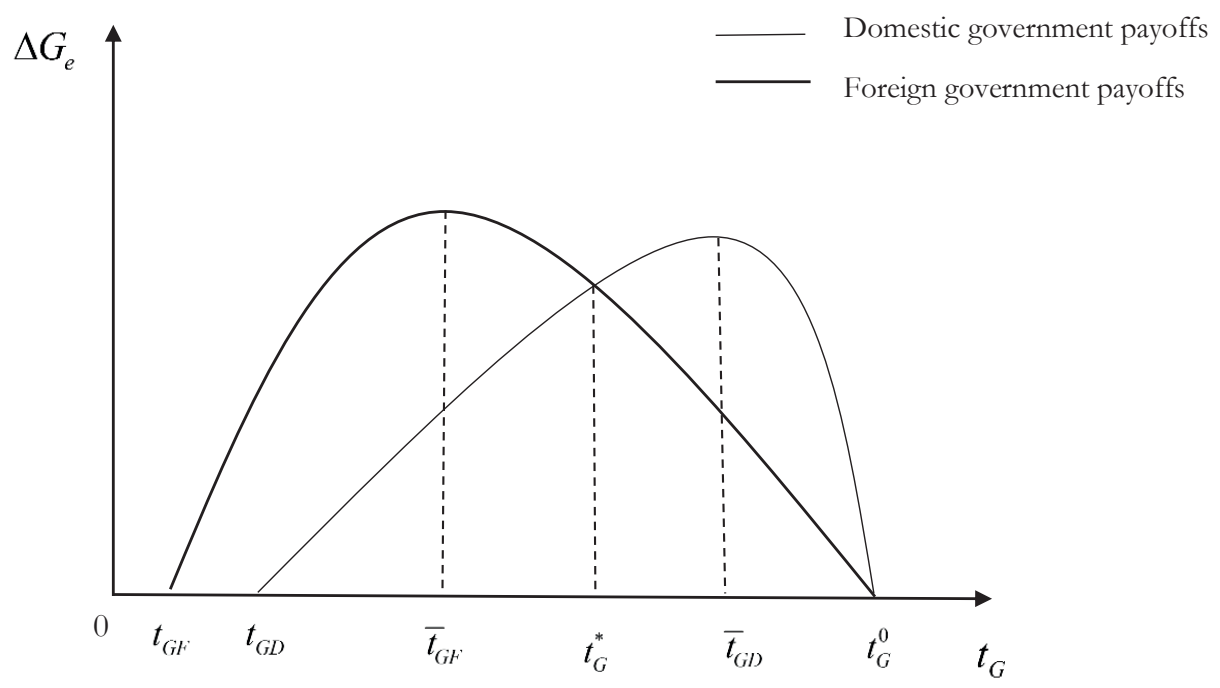

Figure 4.1 A Possible GTA Solution of $t_{G}^{*}$

In Figure 4.1, the equilibrium NTB influences two governments' payoffs, and the payoff functions are determined by their own domestic lobbying game. The negotiation is about a trade cost reduction, so we start the negotiation from the current NTB $t_{G}^{0}$. From $t_{G}^{0}$ to $t_{G D}$ is the feasible set for the domestic unilateral stances and from $t_{G}^{0}$ to $t_{G F}$ is the set for the foreign. The optimal unilateral stances to maximize the government payoffs are $\bar{t}_{G D}$ and $\bar{t}_{G F}$ for the domestic and foreign country, respectively. The overlap distance is from $t_{G}^{0}$ to $t_{G D}$. However, the distance from $t_{G}^{0}$ to $\bar{t}_{G D}$ will not be part of the solution set because the government payoffs for both countries are still increasing. Similarly, the distance from $\bar{t}_{G F}$ to $t_{G F}$ will not be part of the solution set because the payoffs are decreasing for 
both countries. The trade policy solution $\left(t_{G}^{*}\right)$ lies in the possible negotiation solution set from $\bar{t}_{G D}$ to $\bar{t}_{G F}$. Moreover, if we use the Nash Bargaining Solution a pair of payoffs $\left(\Delta G_{D}\left(t_{G}^{*}\right), \Delta G_{F}\left(t_{G}^{*}\right)\right)$ should satisfy

$$
\begin{aligned}
& \max _{t_{G}}\left[\left(u_{D}\left(t_{G}^{*}\right)-u_{D}\left(t_{G}^{0}\right)\right)\left(u_{F}\left(t_{G}{ }^{*}\right)-u_{F}\left(t_{G}^{0}\right)\right)\right] \\
& =\max _{t_{G}}\left[\left(\Delta G_{D}\left(t_{G}^{*}\right)\right)\left(\Delta G_{F}\left(t_{G}{ }^{*}\right)\right)\right]
\end{aligned}
$$

where $u_{e}(\cdot)$ is the governments' payoff possibilities and $u_{D}\left(t_{G}^{0}\right)$ and $u_{F}\left(t_{G}^{0}\right)$ are the threat point payoffs (the change of payoff or the starting point of negotiation). The negotiation for the non-GM food NTB is similar, by setting the GM food NTB to be constant.

We conduct three steps to find the Nash Bargaining Solution for the GTA negotiation. First, we find the unilateral stances for both countries that constitute positive payoff changes for the governments. We use unidimensional search to find the unilateral stances. That is, we keep decreasing the domestic GM food NTB until one of the government payoffs approaches zero, and then we decrease the foreign non-GM food NTBs until one of the government payoff changes equals zero.

Second, we calculate the absolute values of governments payoff changes in the negotiation. We can find the optimal unilateral stances in this step. Lastly, we maximize the product of two government payoff changes. The NTB that maximizes the product is the Nash Bargaining solution for a successful negotiation. We show the details in the simulation section.

\subsection{Simulation}

Whether or not GM and non-GM food products are the same or different products is disputable. Even the WTO has not made a clear statement on this (Punt and Wesseler 2016) argument for trading GMOs. Not all consumers accept the GM food products, but the non-GM food products can be 
accepted by all consumers. The trade standards are different for the two countries, and the model setting in the theoretical part before the GTA negotiation are as follows:

Table 4.2 Specification of the domestic and foreign country

\begin{tabular}{ccccccc}
\hline & GM Policy & Non-GM policy & Import & Export & GM price & Non-GM price \\
\cline { 2 - 7 } $\begin{array}{c}\text { Domestic } \\
\text { Country }\end{array}$ & High & None & GM & Non-GM & $p_{G}=p_{G}^{*}+t_{G}$ & $p_{N}$ \\
$\begin{array}{c}\text { Foreign } \\
\text { Country }\end{array}$ & None & High & Non-GM & GM & $p_{G}^{*}$ & $p_{N}^{*}=p_{N}+t_{N}$ \\
\hline
\end{tabular}

We give the model elaborated initial numbers that satisfy Table 4.1's settings (see Appendix 4.A.3). The GM food policy cost $\theta$ is high in the domestic country (474.35 per unit of capital), and the non-GM food policy cost in the foreign country is also high (3.97 per unit of capital), but much smaller than the GM food policy cost in the domestic country because non-GM food products are not under debate in the foreign country. The initial NTBs are: $t_{G}=0.9$ and $t_{N}=0.5$, which means the GM food policy is strict in the domestic country but is subsidized in the foreign country. There is a competition in the foreign non-GM food market between the foreign and the domestic non-GM firm (exporting non-GM food products). More non-GM food consumers prefer cheaper non-GM products in the foreign country, so the non-GM food lobby needs to balance the group's welfare for the lobbying contribution. There is a similar situation for the GM food lobby in the domestic country. In the simulation, we first study the negotiation starting from a medium $\left(t_{N}=0.5\right)$ non-GM NTB level due to the lenient GM food policy regulation in the foreign country.

In the first step, we need to find the unilateral stance sets for the two governments. We use relative payoff changes to show the policy effects on welfare $\left(\left[\Delta G_{e}\left(t_{G}\right)-\Delta G_{e}\left(t_{G}^{0}\right)\right] / \Delta G_{e}\left(t_{G}^{0}\right)\right)$. The curve is shown in Figure 4.2. 


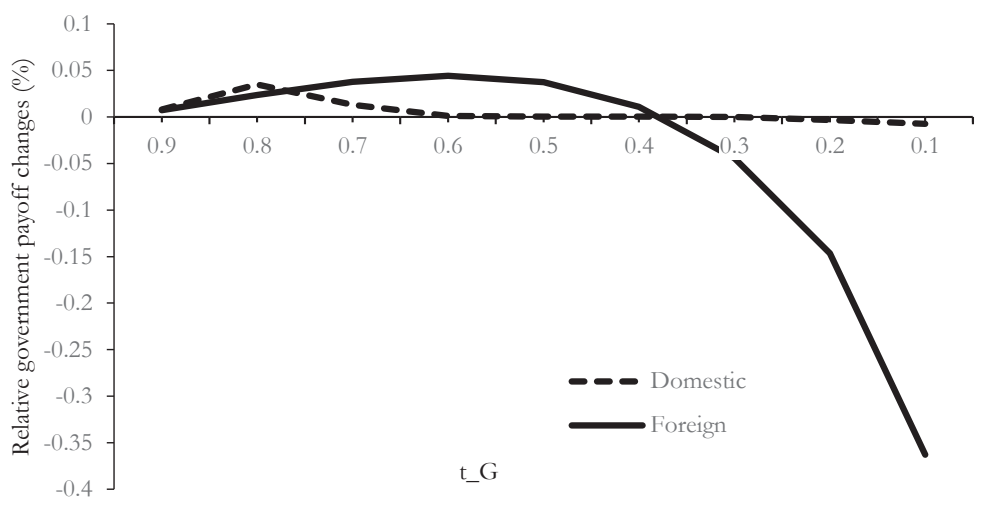

Figure 4.2 Relative payoff changes for the domestic and foreign governments when $\mathrm{t} \_\mathrm{N}=0.5$

In Figure 4.2, we illustrate the domestic and foreign government payoffs under $t_{N}=0.5$. We

find the range of choices for the domestic country is $0.4 \leq t_{G} \leq 1$ for the given $t_{N}=0.5$. The domestic and foreign government payoffs decrease in the interval when $t_{G} \in[0.3,0.4]$. We can see the domestic government payoff increases after the GM food NTB reduces. But the increment is less afterwards because the non-GM food consumers take a large fraction in the domestic country, and more GM food imports will decrease the welfare of the domestic country. Moreover, the decrease of the GM food NTB causes a reduction in the contribution from the non-GM food lobby. The foreign payoff change is higher when the domestic GM food NTB becomes lower, but it decreases a lot when the GM food NTB approaches zero. The reason is that although a lower GM food NTB is more attractive for the foreign GM food firm to export more GM food products, it also requires more labor and thereby a higher labor cost for the production. The output increases, but the labor cost increases faster than the firm's revenue, so the foreign GM food profits decrease. While keeping other variables constant, the government payoff, therefore, decreases as well.

Under our above setting, in the negotiation the foreign country would not like to reduce the non-GM food NTB after the domestic country reduces the GM food NTB because the foreign 
government's payoff decreases once the foreign non-GM food NTB reduces. The reason is that the non-GM food policy in the foreign country is not as strict as the GM food policy in the domestic country, so it allows for foreign non-GM food production. The foreign non-GM profits decrease a lot if cheaper non-GM food products are imported. Therefore, the foreign government payoff will be negative if the non-GM food NTB decreases, regardless of the level of the NTB. For $t_{N}=0.9$ and $t_{N}=0.1$, we find that the level of the foreign non-GM food NTB only influences the level of the governments' payoffs, not the negotiation results because the foreign government is unable to make a concession. The level of the domestic payoff will be influenced by the level of the non-GM food NTB from the foreign country. The level of $t_{N}$ influences the non-GM food exports of the domestic country (see Figure 4.3), the level of non-GM food profits and the lobbying contribution in the domestic country. Income change influences the consumption. Thus, the total government payoff is changed.

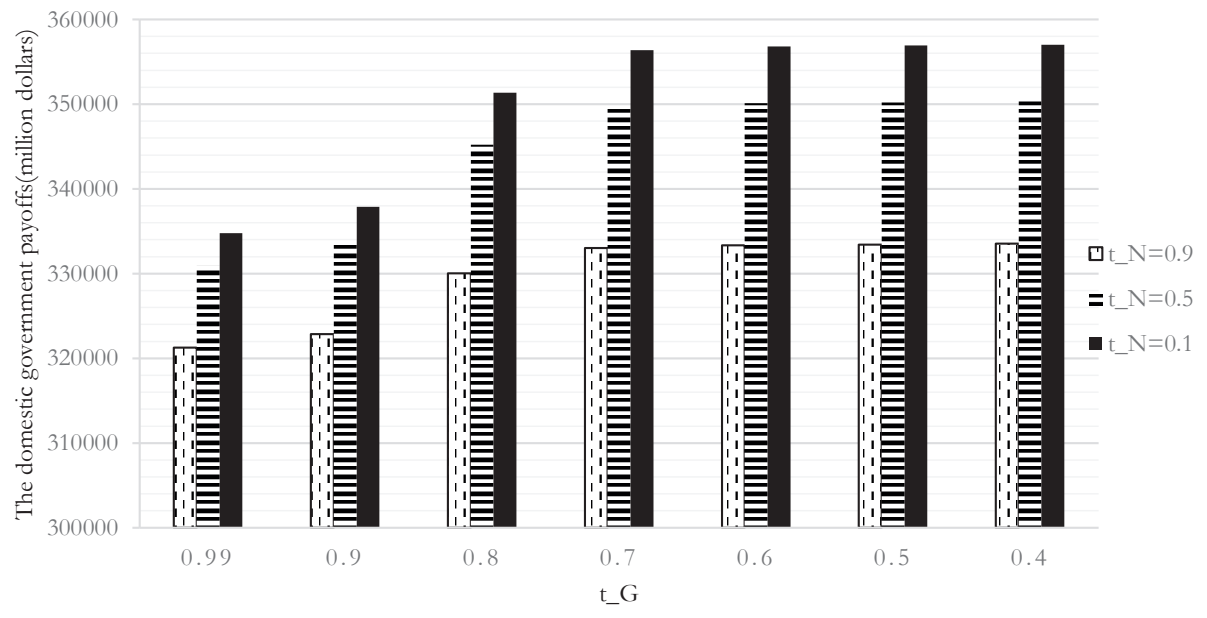

Figure 4.3 Domestic government payoffs under different non-GM food NTBs

In Figure 4.3, we can see that the domestic government payoffs are low when $t_{G}$ and $t_{N}$ are 
high for both countries and that the governments' payoffs (absolute values) are maximized when $t_{G}=0.4$. We only discuss the policy effects on welfare when $0.4 \leq t_{G} \leq 1$ satisfy $\Delta G_{e}\left(t_{G}\right) \geq 0$. The unilateral stances are located within $0.4 \leq t_{G} \leq 1$ regardless of the non-GM food NTB level because the foreign government cannot make a concession in the negotiation.

The unilateral stances are chosen in response to the domestic lobbying contributions. We assume the contribution curves follow logistic functions, with the maximum contribution of the group's income being $C . C^{i}=N^{i} /\left(1+B^{i} e^{-T^{i} t_{G}}\right)+D^{i}$, where $N^{i}$ is the maximum value of the contribution. The domestic GM food group lobbies for a lower $t_{G}$, and likewise, the non-GM food group for a higher one. $B^{i}$ is the shape parameter and $T^{i}$ is the growth rate of contribution. $D^{i}$ is the shift of the contribution curve. Since the contributions are only influenced by their home trade policy, we illustrate the lobbying contribution by setting the foreign non-GM food NTB $t_{N}=0.5$ for displaying the domestic country's lobbying and $t_{G}=0.5$ for presenting the foreign country's lobbying. The lobbying contributions of the two countries are shown in Figure 4.4. In the domestic country, the GM food lobby contributes more for a low GM food NTB. A lower GM food NTB hurts the domestic GM food firm but increases the domestic GM food consumers' surplus. Moreover, a cheaper GM food price attracts more consumers from the indifferent group. The gain from cheaper GM food products compensate the firm's loss and increase the total welfare of the group. But the non-GM food group lobbies for a high GM food NTB because the non-GM food firm and the GM food firm compete for the indifferent consumers. The non-GM food lobby has a large population share in the domestic country, so it has more money for lobbying than the domestic GM food lobby in Figure 4.4 (a). But in the foreign country, the GM food lobby is stronger than the non-GM food lobby, and it prefers a higher non-GM food NTB in the negotiation 
or minor concessions on the non-GM food NTB reduction. The foreign GM and the non-GM food firm compete for the foreign indifferent consumers as well, so the foreign non-GM food lobby prefers a lower non-GM food NTB. Since the non-GM food NTB is not so high as the GM food NTB in the foreign country, the lobbying power of the foreign non-GM food group larger than the GM food group in the domestic country.

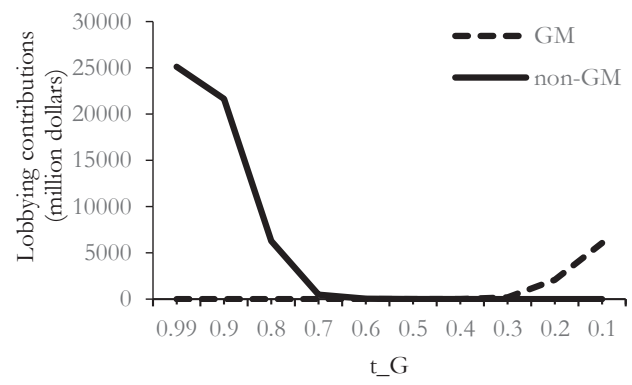

(a) Domestic Country Lobbying

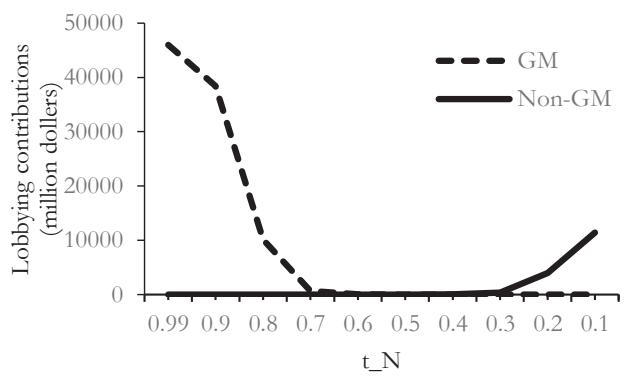

(b) Foreign Country Lobbying

Figure 4.4 Lobbying contributions of the GM and non-GM food groups in the GTA negotiation

In the domestic country, the domestic GM food policy is strict so that the domestic GM food firm earns much less than the domestic non-GM food firm. Therefore, during the GTA negotiation, the contribution from the non-GM food group is larger than the GM food group. In the foreign country, the GM food firm has more market share and earns more profits than the non-GM food firm. The GM food lobby is more powerful in the foreign country than the non-GM food lobby. The total contribution from interest groups in each country influences the governments' payoffs directly (equation (4.6)) and the unilateral stance of the government in the negotiation.

In the second step, we need to find the value of $\Delta G_{e}$ for both countries. We plot the curves of the domestic and foreign governments' payoffs in Figure 4.5. We assume the negotiation starts from an extremely high GM food NTB (i.e. $t_{G}=0.99$ ) at a given $t_{N}=0.5$. We can see that the domestic 
government maximizes its payoff change at $t_{G}=0.8$, whereas the foreign government maximizes its payoff at $t_{G}=0.6$. In the domestic country, the GM food imports increase when the GM food NTB is reduced up to $t_{G}=0.8$. If the price of GM food products decreases, more GM and indifferent consumers purchase cheaper food products and the domestic welfare increases. Moreover, the lobbying income from the non-GM food group is still high for the domestic government. The foreign country, however, prefers an even lower GM food NTB, considering the powerful GM food lobby. Its payoff is maximized when $t_{G}=0.6$. The reason is that the foreign country would like to export more GM food products to the domestic market and prefers a lower GM food NTB so that it can compete with the non-GM food products in the domestic food market. Thus, $t_{G}=0.8$ is the optimal unilateral stance for the domestic country and $t_{G}=0.6$ for the foreign country. We also find that the zero NTB is not the optimal choice for both countries. This occurs because the government will lose a part of the lobbying contribution from the interest groups. Agricultural protection is the reason for the political support in the negotiation.

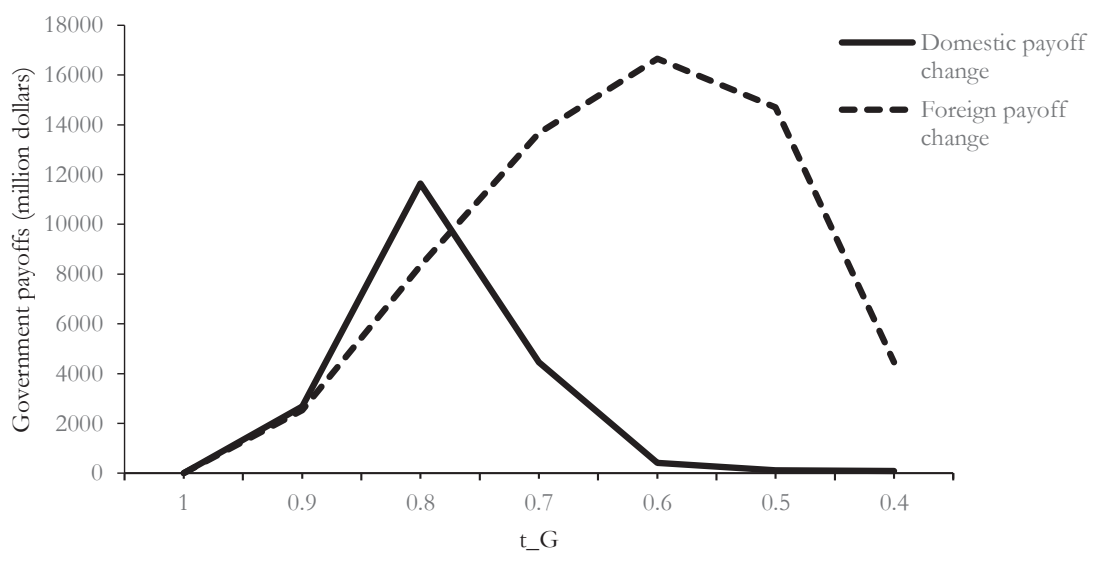

Figure 4.5 The government payoff change under $\mathrm{t} \_\mathrm{N}=0.5$ 
The third step is to maximize the products of the two governments' payoff changes. We present the products of the changes in Figure 4.6 and find that the equilibrium lies between the domestic and foreign optimal unilateral stances. In our simulation, it is $t_{G}=0.7$ under the high, medium and low level of the non-GM food NTB from the foreign country. From Figure 4.6, we see that the level of the non-GM food NTB only influences the level of government payoffs, but not the bargaining solutions. The foreign country is passive in the negotiation for the non-GM food NTB, as it knows it will not get any concessions anyway. So, the initial non-GM food NTB matters to the payoff levels but not the Nash Bargaining solution. In this case, the domestic country decides the fate of the negotiation, while the foreign country decides the payoffs that the two governments would get.

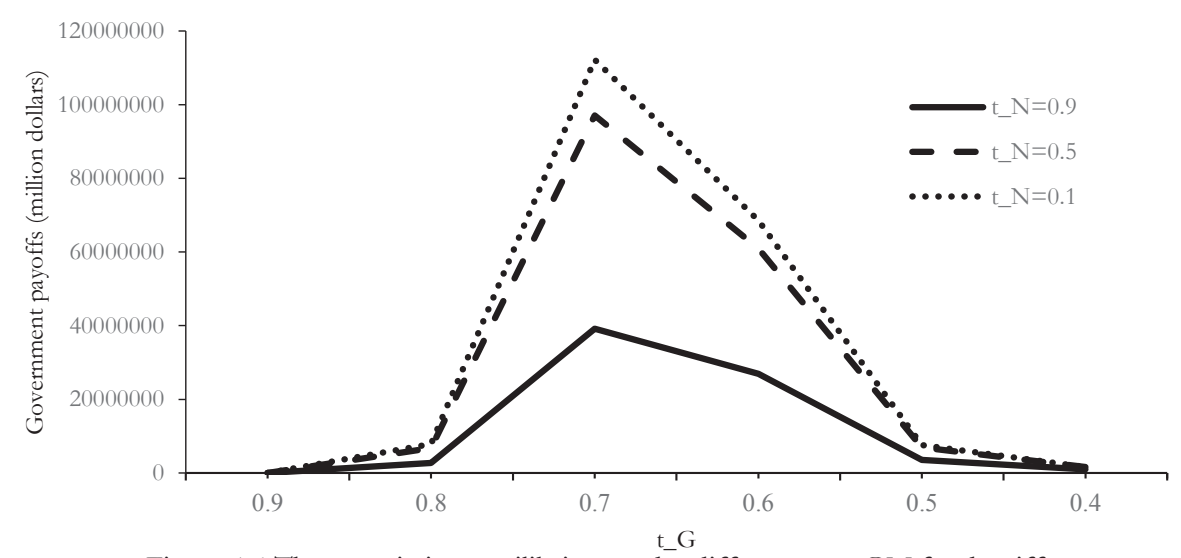

Figure 4.6 The negotiation equilibrium under different non-GM food tariffs

To summarize, we simulate the negotiation process with a high GM food NTB from the domestic country and a high non-GM food NTB from the foreign country. The results illustrate the negotiation in section 4.3: the country who has a high GM food NTB has the initiative to determine the outcome of the negotiation, but the country who has a relatively low non-GM food NTB may not be willing to make concessions during the negotiation. The reasons are both the consumer acceptance and the political rivalries of the GM and non-GM food products. 


\subsection{Discussion and Conclusion}

More countries are pursuing bilateral and multilateral trade agreements to stimulate their domestic economies. They negotiate different policy regimes in trade talks and make concessions on their trade policies. GMOs are one of the most controversial topics in international trade. Now this issue is a part of some trade negotiations, such as the TPP and the TTIP negotiations. Even though as of yet there have been no substantial results from the negotiations, we believe the discussion on the GM food trade policy merits further research. In this paper, we discuss a bilateral negotiation regarding the trading of GMOs between two countries. Two countries pursue an increase of trade volume in food products, both GM and non-GM food products. With a high GM food NTB from the domestic country and a relatively high non-GM food NTB from the foreign country, we find the possible negotiation equilibrium that lies between the two countries' optimal unilateral stances. This equilibrium is the solution of the maximized two governments' payoff change.

We also illustrate the negotiation by simulating two countries reducing the import GM and non-GM food NTBs. We find the foreign country would not like to reduce much of its non-GM food NTB in the negotiation. The level of non-GM food NTB only influences the payoff income of the domestic and foreign governments, but not the negotiation results. The negotiation equilibrium is only dependent on the level of GM food NTB reduction from the domestic country. The reason is that the non-GM food NTB is a protection for the foreign non-GM food firm from the foreign country, but the GM food NTB is a restriction for the domestic country to the domestic GM food production. Our simulation results demonstrate that the Nash bargaining solution of the negotiation between two distinct policy regimes lies in the interval of optimal unilateral stances.

The results also show that zero NTBs cannot maximize trade partners' payoffs because the government cannot get high lobbying contributions from interest groups, compared to what they receive under current NTBs. This has the implication that certain trade protection policies help 
governments gain political support from lobby groups, which are crucial to politicians during the negotiation. The result supports Swinnen (1994)'s discussion of the positive side of agricultural protection. 


\section{A Appendix}

\section{A.1 Calculation of GM, non-GM and numeraire food demands for three groups}

From equation (4.4), we can write the utility function of $\alpha$ consumers:

$\max U^{\alpha}=\left[m\left(x_{G}^{\alpha}\right)^{\rho^{\alpha}}+(1-m)\left(z^{\alpha}\right)^{\rho^{\alpha}}\right]^{\frac{1}{\rho^{\alpha}}}$

s.t. $p_{G} x_{G}^{\alpha}+p_{z} z^{\alpha}=Y^{\alpha}$

So we can get:

$$
\begin{aligned}
& x_{G}^{\alpha}=\left(\frac{m}{p_{G}}\right)^{\sigma^{\alpha}} \frac{I^{\alpha}}{m^{\sigma^{\alpha}} p_{G}^{1-\sigma^{\alpha}}+(1-m)^{\sigma^{\alpha}} p_{z}^{1-\sigma^{\alpha}}} \\
& z^{\alpha}=\left(\frac{1-m}{p_{z}}\right)^{\sigma^{\alpha}} \frac{I^{\alpha}}{m^{\sigma^{\alpha}} p_{G}{ }^{1-\sigma^{\alpha}}+(1-m)^{\sigma^{\alpha}} p_{z}{ }^{1-\sigma^{\alpha}}}
\end{aligned}
$$

where $\sigma^{\alpha}=\frac{1}{1-\rho^{\alpha}}$, and $m=\frac{\varphi_{G}^{\frac{1}{\sigma^{\alpha}}}}{\left(1-\varphi_{G}\right)^{\frac{1}{\sigma^{\alpha}}}\left(\frac{p_{z}}{p_{G}}\right)^{\frac{\sigma^{\alpha}-1}{\sigma^{\alpha}}}+\varphi_{G}^{\frac{1}{\sigma^{\alpha}}}}, \varphi_{G}$ is the expenditure share of

consuming food for $\alpha$ group.

Similarly, we can find demand functions of $\beta$ consumers:

$$
\begin{aligned}
& x_{N}^{\beta}=\left(\frac{n}{p_{N}}\right)^{\sigma^{\beta}} \frac{I^{\beta}}{n^{\sigma^{\beta}} p_{N}{ }^{1-\sigma^{\beta}}+(1-n)^{\sigma^{\beta}} p_{z}^{1-\sigma^{\beta}}} \\
& z^{\beta}=\left(\frac{1-n}{p_{z}}\right)^{\sigma^{\beta}} \frac{I^{\beta}}{n^{\sigma^{\beta}} p_{N}{ }^{1-\sigma^{\beta}}+(1-n)^{\sigma^{\beta}} p_{z}{ }^{1-\sigma^{\beta}}}
\end{aligned}
$$


where $\sigma^{\beta}=\frac{1}{1-\rho^{\beta}}$, and $n=\frac{\varphi_{N}^{\frac{1}{\sigma^{\beta}}}}{\left(1-\varphi_{N}\right)^{\frac{1}{\sigma^{\beta}}}\left(\frac{p_{z}}{p_{N}}\right)^{\frac{\sigma^{\beta}-1}{\sigma^{\beta}}}+\varphi_{N}^{\frac{1}{\sigma^{\beta}}}}, \varphi_{N}$ is the expenditure share of

consuming $x_{N}$.

For $\gamma$ people, they demand both GM and non-GM food products, and they are indifferent to the variety. We assume they consume the aggregate food product $F$ with the price of $p_{F}$, and define $F=x_{G}^{\gamma}+x_{N}^{\gamma}$ and $p_{F}=b_{G}^{\gamma} p_{G}+b_{N}^{\gamma} p_{N}$, where $b_{G}^{\gamma}$ is the consumption share of GM food products for $\gamma$ consumers from the aggregate food purchase and $b_{N}^{\gamma}$ is the non-GM food product share. $\gamma$ consumers solve $\min p_{G} x_{G}^{\gamma}+p_{N} x_{N}^{\gamma}$ s.t. $\sigma_{F}\left[a_{G}\left(x_{G}^{\gamma}\right)^{\frac{\delta_{x}-1}{\delta_{x}}}+\left(1-a_{G}\right)\left(x_{N}^{\gamma}\right)^{\frac{\delta_{x}-1}{\delta_{x}}}\right]^{\frac{\delta_{x}}{\delta_{x}-1}}=1$ where $a_{G}$ is the GM food cost share of reaching one unit of utility from the aggregate food product. $\delta^{x}$ is the elasticity of substitution for the indifference consumers. We solve for the consumption of GM and non-GM food products:

$$
\begin{aligned}
& x_{G}^{\gamma}=\left(a_{G}+\left(1-a_{G}\right)\left(\frac{a_{G} p_{N}}{\left(1-a_{G}\right) p_{G}}\right)^{1-\delta_{x}}\right)^{\frac{\delta_{x}}{1-\delta_{x}}} \frac{1}{\sigma_{F}} \\
& x_{N}^{\gamma}=\left(1-a_{G}+a_{G}\left[\frac{\left(1-a_{G}\right) p_{G}}{a_{G} p_{N}}\right]^{1-\delta_{x}}\right)^{\frac{\delta_{x}}{1-\delta_{x}}} \frac{1}{\sigma_{F}}
\end{aligned}
$$

We have $b_{G}^{\gamma}=x_{G}^{\gamma} / F$ and $b_{N}^{\gamma}=x_{N}^{\gamma} / F$ from the definition. So, $\gamma$ consumers maximize its utility from consuming the aggregate food product and numeraire 
$\max U^{\gamma}=\left[s F^{\rho^{\gamma}}+(1-s)\left(z^{\gamma}\right)^{\rho^{\gamma}}\right]^{\frac{1}{\rho^{\gamma}}}$

s.t. $p_{F} F+p_{z} z^{\gamma}=Y^{\gamma}$

and solve:

$$
\begin{aligned}
& F=\left(\frac{s}{p_{F}}\right)^{\sigma^{\gamma}} \frac{I^{\gamma}}{s^{\sigma^{\gamma}} p_{F}{ }^{1-\sigma^{\gamma}}+(1-s)^{\sigma^{\gamma}} p_{z}{ }^{1-\sigma^{\gamma}}} \\
& z^{\gamma}=\left(\frac{1-s}{p_{z}}\right)^{\sigma^{\gamma}} \frac{I^{\gamma}}{s^{\sigma^{\gamma}} p_{F}{ }^{1-\sigma^{\gamma}}+(1-s)^{\sigma^{\gamma}} p_{z}{ }^{1-\sigma^{\gamma}}}
\end{aligned}
$$

where $\sigma^{\gamma}=\frac{1}{1-\rho^{\gamma}}$, and $s=\frac{\varphi_{F}^{\frac{1}{\sigma^{\gamma}}}}{\left(1-\varphi_{F}\right)^{\frac{1}{\sigma^{\gamma}}}\left(\frac{p_{z}}{p_{F}}\right)^{\frac{\sigma^{\gamma}-1}{\sigma^{\gamma}}}+\varphi_{F}^{\frac{1}{\sigma^{\gamma}}}}, \varphi_{F}$ is the expenditure share of

consuming $F$.

\section{A.2 Calculation of consumer surplus}

From discussion of production and consumption, the indirect utility functions of consumers of three groups are:

$$
\begin{aligned}
& V^{\alpha}=\frac{I^{\alpha}}{\left(m^{\sigma^{\alpha}} p_{G}^{1-\sigma^{\alpha}}+(1-m)^{\sigma^{\alpha}} p_{z}^{1-\sigma^{\alpha}}\right)^{\frac{1}{1-\sigma^{\alpha}}}} \\
& V^{\beta}=\frac{I^{\beta}}{\left(n^{\sigma^{\beta}} p_{N}{ }^{1-\sigma^{\beta}}+(1-n)^{\sigma^{\beta}} p_{z}^{1-\sigma^{\beta}}\right)^{\frac{1}{1-\sigma^{\beta}}}} \\
& V^{\gamma}=\frac{I^{\gamma}}{\left(s^{\sigma^{\gamma}} p_{F}{ }^{1-\sigma^{\gamma}}+(1-s)^{\sigma^{\gamma}} p_{z}^{1-\sigma^{\gamma}}\right)^{\frac{1}{1-\sigma^{\gamma}}}}
\end{aligned}
$$

The expenditure functions for each group consumers are: 


$$
\begin{aligned}
& e^{\alpha}=u_{0}^{\alpha}\left(m^{\sigma^{\alpha}} p_{G}^{1-\sigma^{\alpha}}+(1-m)^{\sigma^{\alpha}} p_{z}^{1-\sigma^{\alpha}}\right)^{\frac{1}{1-\sigma^{\alpha}}} \\
& e^{\beta}=u_{0}^{\beta}\left(n^{\sigma^{\beta}} p_{N}^{1-\sigma^{\beta}}+(1-n)^{\sigma^{\beta}} p_{z}^{1-\sigma^{\beta}}\right)^{\frac{1}{1-\sigma^{\beta}}} \\
& e^{\gamma}=u_{0}^{\gamma}\left(s^{\sigma^{\gamma}} p_{F}{ }^{1-\sigma^{\gamma}}+(1-s)^{\sigma^{\gamma}} p_{z}^{1-\sigma^{\gamma}}\right)^{\frac{1}{1-\sigma^{\gamma}}}
\end{aligned}
$$

where $u_{0}^{i}$ is the utility that a consumer would get with the new price $p_{j}(j=G, N, F)$ and $p_{z}$. In this case, $u_{0}^{i}$ equals to the value of $V^{i}$ in equation (4.A1).

\section{A.3 Key parameters and variables implemented in the simulation}

Table 4.A1 Parameters and variables implemented in the simulation

\begin{tabular}{lccc}
\hline \multicolumn{1}{c}{ Description } & Unit & Domestic country & Foreign country \\
\hline Variables & & & \\
Total Labor & MP $^{\mathrm{a}}$ & 15.32 & 15.32 \\
Total capital & MM $^{\mathrm{b}}$ & 322811 & 322811 \\
GM food supply & $\mathrm{MT}^{\mathrm{c}}$ & 0.00003 & 10.2805 \\
Non-GM food supply & MT & 7.63545 & 2.30192 \\
Annual wage & USD & 1781.27 & 1781.27 \\
Maximum contribution of $\alpha$ group & MM & 7002.07 & 40300.45 \\
Maximum contribution of $\beta$ group & MM & 29286.94 & 13297.02 \\
GM food policy cost & USD & 474.35 & 0 \\
Non-GM food policy cost & USD & 0 & 3.9721 \\
Initial GM food NTB & & 0.9 & 0 \\
Initial non-GM food NTB & & 0 & 0.5 \\
Parameters & & & 0.04 \\
GM food group fraction & & 0.02 & 0.03 \\
Non-GM food group fraction & & 0.06 & -0.3 \\
Own-price elasticity of demand of & & -0.3 & 0.12214 \\
food products of individual group & & & 0.42405 \\
Share of food consumption in total & & 0.12214 & 0.37595 \\
expenditure & & 0.19128 & \\
Share of labor costs in GM food & & 0.60872 & \\
production & & 0.42405 & \\
Share of capital costs in GM food & & & \\
production & & & \\
Share of labor costs in non-GM food & & & \\
production & & & \\
\end{tabular}


Share of capital costs in non-GM food production

Share of labor costs in $z$ production

0.04126

0.04126

Note: $\mathrm{a} . \mathrm{MP}=$ million people; $\mathrm{b}$. $\mathrm{MM}=$ million US Dollars; $\mathrm{c}$ MT $=$ million tons. 


\title{
Chapter $5^{10}$
}

\section{The Conservation Effects of Trade with Imperfect Competition and Biased Policymakers}

\begin{abstract}
In this paper, we study the effects of international trade on forest conservation and welfare in a twocountry model with industry-biased policymakers and Cournot-competing firms. We find that opening up to trade increases the harvest taxes that the industry-biased governments impose compared to autarky taxes. The tax increase is large enough to decrease the production levels, which leads to higher forest conservation levels. In addition, the numerical simulation predicts that the industry-bias monotonically increases the production costs and the welfare-gains from trade. The intuition behind the results is that industry-biased governments already degrade the environment under autarky. We conclude that, even if industry-bias decreases forest conservation, it does not have to increase the environmental costs of trade.
\end{abstract}

\footnotetext{
10 This chapter is based on the article: Qianqian Shao, Thorsten Janus, Maarten J. Punt and Justus Wesseler. The Conservation Effects of Trade with Imperfect Competition and Biased Policymakers. Summited to Resource and Energy Economics.
} 


\subsection{Introduction}

International competition can potentially lead governments to disregard forest conservation and engage in a regulatory race to the bottom designed to increase competitiveness. Further, if the government is industry-biased and weighs industry income more heavily than consumption and conservation benefits, it may be even more willing to sacrifice the environment (Nordström and Vaughan 1999). According to Peterson and Bielke (2001), for example, ${ }^{11}$

"A decree by Russian President Vladimir Putin in May 2000 abolished the Russian Federation State Committee for Environmental Protection and shifted its personnel and responsibilities for environmental protection to the Russian Federation Ministry of Natural Resources...Putin also rolled over the duties of the 200 -year-old Federal Forestry Service (Goskomles)... [which] was responsible for regulating logging, for forest health monitoring, and for fire protection...[The] probable goals of the Russian leadership in abolishing Goskomekologiya were to reduce environmental regulation of industry, encourage natural resource development, and attract foreign investors to the natural resources sector... Putin's support for energy and natural resource development likely is the result of pressure from the country's powerful corporate interests, particularly in the energy sector."

In this paper, we ask how the presence of industry-biased rather than welfare-maximizing governments affects the impact of international trade in a two-country model under imperfect competition forest conservation levels and national welfare. The model combines the Brander and Krugman (1983) "reciprocal dumping" model of trade, where firms export identical products to capture market share abroad, the Brander and Spencer (1985) model, which adds a pre-trade policymaking stage, and the assumption that the policymakers are industry-biased. We model the industry bias (e.g. Grossman and Helpman 1994; Coen 1997; Rogers 1997) by assuming that the government weighs industry income more heavily than consumer surplus and utility from forest conservation.

\footnotetext{
11 The case study in Crotty (2003) however, suggests that the regional responses to the federal Russian regulation changes may have been limited or varied because of the decentralized nature of the Russian state and, perhaps, the varying degrees of natural resource production bias in different regions.
} 
The model allows us to derive several results. First, increases in the industry bias, increases in the production costs, and falling demand for the final good decrease the harvest tax under both autarky and trade. Second, opening up to trade has three, partly opposing effects on the optimal harvest tax: i) the marginal decrease in profit from the tax increases; ii) the marginal loss of consumer surplus decreases; iii) since trade increases the output level and resource scarcity for every value of the harvest tax, the marginal environmental benefit of the tax increases. The first two effects resemble the "rentcapture" and "pollution-shifting" effects of trade on pollution taxes in Kennedy (1994), although it is important to note that Kennedy's analysis compared the equilibrium taxes under trade to the efficient taxes and not the autarky taxes. The third effect resembles the output effect in Burguet and Sempere (2003), which is the observation as long as trade increases output, it should increase resource scarcity and regulation ceteris paribus.

Despite the complicated effects of trade on the tax incentive, we show that the net effect is always positive. Moreover, the tax increase due to trade is large enough to decrease the production level and increase conservation as long as either the international shipping cost is positive or the government is even marginally industry-biased. Thus, the industry bias never exacerbates the environmental costs of trade. The numerical simulation we present shows that the upward tax jump and downward production jump due to opening up to trade increases monotonically with the industry bias, and that increasing the industry bias increases the welfare gains from trade.

The intuition behind the perhaps encouraging result that industry bias does not increase the environmental costs of trade, however, is not that industry-biased governments protect the environment. The reason, instead, is that they have already degraded their resources under autarky. Even if the conservation level remains downward distorted under trade, it can be higher than the autarkic conservation level. Nonetheless, the model demonstrates that industry bias does not have to increase the environmental costs of international trade. 
In our model the government only uses harvest taxes to affect output, that is, we assume that the government does not use other policy instruments, such as output subsidies. In practice, however, it is costly to collect taxes and finance subsidies and the subsidies may be infeasible due to political constraints and "level-playing-field" clauses in trade agreements. We, therefore, believe that it is ultimately an empirical question whether governments can access a sufficient number of policy instruments to address the combination of a negative externality from resource harvest and a deadweight loss from imperfect competition in the output market in our model. Since we also assume that the governments are industry-biased rather than welfare-maximizing, which may reflect a political distortion, it is also not entirely clear how the governments in the model would use any additional policy instruments at their disposal. The assumption that policy makers use environmental policy to achieve non-environmental objectives like increasing international competitiveness also motivates many papers in the race-to-the-bottom literature (Barrett 1994; Kennedy 1994; Pflüger 2001; Conconi 2003; Nordström and Vaughan 1999; Burguet and Sempere 2003). We believe that the extent to which governments, in fact, use environmental policies to achieve other objectives at least remains an unsettled and empirical question.

The remainder of this paper proceeds as follows: Section 2 reviews the related literature. Section 3 presents the modeling framework and explains the comparative static for the optimal harvest tax under autarky and trade, the effects of trade opening on the harvest tax, and how increasing the industry bias changes the effect of the trade opening. Section 4 concludes the paper and discusses the potential policy implications. We include the theoretical proofs in the appendix.

\subsection{Related literature}

The paper relates to the literature on optimal environmental policy and Pigouvian taxation in the presence of other distortions. This literature started with Buchanan (1969) who argued that 
environmental policy would increase the output distortions already introduced by monopoly power. ${ }^{12}$ As Barnett (1980) and Requate (2006) show, however, the government does not have to choose the Pigouvian tax. Instead, it can choose the second-best tax that balances the marginal environmental cost of production with the marginal benefit of increasing output. The resulting equilibrium is constrained or second-best efficient in the sense that it maximizes welfare subject to the constraint that the number of policy instruments is less than the number of distortions in the economy. If we assume that each of the governments in our two-country model maximizes national welfare, as in Propositions 5.4 and 5.5, we obtain the same second-best equilibrium that Barnett and Requate identify, where the harvest tax balances the marginal environmental cost of production with the marginal increase in producer and consumer surplus from production. Our main research question, however, is how the introduction of industry-biased rather than welfare-maximizing governments changes the environmental and welfare effects of trade.

The paper also relates to the literature on strategic trade and environmental policies that are designed to increase the country's competitiveness. In particular, the model is based on Brander and Krugman (1983), who assume that there are two identical countries with a single firm in each country. When the countries open to trade, the firms start to export to each other's markets to increase firm profit, a phenomenon Brander and Krugman (1983) call "reciprocal dumping". Like Brander and Spencer (1985), we allow the government in each country to choose a cost-reducing policy that can increase the home firm's competitiveness and help it to capture profit from the foreign firm. In contrast to the Brander and Spencer (1985) model, however, we assume that the policymaker reduces the input cost by weakening an environmental regulation (specifically, cutting a tax on resource harvest). The paper is therefore also closely related to Barrett (1994) and Kennedy (1994), who show

\footnotetext{
${ }^{12}$ Requate (2006) recently surveyed the literature on environmental policy under imperfect competition.
} 
that, if the home country has a monopoly firm that engages in Cournot competition with at least one foreign firm, a national welfare-maximizing government sets the environmental damage tax below the marginal damage cost in order to increase the firm's competitiveness. ${ }^{13}$ The reason is that, in Kennedy (1994)'s terminology, the government has a "pollution-shifting” incentive to increase the tax in order to shift production abroad but a "rent-capture" incentive to decrease the tax to help the home firm capture profit from the foreign firm, and the "rent-capture" incentive outweighs the "pollution shifting" incentive except in two limiting cases. Barrett (1994) and Kennedy (1994) compare the equilibrium environmental taxes to the efficient taxes the governments would choose if they coordinated their environmental policies. In contrast, we ask how the transition from autarky to trade affects the taxes by comparing the Nash equilibrium taxes under trade with the Nash equilibrium taxes under autarky (as opposed to the efficient taxes under trade).

We, therefore, address the policy question of whether countries with imperfectly competitive industries and industry-biased governments would coordinate conservation policies when they move from autarky to international trade. ${ }^{14}$ Burguet and Sempere (2003), similarly, ask how exogenous tariff

\footnotetext{
${ }^{13}$ Kennedy (1994) shows that the incentive to weaken the standard remains with transboundary rather than local pollution. Barrett (1994), however, shows that the result disappears under Cournot competition in the home market or Bertrand competition. In the broader international trade literature on the use of strategic trade policies, Qui (1994), Žigić (2000), Zhou et al. (2002), Etro (2011), Ziesemer and Michaelis (2011) and Bastos et al. (2013) study strategic trade policy under, respectively, asymmetric information, imperfect intellectual property rights, competition on both the quality and the price margin, endogenous market entry, knowledge accumulation, and cost shocks.

14 As we explain below, we find that, at least if the governments maximize national welfare, there is no policy coordination gain in our model. Kennedy (1994), however, shows that if the firms can invest in pollution abatement (or resourceconserving production technologies in our framework, which is another way to reduce the "environmental input") there is a policy coordination gain. We leave a model allowing such investments under industry-biased governments to future research.
} 
reductions due, perhaps, to an international trade agreement, affects environmental regulations. Our paper, on one hand, extends their research by asking how industry-biased environmental policymaking will change the welfare gains to trade liberalization. At the same time, however, we model trade liberalization as a transition from autarky with monopoly production to trade with duopolies rather than a marginal tariff reduction for a given market structure. Kennedy (1994) and Burguet and Sempere (2003) assume that firms can invest in pollution abatement for a given output level, a possibility our model ignores. This may explain why, when the governments maximize national welfare, they find that tariff reductions have an ambiguous effect on environmental taxes, while we find that the effect is positive. We leave including this policy option for future research.

Although our model assumes that the government is exogenously industry-biased, the biased objective function can be derived from a Grossman and Helpman (1994) lobbying framework. The paper therefore also relates to the literature on trade and environmental policy lobbying. In the environmental literature, particularly, ${ }^{15}$ Fredriksson (1997), Fredriksson and Svensson (2003), Eerola (2004), Barbier et al. (2005), and Honma (2005) study output taxation in a competitive small open economy with an environmental and a firm lobby; environmental policy under corruption and political instability; cost-increasing conservation policy under monopoly with an environmental and a firm lobby; land conversion under trade and firm lobbying; and the political economy of pollution taxation with heterogeneous firms. Unlike our paper, these authors abstract from strategic competition in the

\footnotetext{
${ }^{15}$ In the trade literature, Tovar (2011), Gawande et al. (2012), and Bombardini and Trebbi (2012) study, respectively, the use of lobbying expenditures to signal firm productivity, endogenous costs and signaling in the lobbying process, simultaneous lobbying by firms located upstream and downstream in the supply chain, and the formation of trade lobbies. Moore and Suranovic (1993), Bandyopadhyay et al. (2004), Fung et al. (2009), Kagitani (2009) and Wang (2011) allow firms to lobby for trade policy under strategic product market rivalry. Kellenberg (2009) presents an analytical framework for studying environmental policy lobbying under strategic international trade but does not present a mathematical model.
} 
international product market. In turn, the governments have no strategic incentive to use environmental policies to increase domestic competitiveness. While Fredriksson (1997) finds a positive conservation effect of trade under perfect competition, for example, the fact that trade increases competition in our model implies that it may decrease conservation even though it increases the harvest tax. ${ }^{16}$ Schleich (1999) similarly studies lobby-determined environmental policy under perfect competition. Eerola (2004) studies lobby-determined environmental policy under a home monopoly firm that exports to a competitive world market. In contrast, we study a two-country model with domestic monopoly before trade and Cournot-duopolies and therefore strategic interaction after trade. The fact that we allow for strategic interaction in the output market leads to strategic interaction with the national government's environmental policy (Barrett 1994; Kennedy 1994).

\subsection{Environmental policy with biased policy makers and Cournot competition}

Following Brander and Krugman (1983), we study a partial equilibrium model of trade between two identical countries. Each country has a wood-using firm which uses a unit of labor and a unit of wood to produce a final good, and consequently, domestic production $q$ is equal to the resource harvest. The inverse demand for the final good is $p(Q)$, where $Q$ is the market quantity. The wood is supplied by a competitive forest sector that uses the Faustmann rule to determine the rotation time (Conrad

\footnotetext{
${ }^{16}$ Conconi (2003) and Damania (2001) show that lobbying can have different results under trade and autarky, respectively. Conconi (2003) shows that a green lobby may decrease its lobbying effort after the country opens to trade because environmental taxation shifts production abroad. Damania (2001) shows that, by investing in dirty production technologies, industries can commit themselves to not abating and extract policy concessions from industry-biased governments. Since we assume that households ignore deforestation abroad and the production technologies are fixed, these issues do not arise in our paper.
} 
2010). The forest sector is able to supply wood at a constant long-run price which we normalize to zero. In the absence of a harvest tax, therefore, the firm only pays the wage cost $w$ to produce the final good. Whenever the firm increases production, however, although it can continue to hire labor at the original price, its demand for the wood input increases, which increases the short-run wood price. The rising wood price makes the forest owners decrease the rotation time, which decreases the yield in short run. In order to meet the excess demand, the forest owners also convert additional forest from its natural state to industrial use Conrad (2010). In the new long-run equilibrium, the forest sector supplies more wood at the original price but the natural forest stock is smaller. The loss of natural forest due to the final goods sector imposes a utility loss on households equal to $l(q), l_{q}, l_{q q}>0$ , where the subscripts denote the first and second partial derivatives. Since the utility loss reflects a negative externality, the government can potentially increase welfare by introducing a harvest tax. For simplicity, we assume that the firm pays the harvest tax. ${ }^{17}$ In addition, we simplify the analysis of the effects of opening to trade by comparing the original and new steady state outcomes rather than accounting for the transition period until the economy reaches the new steady state. ${ }^{18}$

Before the countries open to trade, the firm in each country is a monopoly. After trade, it exports to the foreign market subject to Cournot competition and a per-unit transportation cost, $s>0$ . The marginal cost of producing for the domestic firm in the home market is therefore $w+t$ and the marginal cost of exporting is $w+t+s$. We assume that the transportation costs are small enough that the firms export and hence, the market in each country becomes a duopoly. As Brander and Krugman (1983) explain, the reason why each of the two firms wishes to export, despite the fact that the market price abroad equals the monopoly price at home, is that it faces a residual demand curve

\footnotetext{
${ }^{17}$ Since the forest sector is competitive, the tax incidence eventually falls on the firm.

${ }^{18}$ The study of the transition effects requires a dynamic model, which we hope to develop in future research.
} 
abroad: while a price cut in the domestic market would decrease the profit by eroding the revenues from existing sales, the fact that the firm has no initial sales abroad implies that a price cut abroad will not erode its revenues. Brander and Krugman (1983) call these residual demand-driven exports "reciprocal dumping" and show that they have ambiguous welfare effects: although the increased competition level in each country increases welfare, the firms engage in two-way shipping of identical goods and the unnecessary transport costs create deadweight losses.

If the government wished to maximize national welfare, it should choose the harvest tax $t$ that maximizes the sum of firm profits, wages, consumer surplus, the utility loss from forest use, and tax revenues, $\pi(t)+w+c s(t)-l(q(t))+t q(t)$. In this paper, however, we assume that the government may be biased for or against the resource-using industry. For example, it may receive lobby contributions from industry and/or environmental lobbies (Grossman and Helpman 1994; Eerola 2004) or its political ideology causes it to either discount or overweight profit income. Thus, we assume that the government assigns a weight $\mu>1$ to the profit component, which can differ from its weight on the other welfare components, such that $\mu \neq 1$. We refer to $\mu$ as the degree of industry bias. If $\mu=1$, it maximizes national welfare and if $\mu>1$, it overweighs the profit income.

We formulate a policy setting game. The timing of the game is that first the governments in the two countries simultaneously choose their harvest taxes. Second, the firms simultaneously decide how much to produce for the domestic and export markets. These output choices determine the market quantity and price, wood harvest, profits, and consumer surplus in each country. Third, the governments transfer the tax revenues to their households.

We solve the model by backward induction from the output stage to the policy stage. We let $x$ and $y$ to denote the domestic and foreign sales in the home market, and $x^{*}$ and $y^{*}$ denote the domestic and foreign sales in the foreign market. We also use superscripts $x$ and $y$ to identify the 
domestic and foreign tax, and use the superscripts " $A$ " and " $R D$ " to denote the autarky and reciprocal dumping outcomes. Finally, in order to derive analytical results, we assume that the inverse final goods demand is $p(Q)=a-b Q$ with $a, b>0$ and that the environmental utility loss is $l(q)=(q)^{1+\alpha} /(1+\alpha)$, where $\alpha>1$. We also assume that the parameters are such that the equilibrium harvest tax is positive. In other words, if the government used a negative harvest tax to subsidize the firm and correct the output distortion due to imperfect competition, the environmental loss $l(q)$ would become so large that it would switch to a positive harvest tax to protect the forest.

\section{The output stage}

In the output stage under autarky, the profit and household utility net of the profit are

$$
\begin{gathered}
\pi^{A}=p\left(q^{A}\right) x-(w+t) x \\
u^{A}=w+c s\left(Q^{A}\right)-l\left(q^{A}\right)+t q^{A}=w+\int_{0}^{Q^{A}} p(\tilde{Q}) d \tilde{Q}-p Q^{A}-l\left(q^{A}\right)+t q^{A}
\end{gathered}
$$

Under reciprocal dumping, the profits of the domestic and foreign firms, along with household utility net of the profit, are

$$
\begin{gathered}
\pi^{R D}=p(Q) x+p\left(Q^{*}\right) x^{*}-\left(w+t^{x}\right) x-\left(w+t^{x}+s\right) x^{*} \\
\pi^{R D^{*}}=p(Q) y+p\left(Q^{*}\right) y^{*}-\left(w+t^{y}+s\right) y-\left(w+t^{y}\right) y^{*} \\
u^{R D}=w+c s\left(Q^{R D}\right)-l\left(q^{R D}\right)+t q^{R D}=w+\int_{0}^{Q^{R D}} p(\tilde{Q}) d \tilde{Q}-p\left(Q^{R D}\right)-l\left(q^{R D}\right)+t q^{R D}
\end{gathered}
$$

\section{Lemma 5.1:}

(i) Under autarky, the market quantity and wood harvest, price, profit, consumer surplus, and the marginal profit, consumer surplus, and environmental loss effects of the harvest tax are 


$$
\begin{aligned}
& Q^{A}=q^{A}=x^{A}=\frac{a-w-t}{2 b}, \quad p^{A}=\frac{a+w+t}{2}, \quad \pi^{A}=\left(p^{A}-w-t\right) x^{A}=\frac{(a-w-t)^{2}}{4 b}, \\
& c s^{A}=\frac{(a-w-t)^{2}}{8 b}, \pi_{t}=\frac{-(a-w-t)}{2 b}, c s_{t}=\frac{-(a-w-t)}{4 b}, \\
& l_{t}^{A}=l_{q}\left(q^{A}\right) q_{t}^{A}=-\frac{1}{2 b}\left(\frac{a-w-t}{2 b}\right)^{\alpha} .
\end{aligned}
$$

(ii) Under reciprocal dumping, the market quantity, price, profit, consumer surplus, domestic wood harvest, and the marginal profit, consumer surplus, and environmental loss effects of the harvest tax are

$$
\begin{aligned}
& Q^{R D}=x+y=\frac{2 a-2 w-t^{x}-t^{y}-s}{3 b}, p^{R D}=\frac{a+2 w+t^{x}+t^{y}+s}{3} \\
& \pi^{R D}=\frac{\left(a-w-2 t^{x}+t^{y}+s\right)^{2}}{9 b}+\frac{\left(a-w+t^{y}-2 t^{x}-2 s\right)^{2}}{9 b}, \\
& c s^{R D}=\frac{\left(2 a-2 w-t^{x}-t^{y}-s\right)^{2}}{18 b}, q^{R D}=x+x^{*}=\frac{2 a-2 w-4 t^{x}+2 t^{y}-s}{3 b}, \\
& \pi_{t}^{R D}=-\frac{\left(8 a-8 w-16 t^{x}+8 t^{y}-4 s\right)}{9 b}, c s_{t}^{R D}=\frac{-\left(2 a-2 w-t^{x}-t^{y}-s\right)}{9 b}, \\
& l_{t}^{R D}=l_{q}\left(q^{R D}\right) q_{t}^{R D}=\left(q^{R D}\right)^{2} q_{t}^{R D}=-\frac{4}{3 b}\left(\frac{2 a-2 w-4 t^{x}+2 t^{y}-s}{3 b}\right)^{\alpha} .
\end{aligned}
$$

(iii) Consider any given symmetric harvest tax the countries may set. Then the harvests and the marginal profit, consumer surplus, and environmental benefits due to the tax before and after trade, can be ranked as follows:

$$
\begin{aligned}
& q^{R D}-q^{A}=\frac{2 a-2 w-2 t-s}{3 b}-\frac{a-w-t}{2 b}=\frac{a-w-t-2 s}{6 b}>0, \\
& \pi_{t}^{R D}-\pi_{t}^{A}=-\left[\frac{(8 a-8 w-8 t-4 s)}{9 b}-\frac{(a-w-t)}{2 b}\right]=-\left(\frac{7 a-7 w-7 t-8 s}{18 b}\right)<0,
\end{aligned}
$$




$$
\begin{aligned}
& c s_{t}^{R D}-c s_{t}^{A}=-\left[\frac{2 a-2 w-2 t-s}{9 b}-\frac{(a-w-t)}{4 b}\right]=-\left(\frac{-(a-w-t)-4 s}{36 b}\right)>0, \\
& -l_{t}^{R D}-\left(-l_{t}^{A}\right)=\left[\frac{4}{3 b}\left(\frac{2 a-2 w-2 t-s}{3 b}\right)^{\alpha}-\frac{1}{2 b}\left(\frac{a-w-t}{2 b}\right)^{\alpha}\right]>0 .
\end{aligned}
$$

The intuition behind the rankings in part (iii) is as follows: opening up to trade increases the quantity of production because the firms engage in Cournot-competition instead of producing the monopoly quantity, i.e., market competition increases. The marginal profit loss due to the tax increases after trade, because the firm - which is taxed per production unit - produces a larger quantity and loses market share both at home and abroad when its marginal cost increases. On the other hand, the consumer surplus loss due to the tax decreases because, after trade, the supply increases due to imports. Finally, the harvest tax reduces the marginal utility loss from forest use more effectively after trade because the firm produces more output and the forest stock is smaller. The smaller forest stock implies that the marginal value of the forest and the marginal environmental benefit of the harvest tax are larger after trade.

\section{The policy stage}

In the policy stage, the government chooses the harvest tax to maximize the sum of weighted profits, wages, consumer surplus, the utility loss from forest use, and tax revenues:

$$
\max _{t} \Omega^{k}(t)=\mu \pi^{k}(t)+w+c s^{k}(t)-l\left(q^{k}(t)\right)+t q^{k}(t), k=A, R D
$$

with optimality condition:

$$
\Omega_{t}^{k}=\mu \pi_{t}^{k}+c s_{t}^{k}-l_{q}^{k} q_{t}^{k}+q^{k}+t q_{t}^{k}=0
$$

Lemma 5.2 defines the optimal harvest taxes under autarky and reciprocal dumping. 
Lemma 5.2 The equilibrium harvest taxes under autarky and reciprocal dumping solve

$$
\begin{aligned}
& \Omega_{t}^{A}=\frac{1}{2 b}\left(-\frac{(2 \mu-1)\left(a-w-t^{A}\right)}{2}+\left(\frac{a-w-t^{A}}{2 b}\right)^{\alpha}-t^{A}\right)=0 \\
& \Omega_{t}^{R D}=\frac{4}{3 b}\left(-\frac{(2 \mu-1)\left(2 a-2 w-2 t^{R D}-s\right)}{6}+\left(\frac{2 a-2 w-2 t^{R D}-s}{3 b}\right)^{\alpha}-t^{R D}\right)=0 .
\end{aligned}
$$

In the next two propositions, we study the effects of different parameter changes on the regulation level as measured by the harvest tax after conditioning on the trade situation.

Proposition 5.1 Conditional on autarky, increases in the strength of the firm lobby effort and the wage level decrease the harvest tax. An increase in the demand for the final goods increases the barvest tax. That is,

$$
\begin{aligned}
& \text { (1) } \partial t^{A} / \partial \mu<0 \\
& \text { (2) } \partial t^{A} / \partial w<0 \\
& \text { (3) } \partial t^{A} / \partial a>0
\end{aligned}
$$

Proposition 5.2 Conditional on reciprocal dumping, increases in the strength of the firm lobby, the wage level, and the transportation cost decrease the harvest tax. An increase in the demand for the final goods increases the harvest tax. That is,
(1) $\partial t^{R D} / \partial \mu<0$
(2) $\partial t^{R D} / \partial w<0$
(3) $\partial t^{R D} / \partial a>0$
(4) $\partial t^{R D} / \partial s<0$

The intuition for Propositions 5.1 and 5.2 is relatively straightforward. Under autarky as well as trade, if the government is more industry-biased, it sets a smaller harvest tax in order to increase 
firms' profits. A higher wage level decreases the production level and therefore the magnitude of the environmental externality (the forest loss). The marginal cost of the tax in terms of foregone profit and consumer surplus stays constant, while the marginal benefit associated with reducing the forest loss is smaller. The government, therefore, decreases the tax. Conversely, if demand for the product is strong, the production level and the environmental externality are large, causing the government to increase the tax to counteract the externality. A higher shipping cost again decreases the production level and therefore the magnitude of the environmental externality. Since the marginal benefit associated with reducing the forest loss is smaller, the government decrease the tax.

The following proposition presents the paper's main result.

Proposition 5.3 Trade increases the harvest tax $\left(t^{R D}>t^{A}\right)$ regardless of the industry bias.

Proposition 5.3 shows that international trade increases the harvest tax. The introduction of international competition between the firms and governments, therefore, causes a regulatory race to the top even if the government is arbitrarily industry-biased. The reason that increasing the industry bias does not overturn the prediction that the tax increases is that, as we showed in Propositions 5.1 and 5.2, the industry bias decreases the harvest taxes under both autarky and trade. Even as the bias increases arbitrarily, therefore, the tax under trade can continue to exceed the autarky tax. In the numerical example, we present below, we further find that the upward tax jump due to trade increases with the industry bias, although we are unable to prove this result analytically. In the next proposition, we show that, as long as the government is not biased against the industry, the upward tax jump is actually large enough to decrease production. 
Proposition 5.4 If the government maximizes national welfare and the shipping cost is zero $(\mu=1, s=0)$, it implements the same production level under trade as in autarky. If the government is biased against the industry and the shipping cost is small $(\mu<1$ ands $\approx 0)$, it implements more production under trade. If either the shipping cost is positive or the government is industry-biased $(s>0$ or $\mu>1)$, it decreases production under trade.

The fact that the production-level under trade is typically smaller than under autarky unless the government is biased against the industry, implies that the tax increase must be substantial in the sense that it is bounded away from zero. The reason is, as Lemma 5.1 shows, that for a given harvest tax going from autarky to trade causes an upward production jump. In order for the equilibrium production level to fall, therefore, the tax must increase significantly.

In order to see why welfare-maximizing governments keep the production level equal to the autarkic level as long as the shipping cost is zero, we assume without loss of generality that the wage is $w=0$. Thus, the only welfare cost from producing is the environmental cost of the resource harvest $l(q)$. Under autarky, a welfare-maximizing government increases the tax and therefore decreases production until the marginal loss of market surplus $p(q)$ - equivalently, the marginal drop in the sum of profits and consumer surplus or the marginal "stripe" under the demand curve - equals the marginal environmental benefit. International trade does not change the marginal benefit of a unit reduction in the quantity $l^{\prime}(q)$. More surprisingly, it does change the marginal decline in the sum of profit and consumer surplus: when the government in the trading economy implements a unit production decline, the firm sells 0.5 units less in each market. The fall in domestic welfare is, therefore, half of the marginal willingness to pay, $p(Q) / 2$, plus the change in the profit portion of the market surplus that is appropriated by the foreign firm. Since the foreign firm sells half in the domestic market, the change in the foreign profit is $\left(p^{\prime}(Q) d Q\right) Q / 2$, where $p^{\prime}(Q) d Q=(1+\partial y / \partial x) / 2$ is the price increase when 
the domestic firm cuts sales by 0.5 and the foreign firm responds with a sales change $\partial y / \partial x$. The domestic welfare decline linked to home market sales is, therefore $-p(Q) / 2-\left(p^{\prime}(Q) d Q\right) Q / 2$. The price also increases by $p^{*}\left(Q^{*}\right) d Q^{*} / 2$ in the foreign market, which increases the domestic export profit on existing sales by $\left(p^{\prime}(Q) d Q\right) Q / 2$. Finally, the 0.5 decline in the export quantity costs the home country $p\left(Q^{*}\right) / 2=p(Q) / 2$ in export revenues. The total domestic welfare change linked to export sales is, therefore $\left(p^{\prime}(Q) d Q\right) Q / 2-p(Q) / 2$. The overall domestic welfare change is therefore $-p(Q) / 2-\left(p^{\prime}(Q) d Q\right) Q / 2+(p(Q) d Q) Q / 2-p(Q) / 2=-p(Q)$ and is the same as under autarky. Since the welfare-maximizing continues to gain $l^{\prime}(q)$ and lose $p(Q)$ from quantity reductions, it implements the same production and market quantities under trade and autarky. The reason that it nonetheless has to increase the harvest tax (as Proposition 5.3 demonstrates) is that the firm's demand curve is more elastic under trade. If the government kept the harvest tax rate constant, the firm would increase production. Formally, Lemma 5.1 shows that opening to trade increases production for every initial positive harvest tax, so stabilizing production requires a tax increase.

Once we allow the shipping cost to be positive, the marginal benefit to society from exporting decreases. Since the marginal environmental cost of increasing production is the same, but the marginal benefit decreases due to the deadweight loss from shipping, the government prefers to decrease production below the autarkic level.

When the industry bias is positive, the government values the after-tax profit at $\mu \pi>\pi$ and perceives $\mathrm{a}(\mu-1)>0$ loss per tax unit collected in addition to the quantity effects of the tax. As Propositions 5.1-5.2 show, it, therefore, decreases both the autarkic tax and the tax under trade, which increases the respective quantities. The reason that the quantity under trade increases less than under autarky is that under trade, the firm's demand curve is more elastic. As a result, the tax cut needed to 
increase the optimal production quantity by a unit is smaller than the required tax cut under autarky. Formally, the proof of Lemma 5.1 shows that production under trade is $q^{R D}=x+x^{*}=\left(2 a-2 w-4 t^{x}+2 t^{y}\right) / 3 b \quad, \quad$ so increasing production by a unit requires $d q^{R D}=-(4 / 3 b) d t^{x}=1 \Leftrightarrow d t^{x}=-3 b / 4$. In autarky, $q^{A}=\left(a-w-t^{A}\right) / 2 b$, so increasing production by a unit requires $d q^{A}=-d t^{A} / 2 b=1 \Leftrightarrow d t^{A}=-2 b<-(3 b / 4)$, a larger tax cut.

Assume now that we start with a welfare-maximizing government, such that $\mu=1$ and $x^{A}=q^{A}=Q^{A}=Q^{R D}=x+x^{*}$ (the autarky firm's production for the home market equals its total production equals the market quantity under autarky equals the market quantity under trade equals production for the home market plus export production). Then the smaller tax cut implies that the profit on existing sales, $Q^{A} d t^{A}>Q^{A} d t^{R D}=Q^{R D} d t^{R D}$ increases less under trade than under autarky, so the firm benefits less from the output expansion. Formally, the proof of Lemma 5.1 shows that the profits under autarky and trade when the shipping cost is zero can be written $\pi^{A}=b\left(x^{A}\right)^{2}=b\left(Q^{A}\right)^{2}$ and $\pi^{R D}=b\left(x^{2}+\left(x^{*}\right)^{2}\right)=2 b\left(Q^{R D} / 2\right)$. Cutting the tax enough to increase output by a unit in autarky increases the autarky profit by $\partial \pi^{A} / \partial Q^{A}=2 b Q^{A}$ but the profit under trade only increases by $0.5\left(\partial \pi^{R D} / \partial x+\partial \pi^{R D} / \partial x^{*}\right)=0.5\left(2 b x+2 b x^{*}\right)=2 b x=b Q^{R D}=b Q^{A}$, where we use that the firm expands sales by 0.5 in each market. The profit effect of the output expansions is, therefore, smaller. Starting from $Q^{R D}=Q^{A}$, therefore, the government perceives a smaller profit gain from output expansion but the same environmental cost $l^{\prime}\left(Q^{A}\right)=l^{\prime}\left(Q^{R D}\right)$. If the government was not industrybiased but welfare-maximizing, so $\mu=1$, it would not care about the size of the tax cut the firm receives to expand output since the tax cut is financed by households (who receive less lump-sum revenue from the harvest tax). When $\mu>1$ the government benefits more from larger tax cuts, that 
is, shifting a dollar in society from households to firms or profit income increases the government's payoff by $(\mu-1)>0$. As the industry bias increases from unity, therefore, the fact that output expansions have a larger redistributive effect in favor of the industry in the autarky regime relative to the trade regime becomes increasingly important to the government. Thus, the industry-biased regimes benefit more from output expansions under autarky than trade, which is why the autarkic production level increases relative to production under trade and industry bias increases the downward quantity jump due to trade.

\section{The welfare effects of trade}

We can express the welfare change due to trade as a function of the output levels. In order to do so, we will follow Burguet and Sempere (2003) and write welfare as

$$
\Omega^{W}=\int_{\tilde{Q}=0}^{Q} p(\tilde{Q}) d \tilde{Q}-w q-l(q)-s x^{*}
$$

which is the area under the demand curve minus the social cost of production and export. The social cost of production and export equals the wage cost $w q$ plus the environmental utility loss $l(q)$ plus the shipping cost when the country exports $x^{*}$ output units ${ }^{19}$. Once we substitute for the linear demand function and the environmental loss function, substitute the quantities from Lemma 5.1, and substitute the taxes from Lemma 5.2, we can express the welfare change as follows.

Proposition 5.5 The welfare change due to trade is

$$
\left(\Omega^{W R D}-\Omega^{W A}\right)=\left(a-\frac{b}{2}\left(q^{R D}+q^{A}\right)-w\right)\left(q^{R D}-q^{A}\right)-\frac{1}{1+\alpha}\left(\left(q^{R D}\right)^{1+\alpha}-\left(q^{A}\right)^{1+\alpha}\right)-s \frac{b q^{R D}-s}{2 b},
$$

\footnotetext{
19 The tax revenues from the harvest tax drop out of the welfare function since they are purely redistributive from the firm to the households. The trade balance is zero since the countries are symmetric.
} 
where

$$
\begin{aligned}
& q^{R D}=\frac{2 a-2 w-2 t^{R D}-s}{3 b}, t^{R D}=-(2 \mu-1) \frac{b}{2} q^{R D}+\left(q^{R D}\right)^{\alpha} \\
& q^{A}=\frac{a-w-2 t^{A}}{2 b}, t^{A}=-(2 \mu-1) b q^{A}+\left(q^{A}\right)^{\alpha} .
\end{aligned}
$$

implicitly define the optimal output quantities and harvest taxes. If the government maximizes national welfare and the shipping cost is zero $(\mu=1, s=0)$, the welfare change is zero. The absolute welfare levels are $\Omega^{W A}=\left(a-\frac{b}{2} q^{A}-w\right) q^{A}-\frac{\left(q^{A}\right)^{1+\alpha}}{1+\alpha}$ and $\Omega^{W R D}=\Omega^{W A}+\left(\Omega^{W R D}-\Omega^{W A}\right)$, with the terms on the right-hand side are defined above.

The welfare change is theoretically ambiguous. On one hand, just as in the original Brander and Krugman (1983)'s model of trade with reciprocal dumping, the firms ship identical goods to each other's markets. While the exports increase competition, it is costly and technically unnecessary to ship the identical goods in both directions. When $\mu=1$, as Proposition 5.4 shows, the governments keep the trade quantities equal to the autarky quantities, so the welfare change is just the two-way shipping cost, $\left(\Omega^{W R D}-\Omega^{W A}\right)=-s\left(b q^{R D}-s\right) / 2 b \leq 0$ with strict inequality unless $s=0$. Thus, the reciprocal-dumping-driven trade unambiguously decreases welfare. As the governments become industry-biased, however, so $\mu$ increases above unity, the autarky quantity $q^{A}$ increases above the national-welfare maximizing level, which decreases the autarkic welfare level. The fact that under autarky the welfare level, in this case, is relatively low opens the possibility that trade can increase welfare. In the numerical example below, we demonstrate the result that trade with no shipping cost and a national-welfare-maximizing government does not change the welfare level, but that trade with an industry-biased government can actually increase welfare. 
Although our paper mainly focuses on linking industry-biased government policies to the welfare effects of trade, the results in Propositions 5.4 and 5.5 show that, in the absence of transportation $\operatorname{cost}(s=0)$ and industry biases $(\mu=0)$, national-welfare-maximizing governments implement the same harvest tax under autarky and trade may be interesting in their own right. In fact, since the countries are identical and there are no environmental spillovers (Kennedy 1994; Tanguay 2001), the quantities must maximize the global welfare level under both autarky and trade. As we explained earlier, however, trade in this model $(s=0, \mu=1)$ does not provide the government an incentive to change harvest taxes. The reason is that the profit of the domestic firm does not change comparing autarky with trade. The gains in profit of the domestic firm abroad are lost on the domestic market. Thus, there is neither a race-to-the-bottom nor a race-to-the-top effect of trade in this case. Tanguay (2001) derives the same result in an almost identical model, that is, a two-country model with national welfare-maximizing governments, identical countries, and reciprocal dumping of goods under Cournot competition. Comparing the solution for the Nash equilibrium environmental taxes, production quantities, and welfare levels in Tanguay's equations (27), (31), and (38) with the first-best solutions in equations (46), (49), and (53) shows that the solutions for all three variables coincide whenever there is no transboundary production spillover is, which is also the case we study here. In contrast, Kennedy (1994) finds that the two-country equilibrium without transboundary externalities leads to downward-distorted pollution taxes and therefore excessive production. The reason is that Kennedy's model assumes the firms in the two countries can invest in pollution abatement, which would correspond to investing in resource-conserving-production technologies in the present paper. When we solved Kennedy' model without the possibility of investing in abatement, we found that, just as in the model here and Tanguay (2001), the trade outcome is efficient. 


\section{An example and some additional results}

In order to illustrate the results in Propositions 5.1-5.5 and to demonstrate some additional properties, the solution may have. Figure 5.1 depicts the simulation results when we assume that $a=40, b=1, s=0, w=1$, and $\alpha=3$. Thus, we assume that the inverse demand for the final good in each country is $p=40-Q$, the shipping cost is zero, the wage is one, and the environmental loss is $l(q)=q^{3} / 3$. The only reason why we set the shipping cost to zero is that it allows demonstrating the results in Propositions 5.4-5.5 that, if the governments maximize national welfare and face a zero shipping cost $(\mu=1$ and $s=0)$ they implement the same production quantities under trade and autarky, so opening to trade has zero welfare effect. ${ }^{20}$

Figure 5.1 panel (a) depicts the government's marginal benefit from the harvest tax in equation (5.7) under autarky as well as trade when the governments maximize national welfare $(\mu=1)$. The marginal benefit of the tax is always higher in the reciprocal dumping or trade scenario compared to the autarky scenario. The equilibrium taxes are about $t^{A}=27.5$ under autarky and $t^{R D}=28.6$ under reciprocal dumping. In Panel (b) we depict the optimal taxes as the industry bias gradually increases from $\mu=1$ to $\mu=4$. As we showed analytically in Propositions 5.1-5.3, the taxes decrease with the industry bias, but the tax remains higher under trade than in the autarky scenario. In panel (c) we depict the corresponding output quantities as the industry bias increases from 1 to 4 . Consistent with Proposition 5.3, the output quantity is smaller under trade unless $\mu=1$. It is also interesting to note

\footnotetext{
20 Allowing positive shipping costs simply shifts all the curves for the trade scenario in Figure 5.1a-d (so the marginalbenefit-of-the-tax curve, the equilibrium-tax curve, the quantity curve, and the welfare curve downward). The welfare change when $\mu=1$ then becomes negative, which reflects the efficiency loss due to the two-way shipping of identical goods in the Brander and Krugman (1983) reciprocal dumping model.
} 
that the upward tax jump and downward quantity jump due to trade in panels b-c increase with the industry bias. The reason is that, as the industry bias increases, the tax decreases more rapidly, and the production quantity increases more rapidly, in the autarky scenario than in the trade scenario. We have unfortunately been unable to establish the analytical counterparts to these results, however, that is, to demonstrate that $\partial\left(t^{R D}-t^{A}\right) / \partial \mu$ is always positive and $\partial\left(q^{R D}-q^{A}\right) / \partial \mu$ is always negative.

Finally, panel (d) depicts the welfare change due to trade as the industry bias increases. As Propositions 5.4-5.5 jointly demonstrate, when $\mu=1$ and $s=0$, trade has zero welfare effects since the production levels remain unchanged and the new two-way shipping of goods due to trade is costless. As the industry bias increases, however, the governments gradually decrease the harvest taxes under both autarky and trade. Since the autarky quantity is above the national welfare-maximizing level, trade opening is able to increase welfare. Despite the fact that industry bias can increase the change in the absolute welfare level due to trade, however, it still decreases the absolute welfare level. In other words, industry bias still decreases absolute welfare. 

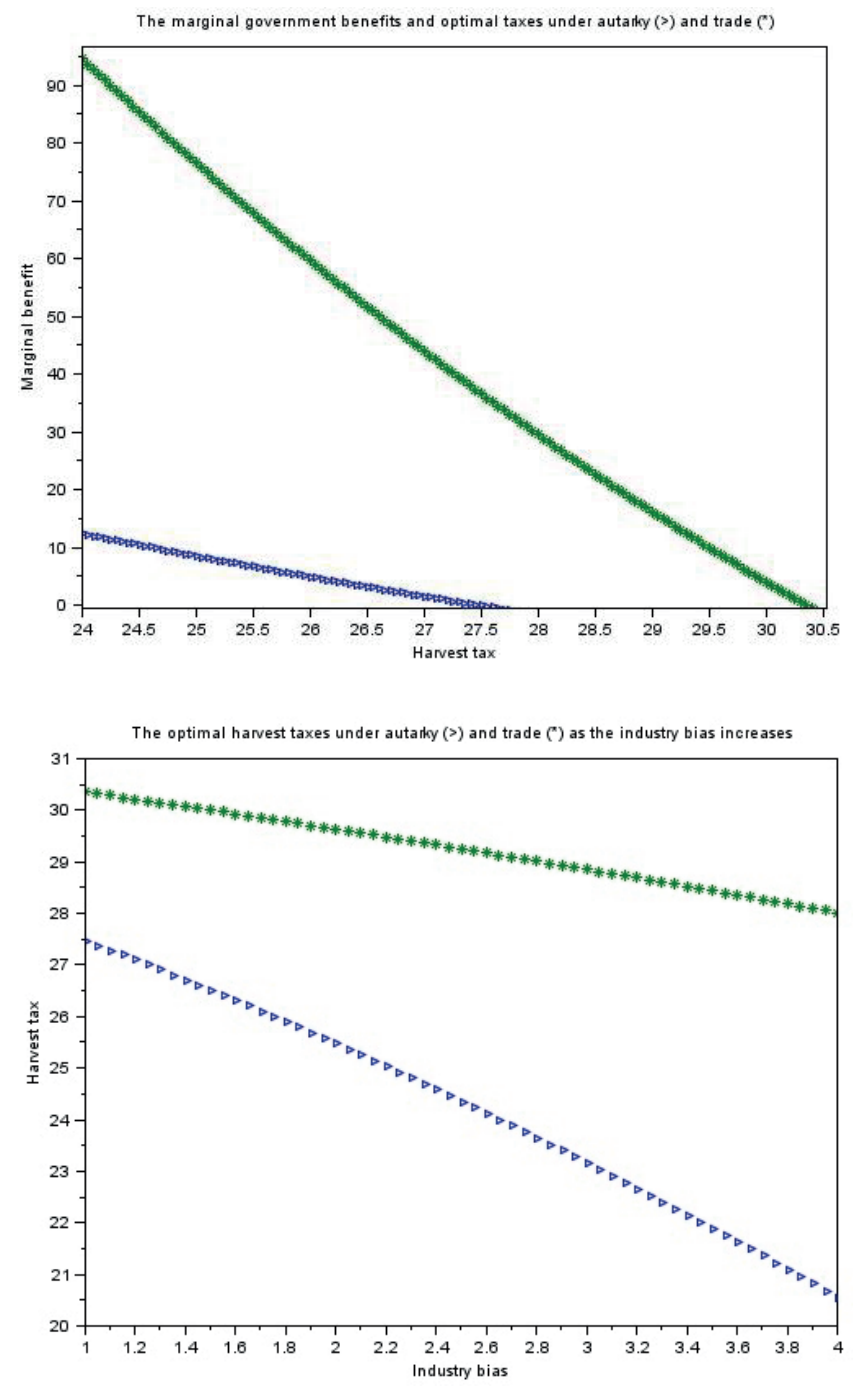

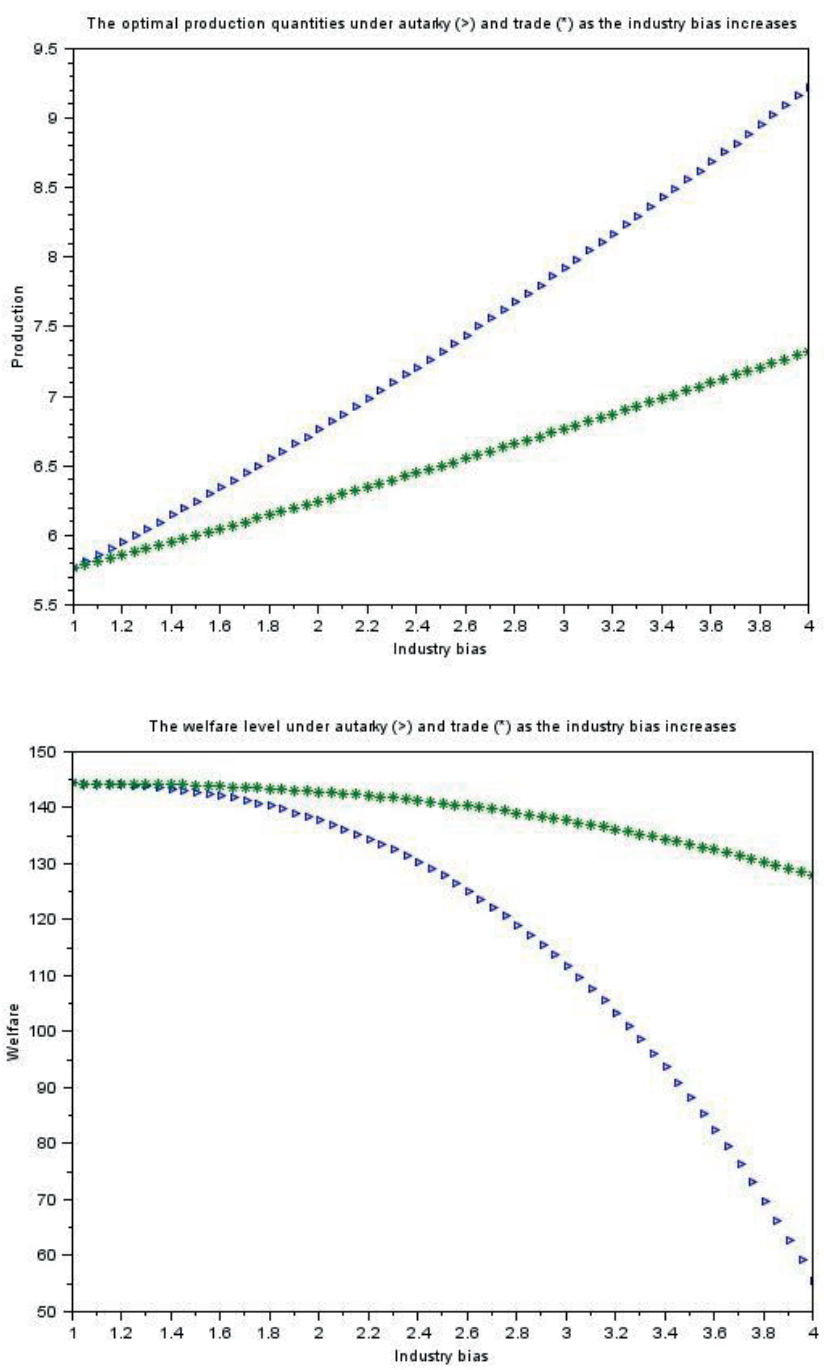

Figure 5.1 Marginal benefits of the government, harvest tax, production and welfare under autarky and trade.

Parameter values: $a=40, b=1, s=0, w=1$, and $\alpha=2$.

\subsection{Discussion and Conclusion}

In this paper, we study the effects of international trade on conservation and welfare in a twocountry model with industry-biased policymakers and Cournot-competing firms that pursue reciprocal 
dumping exports to capture profits in the foreign market (Brander and Krugman 1983). The model is motivated by the policy question: "Should we be more concerned about the environmental effects of trade when the trade-liberalizing governments are industry-biased?" We find that, within the twocountry-reciprocal-dumping framework we study, the answer is no. Instead, opening up to trade increases the harvest taxes compared to the autarky taxes and the tax increase is large enough to decrease the production levels, which increases the conservation level. In addition, the paper's numerical simulation illustrates that the industry bias monotonically increases production and decreases the welfare gains from trade.

The intuition behind the results we find is not that that industry-biased governments somehow protect the environment and maximize welfare, however. The reason, instead, is that the trade effect is only the difference between the outcomes under trade and autarky and the industry-biased governments generate worse outcomes under autarky compared to the outcomes they generate under trade. We conclude that industry-biased policymaking does not have to increase the environmental costs of trade.

Despite the reassuring result that industry bias does not exacerbate the environmental costs of trade in the model we studied, it is unclear that we would obtain the same results in either a reciprocal dumping model when firms can invest in abatement (Kennedy 1994; Withagen 2007), with multiple symmetric countries, exports to a third country (Brander and Spencer 1985), and/or Bertrand rather than Cournot competition (Eaton and Grossman 1983; Barrett 1994), or a trade model without reciprocal dumping. In particular, in a classical model of comparative advantage where the countries specialize in different products, governments that are willing to disregard the citizen's environmental concerns may limit production of environmentally harmful products under autarky when the demand for the products are limited. Once the country opens to trade and can export the products to a much larger world market with a potentially flat rather than downward-sloping demand curve, they may 
prefer to vastly scale up production (Fischer 2010; Tisdell and Fairbaim 1984; Bulte and Barbier 2005), potentially resulting in severe pollution and environmental degradation problems. We leave these considerations to further research. 


\section{A Appendix: Proofs}

\section{Proof of Lemma 5.1}

We first determine the marginal effects $c s_{t}^{A}, \pi_{t}^{A}, c s_{t}^{R D}$, and $\pi_{t}^{R D}$. We then compare them.

(i) Consumer surplus, profit, and the effects of the harvest tax in autarky

In autarky the firm solves

$$
\max _{x} \pi^{A}=\max _{x}(p-w-t) x=\max _{x}(a-b x-w-t) x
$$

Setting the first-order condition equal to zero and solving implies

$$
\begin{aligned}
& x^{A}=\frac{a-w-t}{2 b}, \quad p^{A}=\frac{a+w+t}{2}, \quad \pi^{A}=\left(p^{A}-w-t\right) x^{A}=\frac{(a-w-t)^{2}}{4 b}=b\left(x^{A}\right)^{2}, \\
& c s^{A}=\int_{\tilde{q}=0}^{\tilde{q}=A^{A}}(a-b \tilde{q}) d \tilde{q}-p^{A} x^{A}=a x^{A}-b \frac{\left(x^{A}\right)^{2}}{2}-p^{A} x^{A}=\left(a-p^{A}\right) x^{A}-b \frac{\left(x^{A}\right)^{2}}{2} \\
& =\left(a-\frac{a+w+t}{2}\right) \frac{(a-w-t)}{2 b}-\frac{b\left(\frac{a-w-t}{2 b}\right)^{2}}{2}=\frac{(a-w-t)^{2}}{4 b}-\frac{(a-w-t)^{2}}{8 b}=\frac{(a-w-t)^{2}}{8 b}
\end{aligned}
$$

The marginal profit and consumer losses from the harvest tax are

$$
\pi_{t}=\frac{-(a-w-t)}{2 b}, c s_{t}=\frac{-(a-w-t)}{4 b} .
$$

The marginal environmental utility effect of the tax is

$$
l_{t}^{A}=l_{q}\left(q^{A}\right) q_{t}^{A}=\left(q^{A}\right)^{\alpha} q_{t}^{A}=-\frac{1}{2 b}\left(\frac{a-w-t}{2 b}\right)^{\alpha}
$$

(ii) Consumer surplus, profit, and the effects of the harvest tax under trade

Under trade, the domestic and foreign firms solve

$$
\max _{x, x^{*}} \pi^{x}=p(x+y) x+p\left(x^{*}+y^{*}\right) x^{*}-\left(w+t^{x}\right) x-\left(w+t^{x}+s\right) x^{*} .
$$


$\max _{y, y^{*}} \pi^{y}=p(x+y) y+p\left(x^{*}+y^{*}\right) y^{*}-\left(w+t^{y}\right) y^{*}-\left(w+t^{y}+s\right) y$

Setting $\pi_{x}^{x}=\pi_{y}^{x}=0$ implies $x=\frac{a-b y-w-t}{2 b}, y=\frac{a-b x-w-t-s}{2 b}$. Solving for $x$ and $y$,

$$
\begin{aligned}
& x=\frac{a-w-2 t^{x}+t^{y}+s}{3 b}, y=\frac{a-w+t^{x}-2 t^{y}-2 s}{3 b} \\
& Q=x+y=\frac{2 a-2 w-t^{x}-t^{y}-s}{3 b}, p^{R D}=a-b Q=\frac{a+2 w+t^{x}+t^{y}+s}{3}
\end{aligned}
$$

The two countries are symmetric, so

$$
\begin{aligned}
& x^{*}=\frac{a-w+t^{y}-2 t^{x}-2 s}{3 b}, y^{*}=\frac{a-w-2 t^{y}+t^{x}+s}{3 b} \\
& Q^{*}=x^{*}+y^{*}=\frac{2 a-2 w-t^{x}-t^{y}-s}{3 b}, p^{R D^{*}}=a-b Q^{*}=\frac{a+2 w+t^{x}+t^{y}+s}{3}
\end{aligned}
$$

Total domestic production is therefore

$$
q^{R D}=x+x^{*}=\frac{2 a-2 w-4 t^{x}+2 t^{y}-s}{3 b} .
$$

Domestic profit is

$$
\begin{aligned}
& \pi^{R D}=\left(p^{R D}-w-t^{x}\right) x+\left(p^{R D^{*}}-w-t^{x}-s\right) x^{*}=\frac{\left(a-w-2 t^{x}+t^{y}+s\right)^{2}}{9 b}+\frac{\left(a-w+t^{y}-2 t^{x}-2 s\right)^{2}}{9 b} \\
& =b x^{2}+b\left(x^{*}\right)^{2}
\end{aligned}
$$

The domestic consumer surplus is

$$
c s^{R D}=\int_{0}^{Q}(a-b Q) d Q-p^{R D} Q=a Q-b \frac{(Q)^{2}}{2}-p^{R D} Q=\frac{\left(2 a-2 w-t^{x}-t^{y}-s\right)^{2}}{18 b}
$$

The marginal profit and consumer losses from the harvest tax are

$$
x_{t}=-\frac{2}{3 b}, x_{t}^{*}=-\frac{2}{3 b}
$$




$$
\begin{aligned}
& \pi_{t}^{R D}=2 b x\left(x_{t}\right)+2 b x^{*}\left(x_{t}^{*}\right)=-\frac{4}{3}\left(\frac{a-w-2 t^{x}+t^{y}+s}{3 b}\right)-\frac{4}{3}\left(\frac{a-w+t^{y}-2 t^{x}-2 s}{3 b}\right) \\
& =-\frac{4}{3}\left(x+x^{*}\right)=-\frac{4}{3}\left(\frac{2 a-2 w-4 t^{x}+2 t^{y}-s}{3 b}\right)=-\frac{\left(8 a-8 w-16 t^{x}+8 t^{y}-4 s\right)}{9 b} \\
& c s_{t}^{R D}=-\frac{2 a-2 w-t^{x}-t^{y}-s}{9 b}
\end{aligned}
$$

The marginal environmental utility effect of the tax is

$$
l_{t}^{R D}=l_{q}\left(q^{R D}\right) q_{t}^{R D}=\left(q^{R D}\right)^{\alpha} q_{t}^{R D}=-\frac{4}{3 b}\left(\frac{2 a-2 w-4 t^{x}+2 t^{y}-s}{3 b}\right)^{\alpha}
$$

(iii) The results follow from parts (i)-(ii) after we impose symmetry $\left(t^{x}=t^{y}\right)$ and note that, in order for the countries to trade, the export profit has to be positive, which requires (see the profit expression for $\pi^{R D}$ in part (ii)) that $a-w-t-2 s>0$.

\section{Proof of Lemma 5.2:}

We have to compute the equilibrium taxes, i.e., the solutions to $\Omega_{t}^{A}=0$ and $\Omega_{t}^{R D}=0$. In the autarky case, after we substitute from Lemma 5.1 into the government's first-order condition for the tax (7),

$$
\begin{aligned}
& \Omega_{t}^{A}=\mu \pi_{t}^{A}+c s_{t}^{A}-l_{t}^{A}+q^{A}+t q_{t}^{A} \\
& =\mu\left(-\frac{(a-w-t)}{2 b}\right)+\left(-\frac{(a-w-t)}{4 b}\right)-\left[-\frac{1}{2 b}\left(\frac{a-w-t}{2 b}\right)^{\alpha}\right]+\left(\frac{a-w-t}{2 b}\right)-t \frac{1}{2 b} \\
& =-\frac{(2 \mu-1)(a-w-t)}{4 b}+\frac{1}{2 b}\left(\frac{a-w-t}{2 b}\right)^{\alpha}-\frac{t}{2 b}=\frac{1}{2 b}\left(-\frac{(2 \mu-1)(a-w-t)}{2}+\left(\frac{a-w-t}{2 b}\right)^{\alpha}-t\right)=0 .
\end{aligned}
$$


Since $\alpha>1$ and $q^{A}=\left(\frac{a-w-t}{2 b}\right)>0$, as the intercept for the demand curve $a$ increases, the industry bias $\mu$ decreases, or the loss parameter $\alpha$ increases, the harvest tax eventually becomes positive. We assume that this is the case. The second-order condition is

$$
\begin{aligned}
& \frac{\partial}{\partial t}\left(\frac{1}{2 b}\left(-\frac{(2 \mu-1)(a-w-t)}{2}+\left(\frac{a-w-t}{2 b}\right)^{\alpha}-t\right)\right)<0 \Rightarrow \frac{1}{2 b}\left(\frac{(2 \mu-1)}{2}-\frac{\alpha}{2 b}\left(\frac{a-w-t}{2 b}\right)^{\alpha-1}-1\right)<0 \Leftrightarrow \\
& \frac{1}{2 b}\left(-\frac{(2 \mu-1)(a-w-t)}{2}+\alpha\left(\frac{a-w-t}{2 b}\right)^{\alpha}+(a-w-t)\right)>\underbrace{\frac{1}{2 b}\left(-\frac{(2 \mu+1)(a-w-t)}{2 b}+\left(\frac{a-w-t}{2}\right)^{\alpha}-t\right)=0}_{\text {The first-order condition }}
\end{aligned}
$$

where the last inequality uses that $\alpha>1,(a-w-t)=2 b\left(\frac{a-w-t}{2 b}\right)=2 b q^{A}>0$, and that the harvest tax is positive, $t>0$.

In the reciprocal dumping case, once we similarly substitute from Lemma 5.1 into (5.7), we get that

$$
\begin{aligned}
& \Omega_{t}^{R D}=\mu \pi_{t}^{R D}+c s_{t}^{R D}-l_{t}^{R D}+q^{R D}+t q_{t}^{R D}=\mu\left[-\frac{\left(8 a-8 w-16 t^{x}+8 t^{y}-4 s\right)}{9 b}\right]+\left(-\frac{2 a-2 w-t^{x}-t^{y}-s}{9 b}\right) \\
& -\left[-\frac{4}{3 b}\left(\frac{2 a-2 w-4 t^{x}+2 t^{y}-s}{3 b}\right)^{\alpha}\right]+\frac{2 a-2 w-4 t^{x}+2 t^{y}-s}{3 b}-\frac{4 t^{x}}{3 b} \\
& =\frac{-(4 \mu-3)\left(2 a-2 w-4 t^{x}+2 t^{y}-s\right)}{9 b}-\frac{2 a-2 w-t^{x}-t^{y}-s}{9 b}+\frac{4}{3 b}\left(\frac{2 a-2 w-4 t^{x}+2 t^{y}-s}{3 b}\right)^{\alpha}-\frac{4 t^{x}}{3 b} \\
& =\frac{4}{3 b}\left(-\frac{(4 \mu-3)\left(2 a-2 w-4 t^{x}+2 t^{y}-s\right)+\left(2 a-2 w-t^{x}-t^{y}-s\right)}{12}+\left(\frac{2 a-2 w-4 t^{x}+2 t^{y}-s}{3 b}\right)^{\alpha}-t^{x}\right)=0 \\
& =\frac{4}{3 b}\left(-\frac{(4 \mu-2)(2 a-2 w-2 t-s)}{12}+\left(\frac{2 a-2 w-2 t-s}{3 b}\right)^{\alpha}-t\right)=0 .
\end{aligned}
$$


Since $\alpha>1$ and $q^{R D}=\left(\frac{2 a-2 w-2 t-s}{3 b}\right)>0$, as the intercept for the demand curve $a$ increases, the industry bias $\mu$ decreases, or the loss parameter $\alpha$ increases, the harvest tax eventually becomes positive. We again assume that this is the case. The second-order condition is:

$$
\begin{aligned}
& \frac{\partial}{\partial t}\left(\frac{4}{3 b}\left(-\frac{(4 \mu-3)\left(2 a-2 w-4 t^{x}+2 t^{y}-s\right)+\left(2 a-2 w-t^{x}-t^{y}-s\right)}{12}+\left(\frac{2 a-2 w-4 t^{x}+2 t^{y}-s}{3 b}\right)^{\alpha}-t^{x}\right)\right)<0 \\
& \Rightarrow \frac{4}{3 b}\left(\frac{4(4 \mu-3)+1}{12}-\frac{4}{3 b} \alpha\left(\frac{2 a-2 w-4 t^{x}+2 t^{y}-s}{3 b}\right)^{\alpha-1}-1\right)<0 \Leftrightarrow \\
& \frac{4}{3 b}\left(\begin{array}{l}
-\frac{4(4 \mu-3)\left(2 a-2 w-4 t^{x}+2 t^{y}-s\right)+\left(2 a-2 w-4 t^{x}+2 t^{y}-s\right)}{12}+4 \alpha\left(\frac{2 a-2 w-4 t^{x}+2 t^{y}-s}{3 b}\right)^{\alpha} \\
+\left(2 a-2 w-4 t^{x}+2 t^{y}-s\right)
\end{array}\right)>0 \Leftrightarrow \\
& \frac{4}{3 b}\left(\begin{array}{l}
-\frac{(4 \mu-3)\left(2 a-2 w-4 t^{x}+2 t^{y}-s\right)+\left(2 a-2 w-4 t^{x}+2 t^{y}-s\right) / 4}{12}+\alpha\left(\frac{2 a-2 w-4 t^{x}+2 t^{y}-s}{3 b}\right)^{\alpha} \\
+\frac{\left(2 a-2 w-4 t^{x}+2 t^{y}-s\right)}{4}
\end{array}\right) \\
& =\frac{4}{3 b}\left(-\frac{(4 \mu-3)\left(2 a-2 w-4 t^{x}+2 t^{y}-s\right)}{12}+\alpha\left(\frac{2 a-2 w-4 t^{x}+2 t^{y}-s}{3 b}\right)^{\alpha}+\frac{11}{48}\left(2 a-2 w-4 t^{x}+2 t^{y}-s\right)\right) \\
& =\frac{4}{3 b}\left(-\frac{(4 \mu-3)(2 a-2 w-2 t-s)}{12}+\alpha\left(\frac{2 a-2 w-2 t-s}{3 b}\right)^{\alpha}+\frac{11}{48}(2 a-2 w-2 t-s)\right) \\
& >\underbrace{\frac{4}{3 b}\left(-\frac{(4 \mu-3)(2 a-2 w-2 t-s)}{12}+\left(\frac{2 a-2 w-2 t-s}{3 b}\right)^{\alpha}+\frac{4}{48}(2 a-2 w-2 t-s)-t\right)}_{\text {The first-order condition }}=0,
\end{aligned}
$$

where the last inequality uses that $\alpha>1$, that $(2 a-2 w-2 t-s)=3 b \frac{(2 a-2 w-2 t-s)}{3 b}=3 b q^{R D}>0$ , and that the harvest tax is positive. 


\section{Proof of Proposition 5.1:}

We have to prove that (1) $\partial t^{A} / \partial \mu<0$,(2) $\partial t^{A} / \partial w<0$, and (3) $\partial t^{A} / \partial a>0$. The proof of Lemma

5.2 shows that the government's optimality condition under autarky, equation (5.7), can be written

$\Omega_{i}^{A}(\mu, w, s, a, t(\mu, w, s, a))=\frac{1}{2 b}\left(-\frac{(2 \mu-1)(a-w-t)}{2}+\left(\frac{a-w-t}{2 b}\right)^{\alpha}-t\right)=0$

By the implicit function theorem, for any $z=\mu, w, a$,

$$
\frac{\partial \Omega_{t}^{A}}{\partial z}+\frac{\partial \Omega_{t}^{A}}{\partial t} \frac{\partial t}{\partial z}=0 \Rightarrow \frac{\partial t}{\partial z}=\frac{-\partial \Omega_{t}^{A} / \partial z}{\underbrace{\partial \Omega_{t}^{A} / \partial t}_{<0, \text { by the second-order condition for optimality }}}
$$

where the denominator is the negative second-order condition for optimality and we omit the " $\mathrm{A}$ " superscript for simplicity. Thus

$\frac{\partial t}{\partial z}=\frac{s \Omega_{t}^{A} s}{\partial z}=\frac{\partial}{\partial z}\left(-\frac{(2 \mu-1)(a-w-t)}{2}+\left(\frac{a-w-t}{2 b}\right)^{\alpha}-t\right)$

where $\stackrel{s}{=}$ denotes "has the sign of". Thus,

(1) $\frac{\partial t}{\partial \mu} \stackrel{s}{=} \frac{\partial}{\partial \mu}\left(-\frac{(2 \mu-1)(a-w-t)}{2}+\left(\frac{a-w-t}{2 b}\right)^{\alpha}-t\right)=-(a-w-t)=-2 b q^{A}<0$ 
(2) $\frac{\partial t}{\partial w} \stackrel{s}{=} \frac{\partial}{\partial w}\left(-\frac{(2 \mu-1)(a-w-t)}{2}+\left(\frac{a-w-t}{2 b}\right)^{\alpha}-t\right)=\frac{(2 \mu-1)}{2}-\frac{\alpha}{2 b}\left(\frac{a-w-t}{2 b}\right)^{\alpha-1}<0 \Leftrightarrow$

$$
\frac{(2 \mu-1)(a-w-t)}{2}-\alpha\left(\frac{a-w-t}{2 b}\right)^{\alpha}<\underbrace{\frac{(2 \mu-1)(a-w-t)}{2 b}-\left(\frac{a-w-t}{2}\right)^{\alpha}+t=0}_{\text {By the first-order condition }},
$$

where the last inequality uses that $\alpha>1$ and $t>0$.

(3) $\frac{\partial t}{\partial a} \stackrel{s}{=} \frac{\partial}{\partial a}\left(-\frac{(2 \mu-1)(a-w-t)}{2}+\left(\frac{a-w-t}{2 b}\right)^{\alpha}-t\right)=-\frac{(2 \mu-1)}{2}+\frac{\alpha}{2 b}\left(\frac{a-w-t}{2 b}\right)^{\alpha-1}>0 \Leftrightarrow$

$$
\frac{(2 \mu-1)(a-w-t)}{2}-\alpha\left(\frac{a-w-t}{2 b}\right)^{\alpha}<\underbrace{\left.\frac{(2 \mu-1)(a-w-t)}{2 b}\right)^{\alpha}+t=0}_{\text {By the first-order condition }}
$$

where the last inequality again uses that $\alpha>1$ and $t>0$.

\section{Proof of Proposition 5.2:}

We have to prove that (1) $\partial t^{R D} / \partial \mu<0$,(2) $\partial t^{R D} / \partial w<0$, (3) $\partial t^{A} / \partial a>0$, and (4) $\partial t^{A} / \partial s<0$. The proof of Lemma 5.2 shows that the government's optimality condition under trade, equation (5.7), can be written

$$
\Omega_{t}^{R D}(\mu, w, s, a, t(\mu, w, s, a))=\frac{4}{3 b}\left(-\frac{(4 \mu-2)(2 a-2 w-2 t-s)}{12}+\left(\frac{2 a-2 w-2 t-s}{3 b}\right)^{\alpha}-t\right)=0
$$

By the implicit function theorem, for any $z=\mu, w, s, a$, 


$$
\frac{\partial \Omega_{t}^{R D}}{\partial z}+\frac{\partial \Omega_{t}^{R D}}{\partial t} \frac{\partial t}{\partial z}=0 \Rightarrow \frac{\partial t}{\partial z}=\frac{-\partial \Omega_{t}^{R D} / \partial z}{\underbrace{\partial \Omega_{t}^{R D} / \partial t}_{<0, \text { by the second-order condition for optimality }}} .
$$

where the denominator is the negative second-order condition for optimality and we omit the "RD" superscript for simplicity. Thus

$$
\frac{\partial t}{\partial z}=\frac{\partial \Omega_{t}^{R D} s}{\partial z}=\frac{\partial}{\partial z}\left(-\frac{(4 \mu-2)(2 a-2 w-2 t-s)}{12}+\left(\frac{2 a-2 w-2 t-s}{3 b}\right)^{\alpha}-t\right)
$$

where $\stackrel{s}{=}$ denotes "has the sign of." Thus,

$$
\begin{aligned}
& \text { (1) } \frac{\partial t}{\partial \mu} \stackrel{s}{=} \frac{\partial}{\partial \mu}\left(-\frac{(4 \mu-2)(2 a-2 w-2 t-s)}{12}+\left(\frac{2 a-2 w-2 t-s}{3 b}\right)^{\alpha}-t\right) \\
& =-\frac{(2 a-2 w-2 t-s)}{3}=-b \frac{(2 a-2 w-2 t-s)}{3 b}=-b q^{R D}<0
\end{aligned}
$$

(2) $\frac{\partial t}{\partial w} \stackrel{s}{=} \frac{\partial}{\partial w}\left(-\frac{(4 \mu-2)(2 a-2 w-2 t-s)}{12}+\left(\frac{2 a-2 w-2 t-s}{3 b}\right)^{\alpha}-t\right)$

$$
=\frac{2(4 \mu-2)}{12}-\frac{2 \alpha}{3 b}\left(\frac{2 a-2 w-2 t-s}{3 b}\right)^{\alpha-1}<0 \Leftrightarrow
$$

$$
\frac{(4 \mu-2)(2 a-2 w-2 t-s)}{12}-\alpha\left(\frac{2 a-2 w-2 t-s}{3 b}\right)^{\alpha}<\underbrace{\frac{(4 \mu-2)(2 a-2 w-2 t-s)}{12}-\left(\frac{2 a-2 w-2 t-s}{3 b}\right)^{\alpha}+t=0}_{\text {By the first-order condition }}
$$

where the last inequality uses that $\alpha>1$ and that $t>0$. 
(3) $\frac{\partial t}{\partial a} \stackrel{s}{=} \frac{\partial}{\partial a}\left(-\frac{(4 \mu-2)(2 a-2 w-2 t-s)}{12}+\left(\frac{2 a-2 w-2 t-s}{3 b}\right)^{\alpha}-t\right)$

$=-\frac{2(4 \mu-2)}{12}+\frac{2 \alpha}{3 b}\left(\frac{2 a-2 w-2 t-s}{3 b}\right)^{\alpha-1}>0 \Leftrightarrow$

$\frac{(4 \mu-2)(2 a-2 w-2 t-s)}{12}-\alpha\left(\frac{2 a-2 w-2 t-s}{3 b}\right)^{\alpha}<\underbrace{\frac{(4 \mu-2)(2 a-2 w-2 t-s)}{12}-\left(\frac{2 a-2 w-2 t-s}{3 b}\right)^{\alpha}+t=0}_{\text {By the first-order condition }}$

where the last inequality uses that $\alpha>1$ and that $t>0$.

(4) $\frac{\partial t}{\partial s}=\frac{\partial}{\partial s}\left(-\frac{(4 \mu-2)(2 a-2 w-2 t-s)}{12}+\left(\frac{2 a-2 w-2 t-s}{3 b}\right)^{\alpha}-t\right)$

$=\frac{(4 \mu-2)}{12}-\frac{\alpha}{3 b}\left(\frac{2 a-2 w-2 t-s}{3 b}\right)^{\alpha-1}<0 \Leftrightarrow$

$\frac{(4 \mu-2)(2 a-2 w-2 t-s)}{12}-\alpha\left(\frac{2 a-2 w-2 t-s}{3 b}\right)^{\alpha}<\underbrace{\frac{(4 \mu-2)(2 a-2 w-2 t-s)}{12}-\left(\frac{2 a-2 w-2 t-s}{3 b}\right)^{\alpha}+t=0}_{\text {By the first-order condition }}$

where the last inequality uses that $\alpha>1$ and that $t>0$.

\section{Proof of Proposition 5.3:}

We have to prove that $t^{R D}>t^{A}$. First, we note that $\Omega^{R D}$ is concave $\left(\Omega_{t t}^{R D}<0\right)$ in the range $t \in\left[0, t^{R D}\right]$

The reason is that, from the proof of Lemma 5.2,

$\Omega_{t t}^{R D}=\frac{4}{3 b}\left(\frac{4(4 \mu-3)+1}{12}-\frac{4}{3 b} \alpha\left(\frac{2 a-2 w-2 t^{R D}-s}{3 b}\right)^{\alpha-1}-1\right)$

This expression is negative when evaluated at $t^{R D}$ and increasing in $t$ (recall that $\alpha>1$ ). Hence it is also negative in the range $t \in\left[0, t^{R D}\right]$. Similarly, $\Omega^{A}$ is concave, that is $\left(\Omega_{t}^{A}<0\right)$ in the range 
$t \in\left[0, t^{A}\right]:$ from the proof of Lemma 5.2, $\Omega_{t t}^{A}=\frac{1}{2 b}\left(\frac{(2 \mu-1)}{2}-\frac{\alpha}{2 b}\left(\frac{a-w-t}{2 b}\right)^{\alpha-1}-1\right)$. This expression is negative when evaluated at $t^{A}$ and increasing in $t$ (recall again that $\alpha>1$ ). Hence it is also negative in the range $t \in\left[0, t^{A}\right]$. Next, we either have $t^{R D}>t^{A}$ or $t^{A}>t^{R D}$.

*If $t^{R D}>t^{A}$ we must have $\Omega_{t}^{R D}\left(t^{A}\right)>\Omega_{t}^{R D}\left(t^{R D}\right)=\Omega_{t}^{A}\left(t^{A}\right)=0$.

*If $t^{A}>t^{R D}$ we must have $\Omega_{t}^{A}\left(t^{R D}\right)>\Omega_{t}^{A}\left(t^{A}\right)=\Omega_{t}^{R D}\left(t^{R D}\right)=0$.

Hence if $\Omega_{t}^{R D}\left(t^{A}\right)>0$ but $\Omega_{t}^{A}\left(t^{R D}\right) \leq 0$ the tax under trade is higher and our proposition is proven.

Using from Lemma 5.2 that $t^{A}=-\frac{(2 \mu-1)(a-w-t)}{2}+\left(\frac{a-w-t}{2 b}\right)^{\alpha}>0$, we must prove that

$$
\begin{aligned}
& \Omega_{t}^{R D}\left(t^{A}\right)=\frac{4}{3 b}\left(-\frac{(4 \mu-2)\left(2 a-2 w-2 t^{A}-s\right)}{12}+\left(\frac{2 a-2 w-2 t^{A}-s}{3 b}\right)^{\alpha}-t^{A}\right) \\
& =\frac{4}{3 b}\left(-\frac{(4 \mu-2)\left(2 a-2 w-2 t^{A}-s\right)}{12}+\left(\frac{2 a-2 w-2 t^{A}-s}{3 b}\right)^{\alpha}-\left(-\frac{(2 \mu-1)\left(a-w-t^{A}\right)}{2}+\left(\frac{a-w-t^{A}}{2 b}\right)^{\alpha}\right)>0\right. \\
& \Leftrightarrow-\frac{(4 \mu-2)\left(2 a-2 w-2 t^{A}-s\right)}{12}+\left(\frac{2 a-2 w-2 t^{A}-s}{3 b}\right)^{\alpha}+\frac{(2 \mu-1)\left(a-w-t^{A}\right)}{2}-\left(\frac{a-w-t^{A}}{2 b}\right)^{\alpha}>0 \\
& \Leftrightarrow\left(\frac{2 a-2 w-2 t^{A}-s}{3 b}\right)^{\alpha}-\left(\frac{a-w-t^{A}}{2 b}\right)^{\alpha}>\frac{(4 \mu-2)\left(2 a-2 w-2 t^{A}-s\right)}{12}-\frac{(2 \mu-1)\left(a-w-t^{A}\right)}{2} .
\end{aligned}
$$

Based on Lemma 5.1, part (iii), at a fixed tax rate, trade increases each firm's production level.

Therefore, on the left-hand side of the last inequality

$$
\left(\frac{2 a-2 w-2 t^{A}-s}{3 b}\right)^{\alpha}-\left(\frac{a-w-t^{A}}{2 b}\right)^{\alpha}=\left(q^{R D}\left(t^{A}\right)\right)^{\alpha}-\left(q^{A}\left(t^{A}\right)\right)^{\alpha}>0 \text {. It is, therefore, sufficient that }
$$

on the right-hand side: 


$$
\begin{aligned}
& \frac{(4 \mu-2)\left(2 a-2 w-2 t^{A}-s\right)}{12}-\frac{(2 \mu-1)\left(a-w-t^{A}\right)}{2}<0 \Leftrightarrow \\
& \frac{(4 \mu-2)}{4} b \frac{\left(2 a-2 w-2 t^{A}-s\right)}{3 b}<b \frac{(2 \mu-1)\left(a-w-t^{A}\right)}{2 b} \Leftrightarrow \\
& \frac{(4 \mu-2)}{4} b q^{R D}\left(t^{A}\right)<(2 \mu-1) b q^{A}\left(t^{A}\right) \Leftrightarrow \frac{q^{R D}\left(t^{A}\right)}{q^{A}\left(t^{A}\right)}<2,
\end{aligned}
$$

such that the Cournot quantity at the autarky tax is less than twice the monopoly quantity. This is always the case since

$\frac{q^{R D}\left(t^{A}\right)}{q^{A}\left(t^{A}\right)}=\left(\frac{2 a-2 w-2 t^{A}-s}{3 b}\right) /\left(\frac{a-w-t^{A}}{2 b}\right)<\left(\frac{2 a-2 w-2 t^{A}}{3 b}\right) /\left(\frac{a-w-t^{A}}{2 b}\right)=\frac{4}{3}$. We conclude that $\Omega_{t}^{R D}\left(t^{A}\right)>0$.

Conversely, we have to show that $\Omega_{t}^{A}\left(t^{R D}\right) \leq 0$. Using from Lemma 5.2 that

$$
t^{R D}=-\frac{(4 \mu-2)(2 a-2 w-2 t-s)}{12}+\left(\frac{2 a-2 w-2 t-s}{3 b}\right)^{\alpha} \text { we must prove that }
$$

$$
\begin{aligned}
& \Omega_{t}^{A}\left(t^{R D}\right) \\
& =\frac{1}{2 b}\left(-\frac{(2 \mu-1)\left(a-w-t^{R D}\right)}{2}+\left(\frac{a-w-t^{R D}}{2 b}\right)^{\alpha}-t^{R D}\right) \leq 0 \Leftrightarrow \\
& \frac{1}{2 b}\left(-\frac{(2 \mu-1)\left(a-w-t^{R D}\right)}{2}+\left(\frac{a-w-t^{R D}}{2 b}\right)^{\alpha}\right. \\
& \left.\Leftrightarrow\left(\frac{(4 \mu-2)\left(2 a-2 w-2 t^{R D}-s\right)}{12}+\left(\frac{2 a-2 w-2 t^{R D}-s}{3 b}\right)^{\alpha}\right)\right) \leq 0 \\
& \Leftrightarrow\left(\frac{2 a-2 w-2 t^{R D}-s}{3 b}\right)^{\alpha}-\left(\frac{a-w-t^{R D}}{2 b}\right)^{\alpha} \geq \frac{(4 \mu-2)\left(2 a-2 w-2 t^{R D}-s\right)}{12}-\frac{(2 \mu-1)\left(a-w-t^{R D}\right)}{2}
\end{aligned}
$$

Based on Lemma 5.1, part (iii), at a fixed tax rate, trade increases each firm's production level. Therefore, on the left-hand side of the last inequality 
$\left(\frac{2 a-2 w-2 t^{A}-s}{3 b}\right)^{\alpha}-\left(\frac{a-w-t^{A}}{2 b}\right)^{\alpha}=\left(q^{R D}\left(t^{A}\right)\right)^{\alpha}-\left(q^{A}\left(t^{A}\right)\right)^{\alpha}>0$. It is, therefore, sufficient that

on the right-hand side:

$$
\begin{aligned}
& \frac{(4 \mu-2)\left(2 a-2 w-2 t^{R D}-s\right)}{12}-\frac{(2 \mu-1)\left(a-w-t^{R D}\right)}{2}<0 \Leftrightarrow \\
& \frac{(4 \mu-2)}{4} b \frac{\left(2 a-2 w-2 t^{R D}-s\right)}{3 b}<b \frac{(2 \mu-1)\left(a-w-t^{R D}\right)}{2 b} \Leftrightarrow \\
& \frac{(4 \mu-2)}{4} b q^{R D}\left(t^{R D}\right)<(2 \mu-1) b q^{A}\left(t^{R D}\right) \Leftrightarrow \frac{q^{R D}\left(t^{R D}\right)}{q^{A}\left(t^{R D}\right)}<2,
\end{aligned}
$$

such that the Cournot quantity at the reciprocal dumping tax is less than twice the monopoly quantity. This is always the case since

$\frac{q^{R D}\left(t^{R D}\right)}{q^{A}\left(t^{R D}\right)}=\left(\frac{2 a-2 w-2 t^{R D}-s}{3 b}\right) /\left(\frac{a-w-t^{R D}}{2 b}\right)<\left(\frac{2 a-2 w-2 t^{R D}}{3 b}\right) /\left(\frac{a-w-t^{R D}}{2 b}\right)=\frac{4}{3} \quad . \quad$ We conclude that $\Omega_{t}^{A}\left(t^{R D}\right) \leq 0$.

Proof of Proposition 5.4: we have to prove that if $\mu=1$ and $s=0$ then $q^{R D}=q^{A}$, and if either $s>0$ or $\mu>1$ then $q^{R D}<q^{A}$.

-Lemma 5.2 identifies unique solutions for $t^{A}$ and $t^{R D}$. In turn, the solutions for the production quantities (see Lemma 5.1), $q^{A}=\frac{a-w-t^{A}}{2 b}$ and $q^{R D}=\frac{2\left(a-w-t^{R D}\right)-s}{3 b}$, are unique.

-We substitute $t^{A}=-(2 \mu-1) b q^{A}+\left(q^{A}\right)^{\alpha}$ from lemma 2 into $q^{A}=\frac{a-w-2 t^{A}}{2 b}$ from Lemma 5.1 to $\operatorname{get} q^{A}=\frac{1}{2 b}\left(a-w-\left(-(2 \mu-1) b q^{A}+\left(q^{A}\right)^{\alpha}\right)\right) \Leftrightarrow\left(q^{A}\right)^{\alpha}=a-w-(3-2 \mu) b q^{A}$ 
-We substitute $t^{R D}=-(2 \mu-1) \frac{b}{2} q^{R D}+\left(q^{R D}\right)^{\alpha}$ from Lemma 5.2 into $q^{R D}=\frac{2 a-2 w-2 t^{R D}-s}{3 b}$ from Lemma 5.1 to get

$$
\begin{aligned}
& q^{R D}=\frac{1}{3 b}\left(2 a-2 w-2 t^{R D}-s\right)=\frac{1}{3 b}\left(2 a-2 w-2\left(-(2 \mu-1) \frac{b}{2} q^{R D}+\left(q^{R D}\right)^{\alpha}\right)-s\right) \Leftrightarrow \\
& 3 b q^{R D}=2 a-2 w-s+(2 \mu-1) b q^{R D}-2\left(q^{R D}\right)^{\alpha} \Leftrightarrow 2 b q^{R D}(2-\mu)=2 a-2 w-s-2\left(q^{R D}\right)^{\alpha} \Leftrightarrow \\
& b q^{R D}(2-\mu)=a-w-0.5 s-\left(q^{R D}\right)^{\alpha} \Leftrightarrow\left(q^{R D}\right)^{\alpha}=a-w-0.5 s-(2-\mu) b q^{R D}
\end{aligned}
$$

- If $\mu=1$ and $s=0$ then $\left(q^{A}\right)^{\alpha}=a-w-b q^{A}$ and $\left(q^{R D}\right)^{\alpha}=a-w-b q^{R D}$. Since the left-hand side in each equation increases in $q>0$ and the right-hand side decreases in $q>0$, each equation has a unique solution. Since the equations are the same, the solutions are the same, so $q^{R D}=q^{A}$.

- If $\mu=1$ and $s>0$, we use that from Propositions 5.1-5.2, for any $\mu, s, \frac{\partial q^{R D}}{\partial s}<0=\frac{\partial q^{A}}{\partial s}$. Thus, if $\mu=1$ and $s>0$, we must have $q^{R D}<q^{A}$.

-In order to prove that $\mu>1$ and any $s \geq 0$ also implies $q^{R D}<q^{A}$, we use proof by contradiction. Thus, assume that for $\mu>1$

$$
\begin{aligned}
& q^{R D}>q^{A} \Leftrightarrow \\
& a-w-(2-\mu) q^{R D}-0.5 s>a-w-(3-2 \mu) q^{A} \Leftrightarrow(3-2 \mu)-0.5 s / q^{A}>(2-\mu) \underbrace{\left(q^{R D} / q^{A}\right)}_{>1} \Leftrightarrow \\
& -\mu\left(2-\left(q^{R D} / q^{A}\right)\right)>2\left(q^{R D} / q^{A}\right)-3+0.5 s / q^{A} \Leftrightarrow \mu<\frac{3-0.5 s / q^{A}-2\left(q^{R D} / q^{A}\right)}{\left(2-\left(q^{R D} / q^{A}\right)\right)} .
\end{aligned}
$$


From Lemma 5.1 and Proposition 5.3,

$\left(q^{R D} / q^{A}\right)=\left(\frac{2 a-2 w-2 t^{R D}-s}{3 b}\right) /\left(\frac{a-w-t^{A}}{2 b}\right)<\left(\frac{2 a-2 w-2 t^{A}}{3 b}\right) /\left(\frac{a-w-t^{A}}{2 b}\right)=\frac{4}{3}$

since $t^{R D}>t^{A}$. However, we assume for any $\varepsilon$, and $0<\varepsilon<1 / 3$ such that $\left(q^{R D} / q^{A}\right) \approx 1+\varepsilon$, the inequality requires $\mu<\frac{3-0.5 s / q^{A}-2(1+\varepsilon)}{(2-(1+\varepsilon))}=\frac{1-2 \varepsilon-0.5 s / q^{A}}{(1-\varepsilon)}<\frac{1-2 \varepsilon}{(1-\varepsilon)}<1$, which contradicts the assumption that $\mu>1$. Thus, if $\mu>1, q^{R D}<q^{A}$.

-Lastly, we prove that if $s \approx 0$ and $\mu<1$, trade opening increases production. We again use proof by contraction. Thus, assume that for $s \approx 0, \mu<1$,

$$
\begin{aligned}
& q^{R D}<q^{A} \Leftrightarrow \\
& a-w-(2-\mu) q^{R D}-0.5 s<a-w-(3-2 \mu) q^{A} \Leftrightarrow(3-2 \mu)-0.5 s / q^{A}<(2-\mu) \underbrace{\left(q^{R D} / q^{A}\right)}_{<1} \Leftrightarrow \\
& -\mu\left(2-\left(q^{R D} / q^{A}\right)\right)<2\left(q^{R D} / q^{A}\right)-3+0.5 s / q^{A} \Leftrightarrow \mu>\frac{3-0.5 s / q^{A}-2\left(q^{R D} / q^{A}\right)}{\left(2-\left(q^{R D} / q^{A}\right)\right)} .
\end{aligned}
$$

For any $\varepsilon>0$ such that $q^{R D} / q^{A}=1-\varepsilon$, the inequality requires $\mu>\frac{3-0.5 s / q^{A}-2(1-\varepsilon)}{(2-(1-\varepsilon))} .=\frac{1+2 \varepsilon-0.5 s / q^{A}}{1+\varepsilon}>1$ for $s \approx 0$. This contradicts the assumption that $\mu<1$. Thus, if $s \approx 0$ and $\mu<1, q^{R D}>q^{A}$

\section{Proof of Proposition 5.5:}

We have to prove that the welfare change between trade and autarky is 
$\Omega^{W R D}-\Omega^{W A}=\left(a-\frac{b}{2}\left(q^{R D}+q^{A}\right)-w\right)\left(q^{R D}-q^{A}\right)-\frac{1}{1+\alpha}\left(\left(q^{R D}\right)^{1+\alpha}-\left(q^{A}\right)^{1+\alpha}\right)-s \frac{b q^{R D}-s}{2 b}$,

that the welfare change when $\mu=1, s=0$ is zero, and that the absolute welfare levels are $\Omega^{W A}=\left(a-\frac{b}{2} q^{A}-w\right) q^{A}-\frac{\left(q^{A}\right)^{1+\alpha}}{1+\alpha}$ and $\Omega^{W R D}=\Omega^{W A}+\left(\Omega^{W R D}-\Omega^{W A}\right)$, where the two terms on the right-hand side are defined above.

In order to calculate the welfare change, we note the market quantity equals the firm quantity under both autarky and trade, such that $Q^{A}=q^{A}$ and $Q^{R D}=q^{R D}$. Lemma 5.1 shows that the export quantity is $x^{*}=\frac{a-w-t^{R D}-2 s}{3 b}$. Since Lemma 5.1 also shows that $q^{R D}=\frac{2 a-2 w-2 t^{R D}-s}{3 b}$ $\Leftrightarrow t^{R D}=\frac{2 a-2 w-s-3 b q^{R D}}{2}$, we can write $x^{*}=\frac{a-w-\frac{2 a-2 w-s-3 b q^{R D}}{2}-2 s}{3 b}$. The welfare change due to trade can now be written 


$$
\begin{aligned}
& \Omega^{W R D}-\Omega^{W A}=\int_{\tilde{q}=q^{A}}^{q^{R D}} p(\tilde{q}) d \tilde{q}-w\left(q^{R D}-q^{A}\right)-\left(l\left(q^{R D}\right)-l\left(q^{A}\right)\right)-s x^{*} \\
& =\int_{\tilde{q}=q^{A}}^{q^{R D}}(a-b \tilde{q}) d \tilde{q}-w\left(q^{R D}-q^{A}\right)-\frac{1}{1+\alpha}\left(\left(q^{R D}\right)^{1+\alpha}-\left(q^{A}\right)^{1+\alpha}\right)-s x^{*} \\
& =\left(a-\frac{b}{2}\left(q^{R D}+q^{A}\right)-w\right)\left(q^{R D}-q^{A}\right)-\frac{1}{1+\alpha}\left(\left(q^{R D}\right)^{1+\alpha}-\left(q^{A}\right)^{1+\alpha}\right)-s \frac{a-w-t^{R D}-2 s}{3 b} \\
& =\left(a-\frac{b}{2}\left(q^{R D}+q^{A}\right)-w\right)\left(q^{R D}-q^{A}\right)-\frac{1}{1+\alpha}\left(\left(q^{R D}\right)^{1+\alpha}-\left(q^{A}\right)^{1+\alpha}\right)-s \frac{2 a-2 w-s-3 b q^{R D}}{2}-2 s \\
& =\left(a-\frac{b}{2}\left(q^{R D}+q^{A}\right)-w\right)\left(q^{R D}-q^{A}\right)-\frac{1}{1+\alpha}\left(\left(q^{R D}\right)^{1+\alpha}-\left(q^{A}\right)^{1+\alpha}\right)-s \frac{b q^{R D}-s}{2 b},
\end{aligned}
$$

where the following equation system from Lemmas 5.1-5.2 implicitly defines the endogenous quantities and taxes in the welfare change expression:

$$
\begin{aligned}
& q^{R D}=\frac{2 a-2 w-2 t^{R D}-s}{3 b}, t^{R D}=-(2 \mu-1) \frac{b}{2} q^{R D}+\left(q^{R D}\right)^{\alpha} \\
& q^{A}=\frac{a-w-2 t^{A}}{2 b}, t^{A}=-(2 \mu-1) b q^{A}+\left(q^{A}\right)^{\alpha}
\end{aligned}
$$

Welfare in autarky is

$$
\Omega^{W A}=\int_{\tilde{q}=0}^{q^{A}} p(\tilde{q}) d \tilde{q}-w q^{A}-l\left(q^{A}\right)=\int_{\tilde{q}=0}^{q^{A}}(a-b \tilde{q}) d \tilde{q}-w q^{A}-\frac{\left(q^{A}\right)^{1+\alpha}}{1+\alpha}=\left(a-\frac{b}{2} q^{A}-w\right) q^{A}-\frac{\left(q^{A}\right)^{1+\alpha}}{1+\alpha}
$$


Welfare under trade equals autarky welfare plus the welfare change due to trade, so $\Omega^{W R D}=\Omega^{W A}+\left(\Omega^{W R D}-\Omega^{W A}\right)$, where the two expressions on the right-hand side are defined above. 


\section{Chapter 6}

\section{Discussion and Conclusions}

The thesis analyzes lobbying effects on politically determined GM food and forest conservation policy, and the associated welfare effects. In Chapters 2 through 4, I discuss GM food policy in different trade settings, ranging from a closed economy, to a small open economy, to a setting with trade negotiations to reduce non-tariff barriers. Chapter 5 discusses the effects of forest conservation policy in both an autarky and a trade setting.

\subsection{Summary of results}

In Chapter 2, I investigate the relationship between global food security and the level of GM food policy regulation. A stricter GM food policy regulation is shown to reduce food security, measured by food availability, access, and utilization. I further show that political rivalry between interest groups worsens the food security status, provided that GM food technology is more productive and the regulatory policy is influenced by lobbying. Finally, I find that in countries that have food security problems, the implementation of stricter GM food policy regulations reduces social welfare while the pay-off to the government does not change or may even increase.

Chapter 3 studies the relationship between GM food policy and the food self-sufficiency rate influenced by political rivalry among interest groups in a small open economy. The results are illustrated using the example of maize produced in South Africa. I assumed that the government implements GM policy to maximize the weighted sum of social welfare and contributions from 
interest groups. I show that strict GM food policy can reduce food self-sufficiency. I also find that the food self-sufficiency rate is a biased measure of food availability when both the production and consumption of a commodity decline due to regulation on GM food, while consumption declines at a higher rate.

Chapter 4 is motivated by attempts to harmonize the regulations of genetically modified organisms in bilateral trade negotiations (e.g., the Transatlantic Trade and Investment Partnership). I discuss a trade agreement on agricultural products between two countries that use different GM food policy regulations. The domestic country exports non-GM food and the foreign country exports GM food, but both produce GM and non-GM food. Both GM and non-GM food groups lobby within their countries. I identify a negotiation equilibrium, in which the domestic country reduces the tariff equivalent GM food policy regulation, and the foreign country reduces its tariff equivalent non-GM food policy regulation. I find that the domestic government maximizes its payoff by reducing its tariff equivalent GM food policy during the negotiation process. Similarly, the foreign government maximizes its payoff by reducing its tariff equivalent non-GM food policy.

A model simulation, assuming a larger share of the non-GM food lobby group over the GM food lobby group in the domestic country and the reverse in the foreign country, shows that the negotiation equilibrium with respect to the tariff equivalent GM food policy in the domestic country lies between the optimal unilateral stances of each government. Hence, as a result, GM food policy in the domestic country will be less stringent and both governments' payoffs increase.

In Chapter 5, I study the effects of international trade on forest conservation and welfare in a symmetric two-country model with industry-biased policymakers and Cournot-competing firms. Opening up to trade is found to increase the harvest taxes imposed by industry-biased governments as compared to taxes under autarky. The tax increase is large enough to decrease the production levels in both countries, which leads to higher forest conservation levels. The numerical simulation 
predicts that industry-bias monotonically increases production costs and welfare gains from trade. This result occurs because industry-biased governments already degrade the environment autarky. Even if industry bias decreases forest conservation, it does not have to increase the environmental costs of trade.

\subsection{Short answers to the research questions}

\section{Question 1: How does a change in GM food policy affect food security from a global perspective?}

I construct a partial equilibrium model to show the GM food policy's effects on three aspects of food security: food availability, food access and food utilization. Food availability is measured as food production in the economy. Food access is proxied by food prices, the total income of consumers, and food demand. Food utilization is measured by consumer surplus and total utility from consuming food products; these indicators proxy the nutritional and social value of food. The GM food lobby prefers a lenient GM food policy, whereas the non-GM food lobby prefers a stricter GM food policy to increase the GM food firm's production cost. The World Nation Official (a social planner) aims to maximize his payoff equal to the weighted sum of social welfare and contributions from GM food and non-GM food lobbies. I find that making GM food policy stricter reduces food security. The political rivalry between interest groups has a negative effect on food security.

\section{Question 2: How do interest groups influence the food security of a country?}

The FAO defines the food self-sufficiency rate (SSR) as the ratio of food supply over food consumption. Both GM food and non-GM food lobby groups are willing to contribute to have their favorable level of GM food policy regulation implemented, but are reluctant to make contributions 
when GM food policy regulation is (not) too strict or lenient from their perspective. I illustrate the quantitative effects of GM food policy on the SSR, using maize production in South Africa as an example, where South Africa is modelled as a small open economy.

I find that the SSR decreases if the GM food policy regulation cost increases. This is because a higher GM food policy regulation cost decreases the GM maize production while the domestic maize consumption remains the same, as demand is determined by world market prices. Strict GM food policy increases the welfare of the non-GM food lobby but reduces the welfare of the GM food lobby, as well as that of the indifferent consumers (who consume both types of maize). GM food policy is predicted to be less strict if the non-GM firm's loss in producer surplus through a lenient GM food policy regulation is smaller than the gain in welfare for the rest of the economy.

A stricter GM food policy reduces food production and consumption. Consequently, if the reduction in consumption outweighs the reduction in production, the SSR will be high. Therefore, the SSR is not sufficient to measure food self-sufficiency; a government should also pay attention to the absolute values of production, and consumption of food.

\section{Question 3: What is the outcome of a GM food trade negotiation between two different policy regimes under lobbying influence?}

There are two possible outcomes of a bilateral GMO trade negotiation: signed or failed. If two countries are reluctant to make concessions to realize welfare gains, the negotiation will fail. I identify the set of non-tariff barrier (NTB) reductions in both countries that generate positive changes in payoffs to both governments. The possible negotiation equilibrium lies between the two countries optimal levels in tariff equivalent GM food policy regulations for the domestic country.

Due to the different consumer acceptance of GM and non-GM food products, the country with a high GM food trade barrier (the domestic country in the model) effectively determines the 
outcome of the trade negotiation. The level of the foreign country's non-GM food NTB only influences the payoff income of the domestic and foreign governments, but not the final negotiation outcomes. The non-GM food NTB is a protection for the foreign non-GM food producing firm in the foreign country, whereas the GM food NTB is a restriction for domestic GM food production in the domestic country.

\section{Question 4: Should we be more concerned about the environmental effects of trade when}

\section{the trade-liberalizing governments are industry-biased?}

I find that opening to trade in a two-country-reciprocal-dumping model increases harvest taxes compared to autarky. The increase in tax is large enough to decrease the timber production, increasing the conservation level. Opening to trade does not necessarily reduce the conservation level.

When I compare welfare levels under autarky and trade, the welfare gain from moving from autarky to trade due to the conservation policy increases when the industry bias increases. The government's marginal benefits from the harvest tax are higher under trade than under autarky. That means that the governments benefit more from conservation under trade than under autarky. Therefore, the policy choice of the industry-biased policymaker does not increase the environmental costs of trade in this case.

In addition, I also find that, when the government has no industry bias and the transportation cost is zero, the output level under trade is the same as under autarky. Positive transportation costs and an industry-biased government reduce production in open trade.

\subsection{Conclusions on methodology}


The political economy model used in this thesis follows Grossman and Helpman (1994,1995)'s framework. Throughout my chapters that focus on biotechnology, I use this model as a basis and extend it as necessary. The public debate on GMO issues, discussed in Chapter 1, divides public interest into two major lobby groups, a pro-GM food lobby and an anti-GM food lobby; there is also a group of consumers that is indifferent towards the GM food technology, but does not participate in the lobbying process. The government maximizes the weighted sum of social welfare and lobbying contributions. Although this model has been criticized for the mismatch between its predictions and empirical applications (Bernhofen and Brown 2005; Gawande and Bandyopadhyay 2000), it has been praised for its solid theoretical foundations. The latter characteristic allows me to obtain clear predictions about the wasteful effects of lobbying and the effects of GM food policy on food security in Chapter 2 and 3.

I discuss the GMO trade agreement negotiation following Grossman and Helpman's (1995) model and extend it to accommodate the modeling of a negotiation process. I focus on non-tariff barriers on GM food trade in the negotiation. I discuss a negotiation between two countries with distinct GM food regulations: strict and lenient. To mimic the negotiation process, I conduct a three-step method to find the Nash bargaining solution for a successful trade negotiation. That is, first finding the set of unilateral stances for both governments, then identifying their optimal unilateral stance, and finally maximizing the product of their payoffs from the agreement. I also simulate the negotiation process and find that the country with stricter trade barriers cannot reduce the non-tariff barrier to zero due to the non-GM food lobby's positive lobbying income.

Finally, I discuss the conservation policy under trade by applying Brander and Krugman's (1983) model of reciprocal dumping combined with an industry-biased policymaker. Although the reciprocal dumping model of trade is not representative of all trade settings, its simplicity allows me to obtain clear predictions regarding the effects of trade in the settings where it does apply. 
Symmetry is another important assumption in my analysis of forest conservation policy that is also associated with reciprocal dumping models.

\subsection{Policy implications}

The policy-making process is influenced by political rivalry between interest groups. The outcome of this process can have a large economic impact. The results of this thesis yield several implications and recommendations for GM food policy regulations and environmental conservation policies.

The first recommendation concerns international organizations that advise on global food policy (e.g., FAO). Agricultural biotechnology involves controversial discussions regarding ethical, human, and environmental concerns. In addition to scientific debate, political lobbying influences the public opinion and policy outcomes as mentioned by several authors (e.g., Herring and Paarlberg 2016; Wesseler and Zilberman 2014). My results suggest that if decision makers support the development of biotechnology, their payoffs do not need to decrease, as by setting a lenient GM food policy regulation they can attract additional contributions from those who support the technologies. Unfortunately, international organizations (e.g., FAO, IAASTD, the International Council for Science) do not unanimously support GM food technology. My results indicate that the non-GM food lobby's contributions outweigh the GM food lobby's contributions or are given higher weight by policy makers.

My second suggestion is that governments should make and implement policies based on the situation in their country. High-income countries, such as some European countries, can afford to implement a strict GM food policy without having a negative effect on their food security, but for more than two-thirds of low- and middle-income countries, the food security issue remains a problem (Economist Intelligence Unit 2015). Again, the results of my thesis indicate that the nonGM food lobby group has a strong effect on government food policies. 
Many developing countries (e.g., China, Nepal) have food policies that support achieving food self-sufficiency for staple food crops (Simelton 2011; Vel et al. 2016). However, my results show that the food self-sufficiency ratio may not be an accurate measure of food availability and food security. If there is a reduction in production and consumption at the same time, and the reduction in consumption exceeds the reduction in production, the ratio can be high but food security may not have improved. Governments need to find out the reasons behind the reductions and also have to pay attention to changes in the absolute value of production and consumption.

The third suggestion relates to trade policies. One important implication of my model in Chapter 4 is that a zero tariff on agricultural trade will be difficult to reach. Governments consider payoffs from interest groups. The payoffs may decline under a low tariff, especially when governments weigh contributions higher than the welfare gains from trade.

This implies that certain trade protection policies gain political support from lobby groups; these are rational for policy makers to pursue during trade negotiations. Therefore, a certain level of domestic agricultural protection from trade is unavoidable (Anderson et al. 2013; Bellemare and Carnes 2015).

The final suggestion of this thesis is related to trade and forest conservation policy under reciprocal dumping. The government imposes a stricter conservation tax under trade than autarky; therefore, the environment could be protected when the country opens up to trade. Trade does not necessarily negatively affect the domestic protection of natural resources. Politically determined conservation policy can support both economic profit and environmental utility at the same time.

\subsection{Relevance}

In this section, I offer some relevant research areas where similar methods to the ones used in this thesis can be applied. 
The political economy models I developed can be applied to assess regulatory policy on innovations in general. New technologies, new equipment, even new ideas may take a long time to be accepted by the public because they replace old ones that people are used to. Some may associate new technologies with potential risks to human health and to environmental safety, and emphasize the uncertainties in their utilization (e.g. Wesseler and Zilberman 2014; Tosun and Schaub 2015). Interest groups can generally be split into supporters and opponents. Regulations on innovations are influenced by the two groups. Consumers could either support one or the other, or be neutral. In this case, the model in this thesis can be applied to the analysis of such issues.

Second, the negotiation model can be applied to trade negotiation between policies under the influence of lobbying. For example, it can be extended to multi-country scenarios, to simulate global environmental negotiations, or to model the effects of climate change on individual countries. This allows the inclusion of heterogeneous countries with different economic structures, resource endowments, and climate change uncertainties. Developed countries require the reduction of $\mathrm{CO}_{2}$ emissions by developing countries, but developing countries ask for financial support. They share common interests, so my model in Chapter 4 can be used to find a carbon tax or cap-and-trade negotiation equilibrium.

The forest conservation model can be applied to other problems of environmental and natural resource conservation. For example, it is suitable for the analysis of other activities involving international firms that generate private economic benefits but also negative externalities.

\subsection{Limitations and recommendations for further research}

The political economy approach that I applied in this thesis has its merits but also limitations. For example, the GM food policy study is not as specific as in Graff et al. (2009). Graff et al. (2009) list many competing interest groups, and each of them weighs differently in the political process. 
However, I categorize all interest into two lobbies for simplification to obtain analytical results and focus on policy effects. This is supported by the analysis of Tosun et al. (2016). Thus, further study on interest gains and the lobbying behavior of large groups can be implemented in a more detailed lobbying game. This analysis can be conducted in combination with empirical studies, including estimations of benefit and cost. Moreover, in the lobbying discussion, I did not offer specific functions for the lobbying in Chapter 2, but only focus on the GM food policy effects on the different aspects of food security. However, I do incorporate logistic lobbying functions in Chapters 3 and 4, and assess lobbying effects on the food self-sufficiency rate in Chapter 3, and GMO trade agreement equilibrium in Chapter 4.

Due to the complexity of the issues, the models that I use for GM food and forest conservation policy are static. However, policy making happens in a dynamic environment. Thus, dynamic political models can offer further information about the firms' and consumers' reactions to the policy change, and update the interest groups' lobbying schedules.

As discussed at the end of Chapter 5, there are some limitations to the two-country model. Despite the reassuring result that industry bias does not exacerbate the environmental costs of trade in the model I studied, it is unclear whether I would obtain the same results in either a reciprocal dumping model in which firms can invest in abatement with multiple symmetric countries, exports to a third country or Bertrand competition. A country alone may have limited demand for products that are pollution intensive. If the country opens to trade and can export the products to a much larger world market with a flat demand curve, they may prefer to increase their production. These thoughts could be considered for further research.

In this thesis, I built theoretical models and extended them with simulations. Although they do not exactly replicate the real world, they offer a basic theory including testable hypotheses for empirical studies. For example, in the cases where opposition to GM agricultural technology is more 
successful in the international debates on GMOs, either the opposition has greater financial resources available for lobbying or the governing bodies are less concerned about food security. This can be tested in empirical research.

For the policy study in each model, we only consider one policy instrument, either the harvest tax or the GM food policy regulation. It would be interesting to study whether different policy instruments, or a combination of them, would change the interest groups' incentives. 


\section{Summary}

Economics and politics interact. Political and economic forces influence the choices of policy instruments, the distribution of economic rent, and the distribution of political power. Politicians balance the interaction of economic rents and political interests in the policy-making process. Some policies aim to correct market failures, others aim to pursue politicians' own interests, some are a combination. I discuss two policies in this thesis, the regulation of genetically modified (GM) food crops, and forest conservation policy.

The relationship between GM food technology and food supply is a dilemma for policymakers in many countries. Theoretical and empirical studies show that GM food technology helps increase crop yields, reduces pesticide and fertilizer use, and generates economic, environmental, and health benefits. However, many consumers are concerned about the potential risks from using the technology and treat GM and non-GM food products as different products. The differences in public attitude towards GM food technology influence GM food policy-making. Many scientists believe that the public attitude is not purely based on scientific evidence, but is influenced by different interest groups. The two major interest groups involved in the GM food policy debate can be clustered into the GM food-supporting and non-GM food-supporting groups, depending on their attitude towards the GM food technology.

The GM food group points to the high yields, environmental benefits, and potential for sustainable agricultural production. The non-GM food group, however, emphasizes the unconfirmed potential risks of genetic modification to human health and the environment. There 
are two major GM food policy regimes: the EU Member States have very strict GM food regulations, whereas the US has relatively lenient GM food policy regulations with respect to cultivation and imports. A stricter GM food policy would generate high welfare costs to countries that face food security issues, and possibly reduce a country's food self-sufficiency. Also, different GM food policy regulations give rise to different national standards, differentiate agricultural trade markets, and result in trade disputes.

Environmental policy regulates economic activity. To balance economic interests and environmental benefits, conservation policy is often needed for the protection of natural resources. Forests as a renewable resource provide both economic and environmental benefits. Forest conservation policy often requires governments to settle the trade-off between interests of the timber industry and the environmental benefit of maintaining parts of the forests. Political conflicts may exist between a profit-maximizing timber industry lobby and an environmental lobby. An industry-biased conservation policy could cause faster exploitation of this domestic resource, while a stricter protection of the resource could result in profit reduction for the timber industry, but increase environmental benefits.

I discuss the relationships between food security and GM food policy regulations in Chapter 2. I develop a standard political economy model of GM food policy regulations and model GM food policy as the outcome of a GM-versus-non-GM food lobbying game. I find that stricter GM food policy has negative effects on three aspects of food security: availability, access, and utilization. Politically determined GM food policy has a negative effect on the food security situation if lobbying is costly. I also discuss the situation in which the policymaker weighs the GM food and non-GM food lobbies' contributions differently, depending on whether the food security target has been reached or not. The GM food lobby becomes more efficient in the political game than the non-GM food group when the country commits itself to improving its food security. If the non-GM food 
lobby is large and strong, it will make high lobbying contributions for stricter GM food policy, even when the country is food-insecure.

Chapter 3 studies the relationship between politically determined GM food policy and domestic food self-sufficiency. I first develop a theoretical model of a small-open economy and investigate the GM food policy. The government maximizes its own payoff, which is the weighted sum of social welfare and lobbying contributions. I take maize production in South Africa as an example for illustrating the politically influenced self-sufficiency rate. I find that the food selfsufficiency rate will decrease with an increase in GM food policy regulation cost. I also specify the mechanism of policy change in this small open economy case. I include changes in the lobby groups' sizes in the model, and assess the effect on food self-sufficiency. In the case of a large non-GM food group, the government payoff does not monotonically decrease when the government weighs social welfare at a low level in the political process. The GM food policy can be strict in this case. In addition, the food self-sufficiency rate can be high when a large non-GM food group is present and the government places a low weight on social welfare. Most importantly, this case demonstrates that the food self-sufficiency rate is not always a good indicator of food availability. In some cases, the food self-sufficiency rate can increase, while food availability may decrease.

In Chapter 4, given the two different GM food policy regimes and in light of the TransPacific Partnership and the Transatlantic Trade and Investment Partnership negotiations, I discuss a bilateral negotiation regarding GM food trade policies. Two countries pursue an increase in trade volume for both GM and non-GM food products. With a high GM food non-tariff barrier (NTB) on the foreign GM food imports and a relatively high non-GM food NTB in the foreign country, I find that the Nash bargaining solution lies between the two countries' optimal unilateral stances for a successful negotiation. Simulation results show that the foreign country would not like to reduce much of its non-GM food NTB in the negotiation. The level of the non-GM food NTB only 
influences the absolute payoffs of the domestic and foreign governments, but not the negotiation results. The outcome of the negotiation only depends on the level of GM food NTB reduction in the domestic country.

In Chapter 5, I discuss the effects of international trade on forest conservation and welfare in a two-country model with an industry-biased policymaker and Cournot-competing firms. I find that opening to trade increases the harvest taxes compared to the taxes under autarky. The tax increase is large enough to decrease the production levels, which increases the conservation level. In addition, the numerical simulation illustrates that the industry bias parameter monotonically decreases the output and increases the welfare gains from trade. As a result, industry-biased policymaking does not necessarily have to increase the environmental costs when opening to trade.

Three main conclusions can be drawn from this thesis. First, strict biotechnology regulations decrease the level of global food security, especially in developing countries. Second, in the GM food trade negotiations, the country that has high trade barriers has to make concessions for a successful trade agreement. Third, second-best conservation policies can still protect the environment in an open economy. This thesis does not provide solutions to either the GM-versusnon-GM or the environmental-versus-trade debates. It does, however, offer some insights into the politically determined GM food and conservation policy-making and the impact of lobbying. 


\section{Samenvatting (summary in Dutch)}

Er is een wisselwerking tussen economie en politiek. Politiek en economie hebben invloed op de keuze van beleidsinstrumenten, de verdeling van economische baten en de politieke machtsverhoudingen. Politici moeten een balans zien te vinden tussen economische en politieke belangen in het beleidsvormingsproces. Beleid kan zich richten op het corrigeren van markt falen, maar kan ook puur het eigenbelang van de beleidsmaker dienen. Een combinatie is ook mogelijk. In dit proefschrift komen twee beleidsterreinen aan bod, beleid gericht op genetisch gemodificeerde (GG) voedselgewassen en beleid gericht op bosbescherming.

In veel landen vormt de relatie tussen GG technieken en voedselvoorziening een dilemma voor beleidsmakers. Theoretische en empirische studies hebben aangetoond dat GG technieken gewasopbrengsten verbeteren, benodigde hoeveelheden bestrijdingsmiddelen en meststoffen verminderen en economische-, milieu- en gezondheidsvoordelen opleveren. Toch maken veel consumenten zich zorgen over de mogelijke risico's van het gebruik van GG technieken, en zien zij GG en niet-GG levensmiddelen als totaal verschillende producten. De verschillen in de publieke opinie met betrekking tot GG technologie beïnvloedt GG voedselbeleidsvorming. Veel wetenschappers geloven dat de publieke opinie niet enkel gebaseerd is op wetenschappelijk bewijs, maar ook beïnvloed wordt door verschillende belangengroepen. De twee grootste belangengroepen 
met betrekking tot GG voedselbeleid zijn de GG voedselgroep en de anti-GG voedselgroep, gebaseerd op hun houding ten opzichte van GG technieken.

De GG voedsel groep benadrukt de hoge gewasopbrengsten en milieuvoordelen en de mogelijkheden voor duurzame landbouw. De anti-GG groep, daarentegen, legt de nadruk op de onbevestigde potentiële riscico's voor de menselijke gezondheid en het milieu. Er zijn twee grote GG beleidsstructuren. De EU lidstaten hanteren zeer strikte GG voedselwetgeving, terwijl de VS een relatief soepele wetgeving hanteert voor teelt en import. Een strenger GG voedsel beleid zal hoge welvaartskosten met zich meebrengen voor landen met een voedselzekerheidsprobleem, en mogelijk de voedselonafhankelijkheid verminderen. Verder leiden verschillen in GG voedselwetgeving tot verschillende handelsvoorwaarden, verschillen in agrarische markten en een toename in handelsgeschillen.

Milieubeleid reguleert economische activiteit. Om de balans te vinden tussen economische belangen en milieubaten is vaak beleid gericht op het behoud van natuurlijke hulpbronnen nodig. Bossen zijn natuurlijke hulpbronnen die zowel economische als milieubaten genereren. Binnen het bosbeheer moet de overheid een afweging maken tussen de belangen van de houtindustrie en de milieubaten die gegenereerd worden door het behoud van delen van het bos. Er kan een politieke strijd zijn tussen een winst gedreven industriële houtlobby en een milieulobby.Enerzijds kan een bosbeleid dat gunstig is voor de industrie leiden tot een snellere exploitatie van de binnenlandse hulpbron, anderzijds kan een striktere bescherming van de hulpbron resulteren in een vermindering van de winst voor de houtindustrie, maar een verbetering van de milieubaten.

De relatie tussen voedselzekerheid en GG voedselbeleid bespreek ik in Hoofdstuk 2. Ik ontwikkel een standaard politiek-economisch model van de GG voedselwetgeving, waarin ik de GG voedselwet modelleer als de uitkomst van een GG versus anti-GG lobbyspel. Ik toon aan dat een strikter GG beleid een negatief effect heeft op drie aspecten van voedselzekerheid: beschikbaarheid, 
toegang en gebruik. Het politiek-bepaalde GG beleid verslechtert de voedselzekerheid als we aannemen dat lobbyen geld kost. Ook bespreek ik de situatie wanneer een beleidsmaker een verschillend gewicht toekent aan bijdragen van de GG en anti-GG lobby groepen, afhankelijk van het feit of de voedselzekerheidsdoelstelling gehaald is of niet. Wanneer het land zich heeft gecommitteerd aan het verbeteren van de voedselzekerheid dan kan de GG lobby het politieke spel efficiënter spelen dan de anti-GG groep. Als de anti-GG lobby groot en sterk is, zal zij hoge lobby bedragen betalen, zelfs wanneer er voedselonzekerheid is in het land.

Hoofdstuk 3 bestudeert de relatie tussen het politiek-bepaalde GG voedselbeleid en de binnenlandse voedselonafhankelijkheid. Eerst ontwikkel ik een theoretisch model van een kleine open economie en analyseer het GG voedselbeleid. De overheid maximaliseert haar eigen belang, wat gelijk is aan de gewogen som van sociale welvaart en lobby bijdragen. Ik gebruik de maisproductie in Zuid Afrika als voorbeeld om de door de politiek beïnvloede mate van voedsel onafhankelijkheid te illustreren. De resultaten laten zien dat de mate van voedselonafhankelijkheid afneemt als de kosten van GG voedselwetgeving toenemen. Ook specificeer ik de kettingreactie die plaatsvindt als gevolg van de beleidsverandering in deze kleine open economie. Ik voeg veranderingen van groepsgrootte toe aan het model, en bekijk wat de effecten daarvan zijn op de voedselonafhankelijkheid. Als de anti-GG groep groot is, dan neemt het overheidsbelang niet monotoon af als de overheid een lage waarde toekent aan sociale welvaart in het politieke proces. Bovendien kan er een hoge mate van voedselonafhankelijkheid voorkomen als er een grote anti-GG groep is en de overheid een laag gewicht toekent aan sociale welvaart. Dit voorbeeld laat bovenal zien dat de mate van voedselonafhankelijkheid niet altijd een goede indicator is voor voedselbeschikbaarheid. Er zijn gevallen waar de voedselonafhankelijkheid groter wordt, terwijl de voedselbeschikbaarheid afneemt. 
Gegeven de twee GG voedselbeleidsstructuren en in het licht van de "Trans-Pacific Partnership" en de "Transatlantic Trade and Investment Partnership" onderhandelingen, behandel ik in hoofdstuk 4 een bilaterale onderhandeling met betrekking tot GG voedsel- en handelsbeleid. Twee landen streven een toename in handelsvolume in zowel GG als niet-GG levensmiddelen na. Uitgaande van hoge non-tarifaire handelsbelemmeringen (NTB) op buitenlandse GG voedselimport en een relatief hoge NTB van het buitenland op de niet-GG voedselexport, toon ik aan dat de Nash onderhandelingsuitkomst tussen de optimale standpunten van de twee landen ligt als de onderhandelingen succesvol zijn. De resultaten van de simulaties laten zien dat het buitenland zijn niet-GG voedsel NTB niet veel wil verlagen in de onderhandelingen. De hoogte van de niet-GG voedsel NTB heeft enkel invloed op de absolute opbrengsten van de binnenlandse en buitenlandse overheden, maar niet op het onderhandelingsresultaat. Het onderhandelingsresultaat hangt enkel af van de hoeveelheid waarmee het binnenland de GG voedsel NTB verlaagt.

In hoofdstuk 5 behandel ik de effecten van internationale handel op bosbescherming en welvaart in een twee-landenmodel met een industriegezinde beleidsmaker en bedrijven in een Cournot-competitie. Ik toon aan dat het toestaan van handel leidt tot een toename van de belasting op houtkap in vergelijking met de belasting in een autarkie. Deze toename in belasting is groot genoeg is om de productie te verlagen, wat resulteert in een toename in het beschermingsniveau. Verder illustreert de getalsmatige simulatie dat de parameter voor industriegezindheid de productie monotoon vermindert en de welvaartsbaten van handel verhoogt. Daarom hoeven de negatieve effecten van handel op het milieu niet toe te nemen in het geval van een industriegezind beleid.

Er zijn drie belangrijke conclusies die we kunnen trekken aan de hand van dit proefschrift. Ten eerste, strikte wetgeving voor biotechnologie heeft een negatief effect op de wereld 
voedselzekerheid, vooral in ontwikkelingslanden. Ten tweede, in de GG voedsel handelsbesprekingen zal het land met hoge handelsbelemmeringen concessies moeten doen willen de onderhandelingen slagen. Ten derde, een suboptimaal milieubeleid kan het milieu nog steeds beschermen als er sprake is van een open economie. Dit proefschrift geeft geen oplossingen voor de GG-versus-geen-GG en milieu-versus-handel conflicten. Echter, dit proefschrift levert enkele inzichten in de politieke beleidsvorming voor GG voedsel en milieubeleid en het effect van lobbygedrag op dat beleid. 


\section{References}

Anderson, K. (1995). Lobbying incentives and the pattern of protection in rich and poor countries. Economic Development and Cultural Change, 43(2), 401-423.

Anderson, K., Rausser, G., and Swinnen, J. (2013). Political economy of public policies: insights from distortions to agricultural and food markets. Journal of Economic Literature, 51(2), 423-477.

Apel, A. (2010). The costly benefits of opposing agricultural biotechnology. New Biotechnology, 27(5), 635-640.

Bandyopadhyay, S., Park, E. S., and Wall, H. J. (2004). Endogenous export subsidies and welfare under domestic cost heterogeneity. Economics \& Politics, 16(3), 347-366.

Barbier, E. B., Damania, R., and Léonard, D. (2005). Corruption, trade and resource conversion. Journal of Environmental Economics and Management, 50(2), 276-299.

Barker, R., and Hayami, Y. (1976). Price support versus input subsidy for food self-sufficiency in developing countries. American Journal of Agricultural Economics, 58(4), 617-628.

Barnett, A. H. (1980). The Pigouvian tax rule under monopoly. American Economic Review, 70(5), 10371041.

Barrett, S. (1994). Strategic environmental policy and intrenational trade. Journal of Public Economics, 54(3), 325-338.

Bastos, P., Straume, O. R., and Urrego, J. A. (2013). Rain, agriculture, and tariffs. Journal of International Economics, 90(2), 364-377.

Becker, G. S. (1983). A theory of competition among pressure groups for political influence. The Quarterly Journal of Economics, 98(3), 371-400. 
Beckmann, V., Soregaroli, C., and Wesseler, J. (2011). Coexistence of genetically modified (GM) and non-modified (non-GM) crops: are the two main property rights regimes equivalent with respect to the coexistence value? In Carter, C., Moschini, G., Sheldon, I. (Eds.), Genetically Modified Food and Global Welfare. Emerald Group Publishing, Bingley, UK, pp. 201-224.

Beckmann, V., Soregaroli, C., and Wesseler, J. (2006). Coexistence rules and regulations in the European Union. American Journal of Agricultural Economics, 88(5), 1193-1199.

Beddington, J. (2010). Food security: contributions from science to a new and greener revolution. Philosophical Transactions of the Royal Society of London B: Biological Sciences, 365(1537), 61-71.

Beghin, J. C., and Bureau, J. C. (2015). The cost of food self-sufficiency and agricultural protection in South Korea. Iowa Ag Review, 8(1), 2.

Bellemare, M. F., and Carnes, N. (2015). Why do members of congress support agricultural protection? Food Policy, 50, 20-34.

Bennett, R., Phipps, R., Strange, A., and Grey, P. (2004). Environmental and human health impacts of growing genetically modified herbicide-tolerant sugar beet: a life-cycle assessment. Plant Biotechnology Journal, 2(4), 273-278.

Bernhofen, D. M., and Brown, J. C. (2005). An empirical assessment of the comparative advantage gains from trade: evidence from Japan. American Economic Review, 95(1), 208-225.

Blake, P. (2016). Obama signs bill mandating GMO labeling. ABC News. July 29, 2006.

http://abcnews.go.com/US/obama-signs-bill-mandating-gmo-labeling/story?id=41004057 (accessed 07.12.2016).

Boccia, F., and Sarnacchiaro, P. (2015). Genetically modified foods and consumer perspective. Recent Patents on Food, Nutrition \& Agriculture, 7(1), 28-34.

Bombardini, M., and Trebbi, F. (2012). Competition and political organization: together or alone in lobbying for trade policy? Journal of International Economics, 87(1), 18-26. 
Brander, J. A., and Krugman, P. (1983). A 'reciprocal dumping' model of international trade. Journal of International Economics, 15(3), 313-321.

Brander, J. A., and Spencer, B. J. (1985). Export subsidies and international market share rivalry. Journal of International Economics, 18(1), 83-100.

Brookes, G., and Barfoot, P. (2013). The global income and production effects of genetically modified (GM) crops 1996-2011. GM Crops \& Food, 4(1), 74-83.

Buchanan, J. M. (1969). External diseconomies, corrective taxes, and market structure. American Economic Review, 59(1), 174-177.

Bulte, E. H., and Barbier, E. B. (2005). Trade and renewable resources in a second best world: an overview. Environmental and Resource Economics, 30(4), 423-463.

Burguet, R., and Sempere, J. (2003). Trade liberalization, environmental policy, and welfare. Journal of Environmental Economics and Management, 46(1), 25-37.

Clapp, J. (2015). Food self-sufficiency and international trade: a false dichotomy. Note for the state of agricultural commodity markets. FAO, Rome.

Coen, D. (1997). The evolution of the large firm as a political actor in the European Union. Journal of European Public Policy, 4(1), 91-108.

Conconi, P. (2003). Green lobbies and transboundary pollution in large open economies. Journal of International Economics, 59(2), 399-422.

Conrad, J. M. (2010). Resource economics, Second edition. Cambridge University Press, New York.

Damania, R. (2001). When the weak win: the role of investment in environmental lobbying. Journal of Environmental Economics and Management 42(1), 1-22.

de Faria, R. N., and Wieck, C. (2015). Empirical evidence on the trade impact of asynchronous regulatory approval of new GMO events. Food Policy, 53, 22-32.

de Gorter, H., Drabik, D., and Just, D. R. (2015). The economics of biofuel policies: impacts on price 
volatility in grain and oilseed markets. Palgrave Macmillan, New York.

Department of Agriculture, Forestry and Fisheries in South Africa. (2012). Maize market value chain profile 2012. http://www.daff.gov.za/daffweb3/Portals/0/Agricultural\%20Marketing \%20Commodity\%20Profiles/Maize\%20Market\%20Value\%20Chain\%20Profile\%202012.pdf (accessed 07.12.2016).

Desquilbet, M., and Bullock, D. S. (2009). Who pays the costs of non-GMO segregation and identity preservation? American Journal of Agricultural Economics, 91(3), 656-672.

Dibden, J., Gibbs, D., and Cocklin, C. (2013). Framing GM crops as a food security solution. Journal of Rural Studies, 29, 59-70.

Downs, A. (1957). An economic theory of political action in a democracy. The Journal of Political Economy, 65(2), 135-150.

Dudek, C. M. (2015). GMO food regulatory frameworks in the US and the EU. In Buonanno L., Cuglesan N., Henderson K. (Ed.), The New and Changing Transatlanticism: Politics and Policy Perspectives. Routledge, New York, pp. 214-232.

Eaton, J., and Grossman, G. M. (1986). Optimal trade and industrial policy under oligopoly. The Quarterly Journal of Economics, 101(2), 383-406.

Economist Intelligence Unit. (2015). Global food security index. Economist Intelligence Unit, London. http:/ / foodsecurityindex.eiu.com (accessed 07.12.2016).

Eerola, E. (2004). Forest conservation-too much or too little? A political economy model. Environmental and Resource Economics, 27(4), 391-407.

Ericksen, P. J., Ingram, J. S., and Liverman, D. M. (2009). Food security and global environmental change: emerging challenges. Environmental Science \& Policy, 12(4), 373-377.

Etro, F. (2011). Endogenous market structures and strategic trade policy. International Economic Review, 52(1), 63-84. 
EUR-Lex. (2015). Directive 2001/18/EC of the European Parliament and of the Council of 12 March 2001 on the Deliberate Release into the Environment of Genetically Modified Organisms and Repealing Council Directive 90/220/EEC (amended version). http://eurlex.europa.eu/legal-content/EN/TXT/?uri=CELEX:02001L0018-20150402 (accessed 07.12. 2016).

European Commission. (2016). Genetically modified commodities in the EU. Commission Staff Working Document, Brussels. https://ec.europa.eu/transparency/regdoc/rep/10102/2016/ EN/10102-2016-61-EN-F1-1.PDF (accessed 07.12.2016).

European Commission. (2013). State of play in the EU on GM-free food labelling schemes and assessment of the need for possible harmonisation: final report. European Commission, Directorate-General for Health and Food Safety, Brussels. https://ec.europa.eu/food/sites/ food/files/plant/docs/gmo-traceability-gm-final_report_en.pdf (accessed 07.12.2016).

Eurostat. (2016). EU-28 - Balance with USA. European Commission - Directorate-General for Agriculture and Rural Development. https://ec.europa.eu/agriculture/sites/agriculture/ files/statistics/trade/2016/trade_2016_part12_bal.pdf (accessed 07.12.2016).

Fajgelbaum, P., Grossman, G. M., and Helpman, E. (2011). Income distribution, product quality, and international trade. Journal of Political Economy, 119(4), 721-765.

FAO. (2015). The state of food insecurity in the world 2015-Meeting the 2015 international hunger targets: taking stock of uneven progress. FAO, Rome. http://www.fao.org/3/a-i4646e.pdf (accessed 07.12.2016).

FAO. (2014). FAOSTAT: total maize production of South Africa in 2014. http://www.fao.org /faostat/en/\#data/QC (accessed 07.12.2016).

FAO. (2012). FAO Statistical Pocketbook 2012. http://www.fao.org/docrep/016/i2493e/i2493e.pdf (accessed 07.12.2016). 
FAO. (2004). The state of food and agricultural 2003-04. Agricultural biotechnology: meeting the needs of the poor. FAO Agricultural Series No.35. FAO, Rome. ftp:/ ftp.fao.org/docrep/ fao/006/Y5160e/Y5160e00.pdf (accessed 07.12.2016).

FAO. (2003). Regulating GMOs in developing and transition countries. http://www.fao.org/biotech /c9doc.htm (accessed 07.12.2016).

FAO. (2000). Panel of eminent experts on ethics in food and agriculture. ftp://ftp.fao.org/docrep /fao/003/x9600e/x9600e00.pdf (accessed 07.12.2016).

FAO. (1996). Rome Declaration on World Food Security and World Food Summit Plan of Action. World Food Summit 13-17 November 1996. FAO, Rome.

Ferrantino, M. (2006). Quantifying the trade and economic effects of non-tariff measures. OECD Trade Policy Working Paper 28, Organisation for Economic Co-operation and Development (OECD), Paris.

Fischer, C. (2010). Does trade help or hinder the conservation of natural resources? Review of Environmental Economics and Policy, 4(1), 103-121.

Francois, J., Manchin, M., Norberg, H., Pindyuk, O., and Tomberger, P. (2013). Reducing transatlantic barriers to trade and investment: an economic assessment. Institute for International and Development Economics, Rotterdam.

Fredriksson, P. G. (1997). The political economy of pollution taxes in a small open economy. Journal of Environmental Economics and Management, 33(1), 44-58.

Fredriksson, P. G., and Svensson, J. (2003). Political instability, corruption and policy formation: the case of environmental policy. Journal of Public Economics, 87(7), 1383-1405.

Freedman, D. H. (2013). Are engineered foods evil? Scientific American, 309(3), 80-85.

Fung, K., Lin, C. C., and Chang, R. Y., (2009). The political economy of strategic trade policies. Review of International Economics, 17(3), 494-509. 
Gaisford, J. D. (2001). The economics of biotechnology. Edward Elgar Publishing, Cheltenham.

Gawande, K., and Bandyopadhyay, U. (2000). Is protection for sale? Evidence on the GrossmanHelpman theory of endogenous protection. Review of Economics and Statistics, 82(1), 139-152.

Gawande, K., Krishna, P., and Olarreaga, M. (2012). Lobbying competition over trade policy. International Economic Review, 53(1), 115-132.

Giller, K. E. (2016). Genetically engineered crops: experiences and prospects. National Academies of Sciences, Engineering, and Medicine. Washington, DC.

Godfray, H. C. J., Beddington, J. R., Crute, I. R., et al. (2010). Food security: the challenge of feeding 9 billion people. Science, 327(5967), 812-818.

Goldberg, P. K. and Maggi, G. (1999). Protection for sale: an empirical investigation. American Economic Review, 89(5), 1135-1155.

Graff, G. D., Hochman, G., and Zilberman, D. (2014). The political economy of regulation of biotechnology in agriculture. In Herring R. (Ed.), Oxford Handbook of Food, Politics, and Society, Oxford University Press, Oxford, pp. 664-668.

Graff, G. D., Hochman, G., and Zilberman, D. (2009). The political economy of agricultural biotechnology policies. AgBioForum, 12(1), 34-36.

Grossman, G. M., and Helpman, E. (1995). The politics of free-trade agreements. American Economic Review, 85(4), 667-690.

Grossman, G. M., and Helpman, E. (1994). Protection for sale. American Economic Review, 84(4), 833850.

Gruère, G. P. (2011). Global welfare and trade-related regulations of GM food: biosafety, markets, and politics. Genetically Modified Food and Global Welfare, 10, 309.

Gruère, G. P., Carter, C. A., and Farzin, Y. H. (2009). Explaining international differences in genetically modified food labeling policies. Review of International Economics, 17(3), 393-408. 
Hamilton, D. S., and Quinlan, J. P. (2014). The transatlantic economy 2014: annual survey of jobs, Trade and Investment between the United States and Europe. Headline Trends, Volume 1/2014. Center for Transatlantic Relations, Washington, DC.

Hanley, N., Shogren, J.F., and White, B. (2007). Environmental economics: in theory and practice. Second edition. Palgrave Macmillan, New York.

Hansen-Kuhn, K., and Suppan, S. (2013). Promises and perils of the TTIP: negotiating a transatlantic agricultural market. Institute for Agriculture and Trade Policy, Minneapolis and Heinrich Böll Foundation, Berlin.

Herberg, H. (1990). Welfare effects of non-tariff barriers: A general equilibrium analysis. Weltwirtschaftliches Archiv, 126(3), 511-522.

Herring, R., and Paarlberg, R. (2016). The political economy of biotechnology. Annual Review of Resource Economics 8, 397-416.

Honma, M. (2015). The TPP and agricultural reform in Japan. In Mulgan, A. G., Honma, M. (Eds.), The Political Economy of Japanese Trade Policy. Palgrave Macmillan UK, London, pp. 94122.

Honma, S. (2005). Pollution tax under lobbying duopolists. Working paper, Faculty of Economics, Kyushu Sangyo University, Fukuoka.

IFPRI. (2014). Global food policy report: ending hunger and undernutrition by 2025 must be a top priority in the post-2015 development agenda. Press Statement by Shenggen Fan, Director General. International Food Policy Research Institute, Washington, DC.

International Trade Centre. (2014). Market Analysis and Research: list of products imported by South Africa. http://www.trademap.org/tradestat/Product_SelCountry_TS.aspx (accessed 07.12.2016).

James, C., Teng, P., Arujanan, M., et al. (2015). Invitational essays to celebrate the 20th anniversary of 
the commercialization of biotech crops (1996 to 2015): progress and promise. Brief 51, ISAAA, Metro Manila.

Josling, T. E., Roberts, D., and Orden, D. (2004). Food regulation and trade: toward a safe and open global system. Institute for International Economics, Washington, DC.

Juma, C. (2016). Innovation and its enemies: Why people resist new technologies. Oxford University Press, New York.

Kagitani, K. (2009). Political economy of strategic export policy in a differentiated duopoly. Japanese Economic Review, 60(2), 236-252.

Kellenberg, D. K. (2009). An empirical investigation of the pollution haven effect with strategic environment and trade policy. Journal of International Economics, 78(2), 242-255.

Kennedy, P. W. (1994). Equilibrium pollution taxes in open economies with imperfect competition. Journal of Environmental Economics and Management, 27(1), 49-63.

Kostandini, G., Mills, B. F., Omamo, S. W., and Wood, S. (2009). Ex ante analysis of the benefits of transgenic drought tolerance research on cereal crops in low-income countries. Agricultural Economics, 40(4), 477-492.

Kreipe, M. (2010). Genetically modified food: trade regulation in view of environmental policy objectives. Diplomica Verlag GmbH, Hamburg.

Laffont, J. J., and Tirole, J. (1993). A theory of incentives in procurement and regulation. MIT Press, Cambridge, MA.

Levy, P. I. (1997). A political-economic analysis of free-trade agreements. American Economic Review, 87(4), 506-519.

Linkins, L. A., and Arce, H. M. (2002). Estimating tariff equivalents of nontariff barriers. Office of Economics No. 94-06-A(r), U.S. International Trade Commission, Washington, DC.

Luan, Y., Cui, X., and Ferrat, M. (2013). Historical trends of food self-sufficiency in Africa. Food Security, 
5(3), 393-405.

Lusk, J. L., and Coble, K. H. (2005). Risk perceptions, risk preference, and acceptance of risky food. American Journal of Agricultural Economics, 87(2), 393-405.

Lusk, J. L., Roosen, J., and Bieberstein, A. (2014). Consumer acceptance of new food technologies: causes and roots of controversies. Annual Review of Resource Economics, 6(1), 381-405.

Mabaya, E., Fulton, J., Simiyu-Wafukho, S., and Nang'ayo, F. (2015). Factors influencing adoption of genetically modified crops in Africa. Development Southern Africa, 32(5), 577-591.

McIntyre, B. D., Herren, H. R., Wakhungu, J. and Watson, R. T. (2009). International assessment of agricultural knowledge, science and technology for development (IAASTD): global report. Island Press, Washington, DC.

Miller, H. I., and Conko, G. P. (2004). The Frankenfood myth: how protest and politics threaten the biotech revolution. Greenwood Publishing Group, Westport, CT.

Moore, M.O., and Suranovic, S.M. (1993). Lobbying and Cournot-Nash competition: Implications for strategic trade policy. Journal of International Economics, 35, 367-376.

Moschini, G., Bulut, H., and Cembalo, L. (2005). On the segregation of genetically modified, conventional and organic products in European agriculture: a multi-market equilibrium analysis. Journal of Agricultural Economics, 56(3), 347-372.

Moses, V. (2016). The debate over GM crops is making history. Nature, 537, 139.

Naylor, R. L., and Falcon, W. P. (2010). Food security in an era of economic volatility. Population and Development Review, 36(4), 693-723.

Nordström, H., and Vaughan, S. (1999). Trade and environment (Vol. 4). WTO, Geneva.

O'Hagan, J. P. (1976). National self-sufficiency in food. Food Policy, 1(5), 355-366.

Olson, M. (1971). The logic of collective action: public goods and the theory of groups. Harvard University Press, Cambridge, MA. 
Oxfam. (2012). Food crisis doomed to repeat until leaders find courage to fix problems. https://www.oxfam.org/sites/www.oxfam.org/files/food-price-crisis-oxfam-mediaadvisory-aug2012.pdf (accessed 07.12.2016).

Paarlberg, R. (2010). GMO foods and crops: Africa's choice. New Biotechnology, 27(5), 609-613.

Paarlberg, R. (2009). Starved for science: How biotechnology is being kept out of Africa. Harvard University Press, Cambridge, MA.

Paarlberg, R. (2001). Shrinking international markets for GM crops. Paper presented at the USDA Agricultural Outlook Forum 2001, Washington, DC, 22-23 February.

Paarlberg, R., and Pray, C. (2007). Political actors on the landscape. Agbioforum, 10(3), 144-153.

Parry, M., Rosenzweig, C., Iglesias, A., Fischer, G., and Livermore, M. (1999). Climate change and world food security: a new assessment. Global Environmental Change, 9, S51-S67.

Peterson, D., and Bielke, E. K. (2001). The reorganization of Russia's environmental bureaucracy: implications and prospects. Post-Soviet Geography and Economics, 42(1), 65-76.

Pflüger, M. (2001). Ecological dumping under monopolistic competition. The Scandinavian Journal of Economics, 103(4), 689-706.

Plastina, A. (2016). Estimated costs of crop production in Iowa - 2016. https://www.extension. iastate.edu/agdm/crops/html/a1-20.html (accessed 07.12.2016)

Punt, M. J., and Wesseler, J. (2016). Legal but costly: an analysis of the EU GM regulation in the light of the WTO trade dispute between the EU and the USA. The World Economy, 39(1), 158-169.

Qaim, M. (2009). The economics of genetically modified crops. Annual Review of Resource Economics, 1, 665-693.

Qaim, M., and Kouser, S. (2013). Genetically modified crops and food security. PloS One, 8(6), e64879.

Qaim, M., and Traxler, G. (2005). Roundup Ready soybeans in Argentina: farm level and aggregate welfare effects. Agricultural Economics, 32(1), 73-86. 
Qaim, M., and Zilberman, D. (2003). Yield effects of genetically modified crops in developing countries. Science, 299(5608), 900-902.

Qui, L. D. (1994). Optimal strategic trade policy under asymmetric information. Journal of International Economics, 36(3-4), 333-354.

Ranganathan, J. (2013). The global food challenge explained in 18 graphics. World Resource Institute. Washington, DC. http://www.wri.org/blog/global-food-challenge-explained-18-graphics. (accessed 07.12.2016)

Rausser, G. C., Simon, L. K., and Zhao, J. (2015). Rational exaggeration and counter-exaggeration in information aggregation games. Economic Theory, 59(1), 109-146.

Rausser, G. C., Swinnen, J., and Zusman, P. (2011). Political power and economic policy: theory, analysis, and empirical applications. Cambridge University Press, New York.

Regier, G., and Dalton, T. (2014). Labour savings of Roundup Ready maize: impact on cost and input substitution for South African smallholders. African Journal of Agricultural and Resource Economics, $9(3), 200-213$.

Requate, T. (2006). Environmental policy under imperfect competition. In Tietenberg T. and Folmer H. (Eds.), The international yearbook of environmental and resource economics 2006/2007. Edward Elgar, Cheltenham UK, pp. 120-207.

Rogers, K. S. (1997). Ecological security and multinational corporations. Environmental Change and Security Project (ECSP) report. Center for Security Studies (CSS), ETH Zurich. http://mercury.ethz.ch/serviceengine/Files/ISN/136188/ichaptersection_singledocument/ 634dadb5-f13f-4795-a2da-d7b143decf38/en/ch_3.pdf (accessed 07.12.2016)

Royal Society of London. (2009). Reaping the benefits: Science and the sustainable intensification of global agriculture. Royal Society, London. https://royalsociety.org/ /media/Royal_ Society_Content/policy/publications/2009/4294967719.pdf (accessed 07.12.2016) 
Ruane, J., and Sonnino, A. (2011). Agricultural biotechnologies in developing countries and their possible contribution to food security. Journal of Biotechnology, 156(4), 356-363.

Sastry, R. K., Rashmi, H., and Rao, N. (2011). Nanotechnology for enhancing food security in India. Food Policy, 36(3), 391-400.

Schleich, J. (1999). Environmental quality with endogenous domestic and trade policies. European Journal of Political Economy, 15(1), 53-71.

Shiferaw, B., Prasanna, B. M., Hellin, J., and Bänziger, M. (2011). Crops that feed the world 6. Past successes and future challenges to the role played by maize in global food security. Food Security, 3(3), 307-327.

Simelton, E. (2011). Food self-sufficiency and natural hazards in China. Food Security, 3(1), 35-52.

Singh, N., and Vives, X. (1984). Price and quantity competition in a differentiated duopoly. The RAND Journal of Economics, 15(4), 546-554.

Smart, R. D., Blum, M. and Wesseler, J. (2016). Trends in approval times for genetically engineered crops in the United States and the European Union. Journal of Agricultural Economics. http://dx.doi.org/10.1111/1477-9552.12171 (accessed 07.12.2016)

Smart, R. D., Blum, M., and Wesseler, J. (2015). EU member states' voting for authorizing genetically engineered crops. German Journal of Agricultural Economics, 64(4), 244-262.

Stanziani, A. (2008). Defining "natural product" between public health and business, 17th to 21 st centuries. Appetite, 51(1), 15-17.

Statistics South Africa. (2014). Quarterly employment statistics. http://www.statssa.gov.za /publications/P0277/P0277December2014.pdf (accessed 07.12.2016)

Stieber, Z. (2013) GMOs, A global debate: South Africa, top GMO-producer in Africa. Epoch Times. October 19, 2013. http://www.theepochtimes.com/n3/323635-gmos-a-globa-debate-southafrica-top-gmo-producer-in-africa/ (accessed 07.12.2016) 
Swinnen, J. F. (1994). A positive theory of agricultural protection. American Journal of Agricultural Economics, 76(1), 1-14.

Swinnen, J. F., and Vandemoortele, T. (2011). Trade and the political economy of food standards. Journal of Agricultural Economics, 62(2), 259-280.

Tanguay, G. A. (2001). Strategic environmental policies under international duopolistic competition. International Tax and Public Finance, 8(5-6), 793-811.

Thomas, H., and Morrison, J. (2006). Trade-related reforms and food security: a synthesis of case study findings. FAO, Rome, pp. 1-117.

Tisdell, C., and Fairbaim, T. I. (1984). Subsistence economies and unsustainable development and trade: Some simple theory. Journal of Development Studies, 20(2), 227-241.

Tomei, J., and Helliwell, R. (2016). Food versus fuel? Going beyond biofuels. Land Use Policy, 56, 320326.

Tosun, J., and Schaub, S. (2015). To mobilize or not: political attention and the regulation of GMOs. International Conference on Coexistence between Genetically Modified (GM) and non-GM based Agricultural Supply Chains (GMCC).November17-20, 2015. Amsterdam, the Netherlands.

Tosun, J., Schaub, S., Smart, R., and Wesseler, J. (2016): Sympathy for the devil? Policy activism and voting behaviour of EU Member States on the approval of genetically modified organisms. The XX International Consortium on Applied Bioeconomy Research (ICABR) Conference, June 26 - 29, 2016, Ravello, Italy.

Tovar, P. (2011). Lobbying costs and trade policy. Journal of International Economics, 83(2), 126-136.

United Nations Population Division. (2011). World population prospects: the 2008 revision and world urbanization prospects. http://esa.un.org/wup2009/unup/ (accessed 07.12.2016)

United States Department of Agriculture, Economic Research Service. (2013). Adoption of genetically engineered crops in the US. https://www.ers.usda.gov/data-products/adoption- 
of-genetically-engineered-crops-in-the-us/ (accessed 07.12.2016)

van Rijssen, F. J., Morris, E. J., and Eloff, J. N. (2013). A critical scientific review on South African governance of genetically modified organisms (GMOs). African Journal of Biotechnology, 12(32), $5010-5021$.

Vecchione, M., Feldman, C., and Wunderlich, S. (2015). Consumer knowledge and attitudes about genetically modified food products and labelling policy. International Journal of Food Sciences and Nutrition, 66(3), 329-335.

Vel, J. A., McCarthy, J. F., and Zen, Z. (2016). The conflicted nature of food security policy: balancing rice, sugar and palm oil in Indonesia. Anthropological Forum, 26 (3), 233-247.

Venus, T., Drabik, D., Wesseler, J. (2016). Investing in emerging vertically differentiated products: The case of voluntary GM-free labeling. Invited paper presented at the AAEA meeting 2016, July 31 August 2, Boston,USA.

Vermeulen, H., Ndibongo Traub, L., and Meyer, F. H. (2009). Impact analysis of food policy response on household food security: the case of South Africa's maize subsector. International Association of Agricultural Economists Conference, August 16-22, 2009, Beijing, China.

Vigani, M., and Olper, A. (2013). GMO standards, endogenous policy and the market for information. Food Policy, 43, 32-43.

Vigani, M., Raimondi, V., and Olper, A. (2012). International trade and endogenous standards: the case of GMO regulations. World Trade Review, 11(3), 415-437.

von Braun, J.(2010). Food insecurity, hunger and malnutrition: necessary policy and technology changes. New Biotechnology, 27(5), 449-452.

von der Walt, J. (2011) Final overview report on GM maize in South Africa for the 2010/2011 season. http://www.maizetrust.co.za/upload/WEBSITE/Market\%20Information/2011 /20160211Dr\%20vd\%20Walt\%20\%20GMO\%20Final\%20Report\%20Sep\%202011.pdf 
(accessed 7.12. 2016).

Wafula, D., and Gruère, G. (2013). Genetically modified organisms, exports, and regional integration in Africa. In Falck-Zapeda, J., Gruère, G. and Niang, I. S. (Eds.), Genetically Modified Crops in Africa. International Food Policy Research Institute, Washington, DC, pp. 143-157.

Wang, T. K. (2011). Lobbying paradox of strategic export policy in a differentiated duopoly. International Economics and Economic Policy, 8(3), 323-336.

Weitzman, M. L. (2001). Gamma discounting. American Economic Review, 91(1), 260-271.

Wesseler, J., and Kalaitzandonakes, N. (2011). Present and future EU GMO policy. In Oskam, A., Meesters, G., Silvis, H. (Eds.), EU Policy for Agriculture, Food and Rural Areas. Wageningen Academic Publishers, Wageningen, pp. 403-414.

Wesseler, J., and Punt, M. (2016). Coexistence in European agriculture? EuroChoices, 15(1), 3-4.

Wesseler, J., Scatasta, S., Fall, E., Carter, C., Moschini, G., and Sheldon, I. (2011). The environmental benefits and costs of genetically modified (GM) crops. In Carter, C., Moschini, G., Sheldon, I. (Eds.), Genetically Modified Food and Global Welfare. Emerald Group Publishing, Bingley, UK, pp. 173-199.

Wesseler, J., Smart, R., Thomson, J., and Zilberman D. (2016): Foregone benefits of important food crop improvements in Sub-Saharan Africa. Invited Paper presented at the 2016 AAEA Annual Meeting, July 31 - August 2, Marriott Copley Place, Boston MA.

Wesseler, J., and Zilberman, D. (2014). The economic power of the Golden Rice opposition. Environment and Development Economics, 19(6), 724-742.

Winchester, N. (2009). Is there a dirty little secret? Non-tariff barriers and the gains from trade. Journal of Policy Modeling, 31(6), 819-834.

Winters, L. A. (1987). Negotiating the abolition of non-tariff barriers. Oxford Economic Papers, 39(3), $465-480$. 
Withagen, C. (2007). International trade and environmental policy under imperfect competition. International Review of Environmental and Resource Economics, 1(2), 151-183.

World Bank. (2010). International assessment of agricultural knowledge, science, and technology for development. http://siteresources.worldbank.org/EXTGLOREGPARPROG/ Resources/IAASTD_GPR.pdf (accessed 07.12.2016)

World Bank. (2008).World development report 2008: agriculture for development. World Bank, Washington, DC.

World Trade Organization. (2015). WTO Statistics database: US trade data. http://stat.wto.org/ CountryProfile/WSDBCountryPFView.aspx?Language=E\&Country=US (accessed 07.12. 2016)

Zerbe, N. (2004). Feeding the famine? American food aid and the GMO debate in Southern Africa. Food Policy, 29(6), 593-608.

Zhou, D., Spencer, B.J., and Vertinsky, I. (2002). Strategic trade policy with endogenous choice of quality and asymmetric costs. Journal of International Economics, 56(1), 205-232.

Ziesemer, T., and Michaelis, P. (2011). Strategic environmental policy and the accumulation of knowledge. Structural Change and Economic Dynamics, 22(2), 180-191.

Žigić, K. (2000). Strategic trade policy, intellectual property rights protection, and North-South trade. Journal of Development Economics, 61(1), 27-60. 


\section{Acknowledgement}

\section{致谢}

二十年前对经济学買懂的热爱, 没想到现在竟有一本博士论文在手。对经济学的追求, 既 是载体, 也是内容, 在过去的数载中丰富着我的世界。个中滋味也在毕业之时的回想中一 笑泯恩仇。如果时光倒流, 我希望可以不用对彼时少年土下座。

对经济学的探索, 前路漫漫。作为阶段性总结, 这篇论文的完成离不开很多人的帮助, 在 此真心感谢。This thesis presents not only my work through past years, but it is also a work by many people, who I wish to thank.

I would like to thank my promoter, Professor Justus Wesseler. You have been supportive since the day I began working in Technical University of Munich. You offered me chances to explore myself. Thanks for bringing me to Wageningen University and getting to know more nice people from the AEP group. Maarten, thank you so much for encouraging me every time when I am down. Your words echoed when I was fighting with those invisible enemies. Dusan, thanks a lot for teaching me so much, both economic models and life. I also would like to thank everyone in the AEP group and my previous colleagues from TUM. Special thanks to Thorsten and Rong-Gang, my thesis could not be completed without your help.

感谢父母。你们给了我自由追逐的空间, 也是我最温柔的后盾。感谢家人的各种支持。感 谢蝈蝈与我分享笑与泪。感谢陪我成长直到现在的朋友们。

感谢 Lee。如果没有在二十年前遇见你, 那一定不会有现在的我, 是你让我知道要去追求 什么。感谢那几箱的音乐和电影, 感谢书架壁梪和床头的书, 你们帮我滋生了梦想, 让我 知道应当成为什么样的人, 让我能在校园和社会的五次辗转中将过去二十年间大大小小的 心愿一一实现。

感谢生日时盛开的杏花。

茜茜 二零一七年二月 于荷兰瓦赫宁根 


\begin{tabular}{|c|c|c|c|}
\hline Name of the learning activity & Department/Institute & Year & ECTS* \\
\hline \multicolumn{4}{|l|}{ A) Project related competences } \\
\hline Topics in Industrial Organization & $\begin{array}{l}\text { Martin Luther university, } \\
\text { Halle/Saale }\end{array}$ & 2013 & 3 \\
\hline $\begin{array}{l}\text { Time Series Analysis: Applications in } \\
\text { Agricultural and Food Economics }\end{array}$ & Christian Albrechts University, Kiel & 2013 & 3 \\
\hline $\begin{array}{l}\text { Welfare Economics Analysis of } \\
\text { Agricultural Policy: Theory and } \\
\text { Applications }\end{array}$ & Technical University München & 2014 & 3 \\
\hline Economic Models (AEP 30806) & WUR & 2015 & 6 \\
\hline Proposal writing & WUR & 2015 & 6 \\
\hline \multicolumn{4}{|l|}{ B) General research related competences } \\
\hline $\begin{array}{l}\text { 'Forest Conservation under } \\
\text { International Trade' }\end{array}$ & EAERE, Prague; TUM, Munich & 2012 & 1 \\
\hline $\begin{array}{l}\text { 'GMO Regulations and the Food Self- } \\
\text { sufficiency' }\end{array}$ & $\begin{array}{l}\text { ICABR, Ravello; IfW, Kiel; CES, } \\
\text { West Lafayette, USA }\end{array}$ & 2012-2014 & 1 \\
\hline $\begin{array}{l}\text { 'A Political-Economy Analysis of a GMO } \\
\text { Trade Agreement' }\end{array}$ & $\begin{array}{l}\text { AAEA, Minneapolis; ICABR, } \\
\text { Nairobi, Kenya }\end{array}$ & 2014 & 1 \\
\hline Introduction course & WASS & 2014 & 1 \\
\hline $\begin{array}{l}\text { 'Trade Liberalization on the EU-US } \\
\text { GMO' }\end{array}$ & ICAE, Milan; GMCC, Amsterdam & 2015 & 1 \\
\hline $\begin{array}{l}\text { Techniques for Writing and Presenting a } \\
\text { Scientific Paper }\end{array}$ & WUR & 2015 & 1.2 \\
\hline $\begin{array}{l}\text { 'A Political Economy of a GMO Trade } \\
\text { Agreement' }\end{array}$ & WUR; LICOS, KU Leuven & 2016 & 1 \\
\hline \multicolumn{4}{|c|}{ C) Career related competences/personal development } \\
\hline Lecturing: Mathematics for Economists & TUM, Munich & 2012-2014 & 1 \\
\hline $\begin{array}{l}\text { Teaching Assistant: Value Chain } \\
\text { Economics }\end{array}$ & TUM, Munich & 2012-2013 & 1 \\
\hline Supervision of Master Thesis & WUR & 2015-2016 & 1 \\
\hline Paper Writing Cooperation & Lund University & 2016 & 1.4 \\
\hline Total (30 - 45 ECTS) & & & 33.6 \\
\hline
\end{tabular}

*One credit according to ECTS is on average equivalent to 28 hours of study load 
The research described in this thesis was financially supported by Technical University of Munich and Wageningen University.

Financial support from Wageningen University for printing this thesis is gratefully acknowledged.

Cover designed by Gaoliang Fotodesign

Printed by Digiforce-Proefschriftmaken.nl 


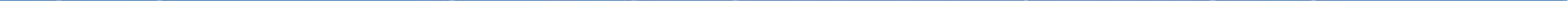

